\title{
Control Interfaces for Active Trunk Support
}

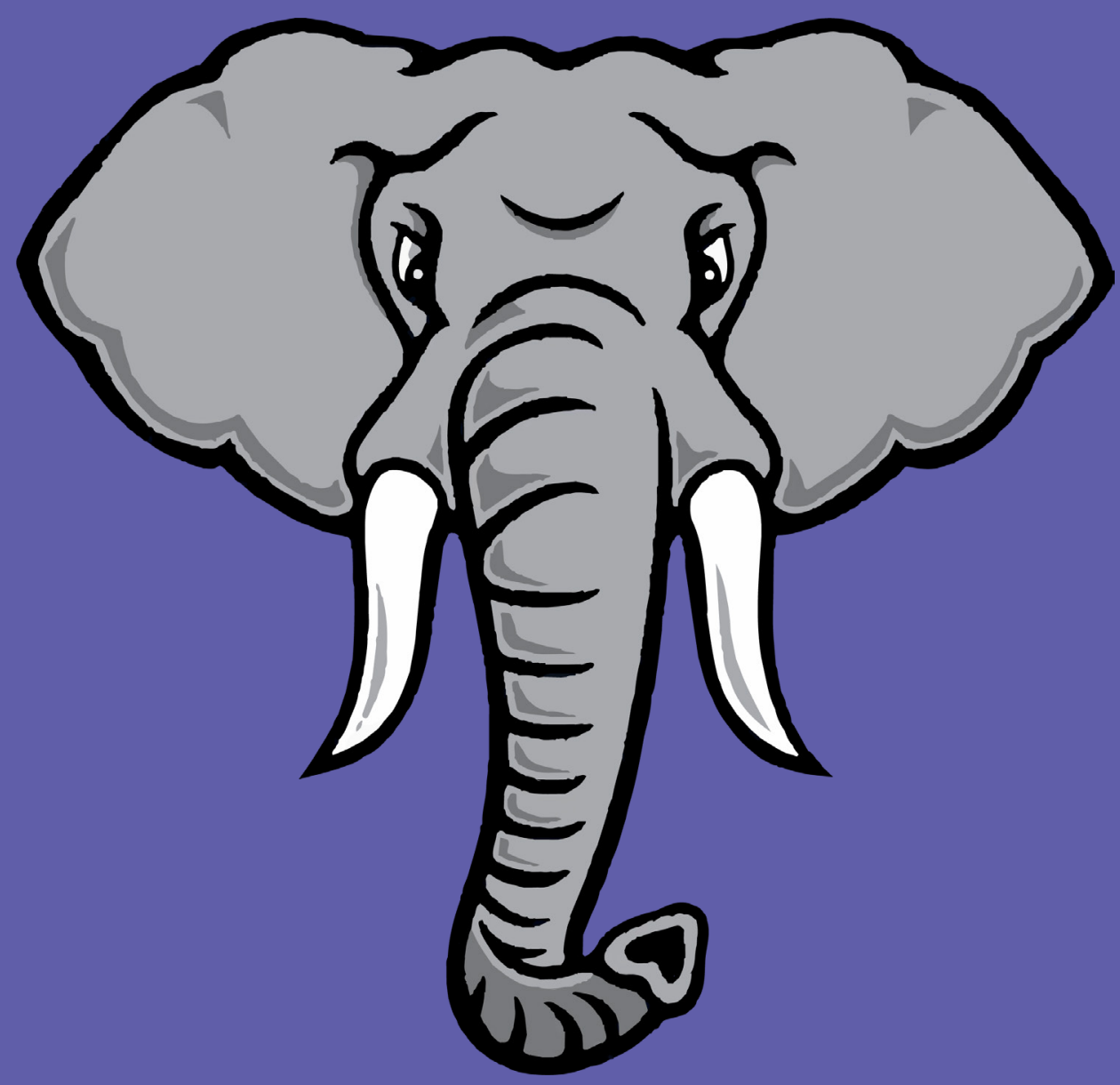

Stergios Verros 
Control Interfaces for Active Trunk Support

Stergios Verros 


\section{DISSERTATION}

to obtain

the degree of doctor at the University of Twente,

on the authority of the rector magnificus

prof.dr. T.T.M. Palstra,

on account of the decision of the Doctorate Board,

to be publicly defended

on Friday the $27^{\text {th }}$ of March 2020 at 16:45

by

Stergios Verros

born on the $21^{\text {st }}$ December, 1983,

in Kos, Greece 
This dissertation has been approved by:

Supervisor(s): Prof.dr.ir H.F.J.M. Koopman

Prof.dr.ir. G.J. Verkerke

Co-supervisor: Dr. A. Bergsma

ISBN 978-90-365-4991-2

https://doi.org/10.3990/1.9789036549912

Cover design ProefschriftMaken

Printed by ProefschriftMaken

(c) 2020 by Stergios Verros, Enschede, The Netherlands All rights reserved. No parts of this thesis may be reproduced, stored in a retrieval system or transmitted in any form or by any means without permission of the author. Alle rechten voorbehouden. Niets uit deze uitgave mag worden vermenigvuldigd, in enige vorm of op enige wijze, zonder voorafgaande schriftelijke toestemming van de auteur. 
The graduation committee consists of:

Chairman and secretary

Prof.dr. G.P.M.R. Dewulf

University of Twente

Supervisors

prof.dr.ir H.F.J.M. Koopman

University of Twente

prof.dr.ir. G.J. Verkerke

University of Twente

Co-supervisor

dr.ir. A. Bergsma

Members

prof.dr. J.S. Rietman

University of Twente

prof.dr.ir. R.M. Verdaasdonk

Universtiy of Twente

dr. I.J.M. De Groot

prof.dr. J. Van Dieen

prof.dr.ir. J.M.A. Scherpen

Radboud University Nijmegen

Free University Amsterdam

University of Groningen

Paranymphs

Laura Peeters

M.N. Mahmood (Nauzef) 
This work is part of the research programme Symbionics with project number 13527, which is (partly) financed by the Netherlands Organisation for Scientific Research (NWO). The funding party had no role in study design, analysis, manuscript preparation, or decision to publish.

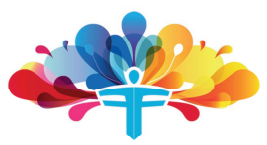

SYMBIDNICS

MANIPULATION • BODY SUFPORT • FORM ADAPTATION

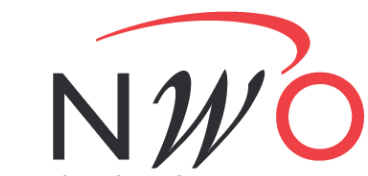

Netherlands Organisation

for Scientific Research

This work has also benefited from the advice and financial support of the following companies and organisations. Their support is thankfully acknowledged.

\section{Radboudumc UNIVERSITEIT TWENTE. VU Mastricht FOCAL meditech (1) $\frac{B A A T}{M E D I C A L}$

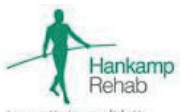 intespring
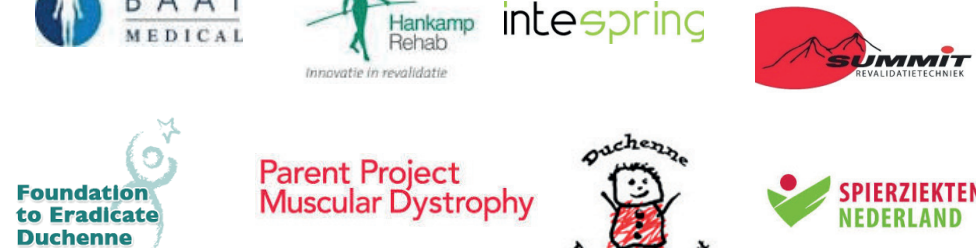 \\ Parent Project Muscular Dystrophy

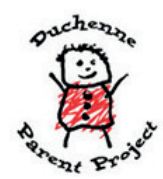 \\ SPIERZIEKTEN \\ NEDERLAND}




\section{TABLE OF CONTENTS}

1 General Introduction $\quad 1$

1.1 Symbionics project $\ldots \ldots \ldots \ldots \ldots \ldots \ldots \ldots$

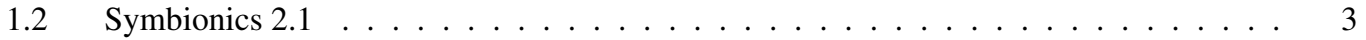

1.3 Duchenne Muscular Dystrophy . . . . . . . . . . . . . . . . . . 4

1.4 Assistive devices for people with DMD . . . . . . . . . . . . . . . . 4

1.5 Importance of a Trunk Support $\ldots \ldots \ldots \ldots \ldots$

1.6 Control Interfaces . . . . . . . . . . . . . . . . . . . . . 6

1.7 Experimental Evaluation Methods for Control Interfaces $\ldots \ldots \ldots$

$1.8 \quad$ Objectives and Research Questions . . . . . . . . . . . . . . . . . . . . . . . . . 10

1.9 Dissertation outline $\ldots \ldots \ldots \ldots \ldots \ldots \ldots \ldots$

2 Evaluation of intuitive trunk and non-intuitive leg sEMG control interfaces as command input for a 2-D Fitts' law style task $\quad 15$

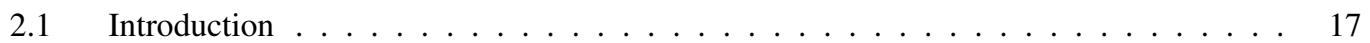

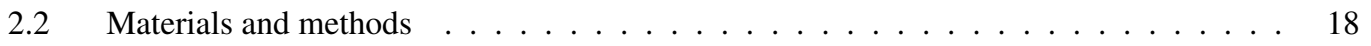

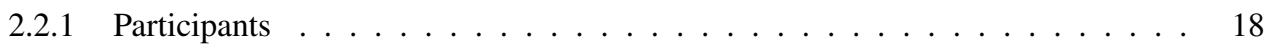

2.2.2 Test set-up and signal acquisition . . . . . . . . . . . . . . . . . 19

2.2 .3 (E) Signal processing . . . . . . . . . . . . . . . . . . . . . . 19

2.2 .4 Experimental procedure . . . . . . . . . . . . . . 21

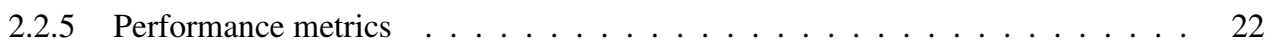

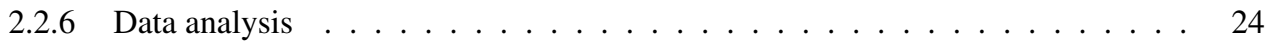

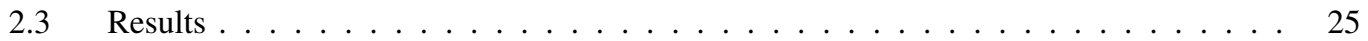

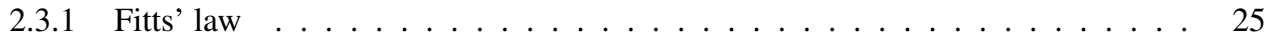

2.3.2 Movement Time . . . . . . . . . . . . . . . . . . . . 25 
2.3.3 Path efficiency and Throughput . . . . . . . . . . . . . . 28

2.3.4 Learning Behaviour . . . . . . . . . . . . . . . . . . . 28

2.4 Discussion . . . . . . . . . . . . . . . . . . . . . 29

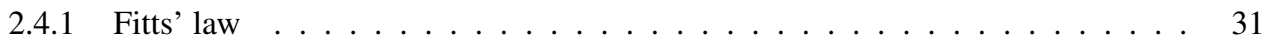

2.4.2 Performance Comparison . . . . . . . . . . . . . . . 31

2.4.3 Pattern recognition and abstract decoding . . . . . . . . . . . 32

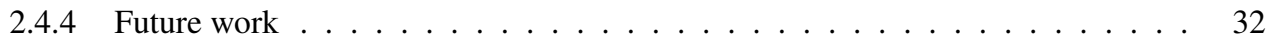

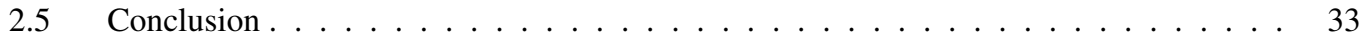

$3 \quad$ Evaluation of Control Interfaces for Active Trunk Support 35

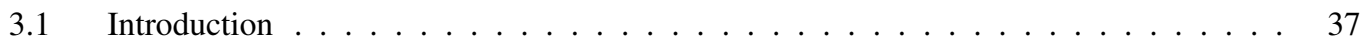

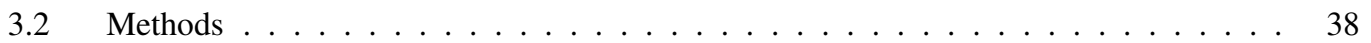

3.2 .1 Design and Actuation . . . . . . . . . . . . . . . 38

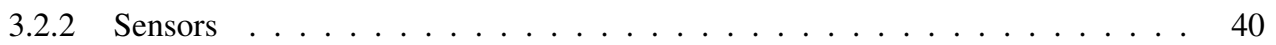

3.2.3 Signal Acquisition and Control Hardware . . . . . . . . . . . . . . . 40

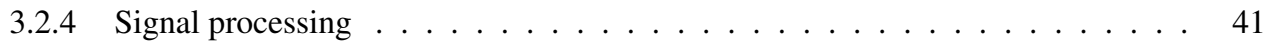

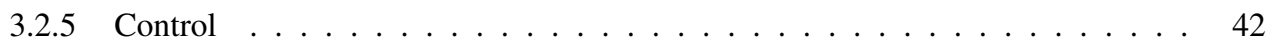

3.3 Experimental Design $\ldots \ldots \ldots \ldots \ldots \ldots \ldots$

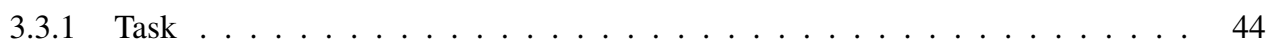

3.3.2 Performance Metrics . . . . . . . . . . . . . . . . 45

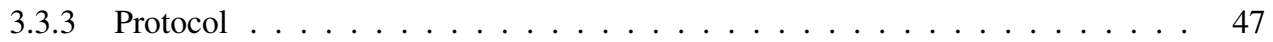

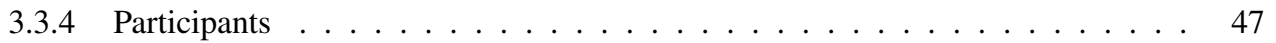

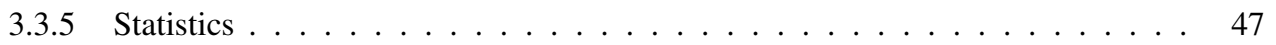

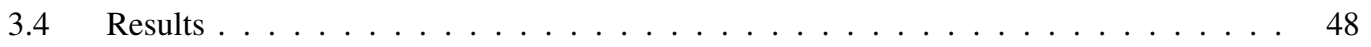

3.4 .1 Movement Time . . . . . . . . . . . . . . . . . 48

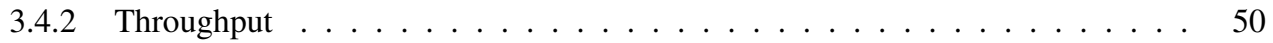

3.4 .3 Reaction Time . . . . . . . . . . . . . . . . . . 50

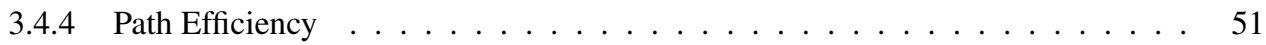

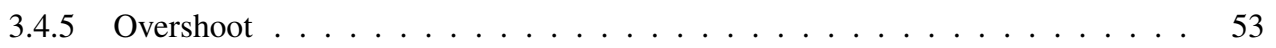

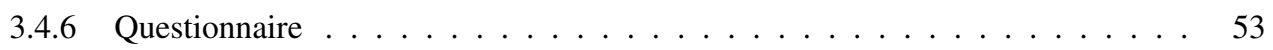

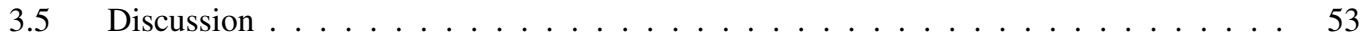


3.5.1 Performance Metrics and Acceptance . . . . . . . . . . . . . . 54

3.5 .2 Fitts' Law . . . . . . . . . . . . . . . . . 55

3.5.3 Overall Performance ....................... 55

3.5.4 Control Interfaces . . . . . . . . . . . . . . . . . . . . 56

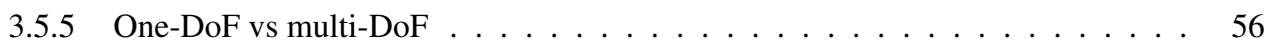

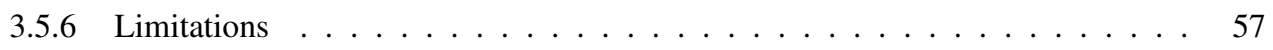

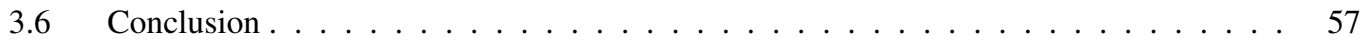

4 Comparing Assistive Admittance Control Algorithms For A Trunk Supporting Exoskeleton $\quad 59$

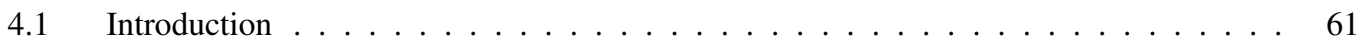

4.1.1 Mechanical Design . . . . . . . . . . . . . . . . 61

4.1 .2 Control Interfaces $\ldots \ldots \ldots \ldots \ldots \ldots$

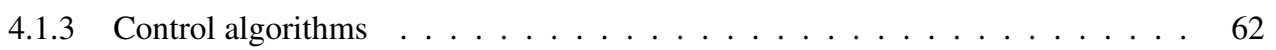

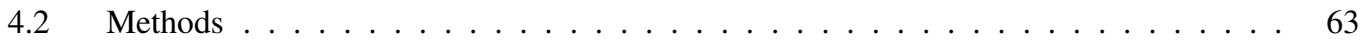

4.2.1 Prototype Trunk Drive $\ldots \ldots \ldots \ldots$. . . . . . . . . . 63

4.2.2 Basic Control Design . . . . . . . . . . . . . . . . . 64

4.2 .3 Control Laws . . . . . . . . . . . . . . . . . . . 65

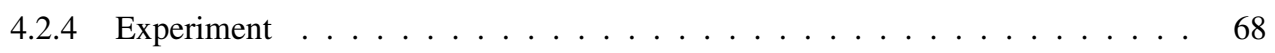

4.2 .5 Subject Information . . . . . . . . . . . . . . . . . 71

4.2.6 Quantitative Measures . . . . . . . . . . . . . . . . . . . . . 71

4.2 .7 Statistical Analysis f . . . . . . . . . . . . . . . 72

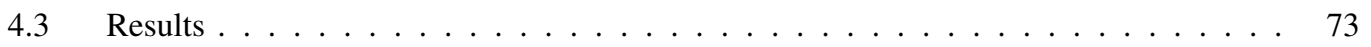

4.3 .1 Movement Time . . . . . . . . . . . . . . . 73

4.3 .2 Questionnaire ............................ 74

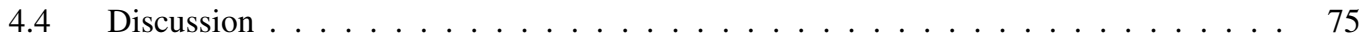

4.4.1 Movement Time and Fitts' law . . . . . . . . . . . . . . . . . . 75

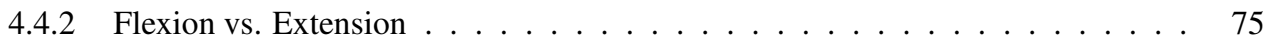

4.4 .3 Comparison ........................ 76

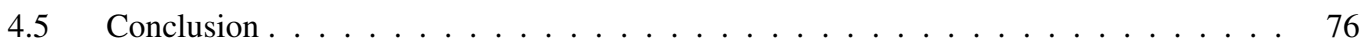


5 Exploring physiological signals on people with Duchenne muscular dystrophy for an active trunk support: A case study $\quad 77$

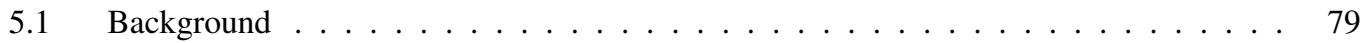

5.2 Methods . . . . . . . . . . . . . . . . . . . . . . 79

5.2 .1 Test set-up . . . . . . . . . . . . . . . . . . 79

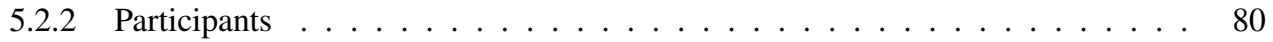

5.2 .3 Experimental Design . . . . . . . . . . . . . . . . 80

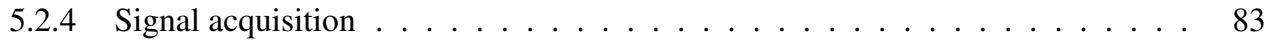

5.2 .5 Signal processing . . . . . . . . . . . . . . . . . 84

$5.3 \quad$ Results .............................. 84

5.3 .1 Active experiment . . . . . . . . . . . . . . 84

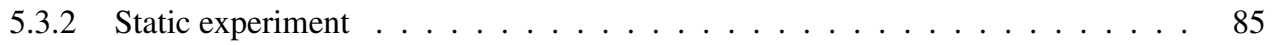

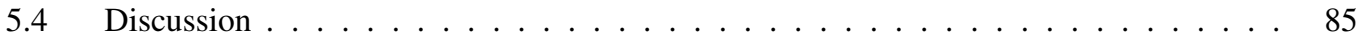

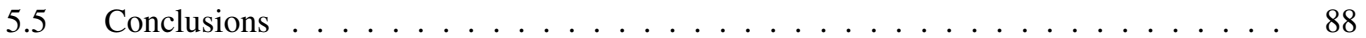

$\begin{array}{llr}6 & \text { General discussion } & 89\end{array}$

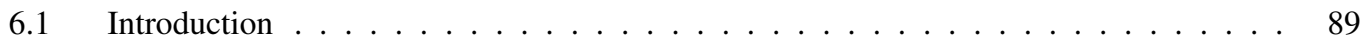

6.2 Interpretation of findings $\ldots \ldots \ldots \ldots$

6.3 Control interface selection overview . . . . . . . . . . . . . . 93

6.4 Decisions and limitations $\ldots \ldots \ldots \ldots \ldots$

6.4.1 Focus Group and 1-Dof vs multi-Dof . . . . . . . . . . . . . . . . . 95

6.4 .2 Position vs speed vs acceleration control . . . . . . . . . . . . . . . . 95

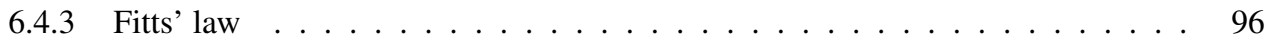

6.4 .4 Admittance values . . . . . . . . . . . . . . . . . . . . 97

6.4.5 Mechanical limitations of the experimental trunk support . . . . . . . . . . 97

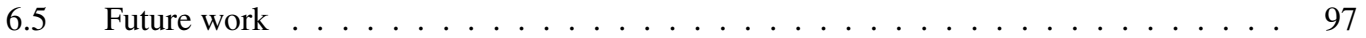

$6.5 .1 \quad$ Active device first . . . . . . . . . . . . . . . . . . 97

6.5.2 Control interfaces and rehabilitation ................ . 98

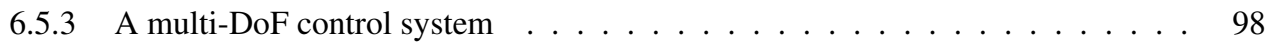

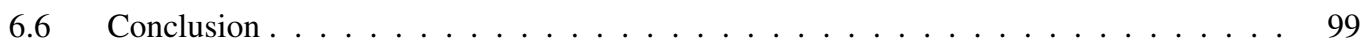

REFERENCES . . . . . . . . . . . . . . . . . . . . . . . . . . . . . . 99 
ACKNOWLEDGEMENTS . . . . . . . . . . . . . . . . . . . . . . 109

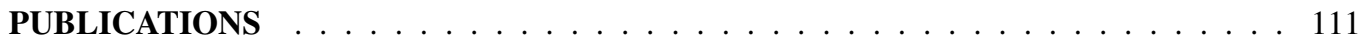

ABOUT THE AUTHOR $\ldots \ldots \ldots \ldots \ldots \ldots \ldots \ldots \ldots \ldots$ 


\begin{abstract}
People with Duchenne muscular dystrophy (DMD) lose the ability to move due to severe muscular weakness hindering their activities of daily living (ADL). As a consequence, they have difficulties with remaining independent and have to depend on caregivers. Medication cannot prevent or cure DMD but it can increase the life expectancy of patients. Notwithstanding the increase in life expectancy, people with DMD have a lower Health Related Quality of Life (HRQoL) compared to people without DMD. A possible improvement could be achieved with assistive devices to perform $\mathrm{ADL}$ and, as a result, to depend less on caregivers.

The Flextension A-gear project developed an assistive device to support the arm. However, trunk movement also plays a significant role in most daily tasks. Reaching for a target (e.g., picking up a glass of water) requires trunk coordination with respect to the reaching arm and it is a rather complex motor task. Also, maintaining postural stability during daily tasks needs trunk motions.

As a continuation of the Flextension project, the Symbionics project was set up with the aim to develop body-bounded devices that can actively support humans in order to improve their quality of life by focusing on the hand, trunk, head and foot. One sub-project (2.1) has been focusing on developing dynamic trunk and head supportive devices for people with neuromuscular disorders to assist them when performing daily activities. Three sub-projects were defined; they investigated user involvement, passive trunk support and active trunk support. User involvement entailed the interaction between the trunk and arm when accomplishing daily tasks. A passive trunk support was designed and tested in an experimental environment by people without and with an early stage of DMD. As the DMD progresses, more assistance is needed which could possibly be provided by an active trunk support. Thus, an active trunk support (which is the focus of this thesis) concentrates on the actuation and control of a passive trunk support.

Operating and controlling an active assistive device requires a control interface. The control interface is responsible for converting the intended movement of the user into a device movement. Several control interfaces have been proposed for the control of assistive devices, the most common ones being a joystick, force sensors and sEMG (surface electromyography). We evaluated their performance by building an experimental user-controllable trunk support.

The goal of this dissertation, therefore, is to evaluate control interfaces for active trunk support. To this end, several research questions were formulated and investigated:

I. Is there an alternative to the intuitive trunk control interface to steer trunk muscles?

Current research on the control of orthotic devices that use sEMG signals as control inputs, focuses mainly on muscles that are directly linked to the movement being performed (intuitive control). However, in some cases, it is hard to detect a proper sEMG signal (e.g., when there is a significant amount of fat) or specifically for EMG from trunk muscles, respiratory muscles are located in the
\end{abstract}


trunk as well and can easily disturb the control signal, which can result in poor control performance. A way to overcome this problem might be the introduction of other, non-intuitive forms of control. We performed an explorative, comparative study on the learning behaviour of two different control interfaces, one with trunk muscle sEMGs (intuitive) and one with leg muscle sEMGs (non-intuitive) that can be potentially used for an active trunk support. Six healthy subjects undertook a 2-D Fitts' law style task. They were asked to steer a cursor towards targets that were radially distributed symmetrically in five directions. We found that:

- the subjects could learn the tasks and improve their performance over time

- the leg control interface was faster

- the subjects were able to control a non-intuitive control interface with high performance

- a non-intuitive control may be a viable solution for controlling an active trunk support

II. Which control interface aids an active trunk support better?

A feasibility study evaluated control interface performance with a novel trunk support assistive device (Trunk Drive) for adult men with Duchenne Muscular Dystrophy (DMD) namely, joystick, force on sternum, force on feet and sEMG (electromyography). This was done as a discrete position tracking task. We built a one degree of freedom active trunk support device that was tested on 10 healthy men. An experiment, based on Fitts' law, was conducted for the evaluation. We found that:

- force on sternum and the joystick control interfaces were faster than the ones based on force on feet and EMG

- force on sternum was the most fatiguing interface for the participants, and they preferred the joystick

- all the control interfaces proved to be feasible solutions for controlling an active trunk support; each had specific advantages.

III. Which assistive admittance controller performs best in a 1-D Fitts' law task?

This study was dedicated to the development and assessment of three different admittance control algorithms for a trunk supporting robot; a law with constant parameters, a law with added feedforward force, and a law with variable parameters. A Fitts'-like experiment with 12 healthy subjects was performed to compare the control laws. We found that:

- the movement times for the feed-forward and variable admittance controllers, with respect to the standard admittance, were less 
IV. Do people with DMD generate satisfactory signals which can potentially drive an active trunk support?

In a previous study, we showed that healthy people were able to control an active trunk support using four different control interfaces (based on joystick, force on feet, force on sternum and sEMG). All four control interfaces had different advantages and disadvantages. The aim of this study was to explore which of the four inputs could be detectably used by people with DMD to control an active trunk support. Three subjects with DMD participated in two experiments: an active experiment with an active trunk support assistive device and a static experiment without the active trunk support. The challenge in both experiments was to steer the cursor into a target of a graphical user interface using the signals from the different control interfaces. We found that:

- the results were subject-dependent in both experiments

- in the active experiment, the joystick was the most promising control interface

- in the static experiment, sEMG and force on feet worked for two out of the three subjects

- the control interfaces have to be customised to every DMD subject.

We concluded that, although the non-intuitive force on feet control is one of the best interfaces for people with DMD to control an active trunk support some DMD patients find it easier to use the EMG from their leg muscles. The joystick is the only usable intuitive control interface but, the function of one hand has to be sacrificed. The decision, as to which control interface works best, must be made per individual. 


\section{SAMENVATTING}

Mensen met Duchenne Spierdystrofie (DMD) verliezen hun vermogen om te bewegen vanwege een ernstige musculaire beperking die de Activiteiten in hun Dagelijks Leven (ADL) bemoeilijkt. Als gevolg hiervan hebben ze problemen om onafhankelijk te blijven en zijn ze afhankelijk van zorgverleners. Met medicatie kan DMD niet worden voorkomen of genezen, maar het kan wel de levensverwachting van patiënten verhogen. Ondanks de verhoogde levensverwachting hebben mensen met DMD een lagere aan gezondheid gerelateerde levenskwaliteit (Health Related Quality of Life of HRQoL) in vergelijking met mensen zonder DMD. Een mogelijke verbetering bereikt worden met behulp van hulpmiddelen om ADL te ondersteunen en als gevolg daarvan de afhankelijkheid van zorgverleners te beperken.

Het Flextension A-gear project ontwikkelde een hulpmiddel ter ondersteuning van de arm. Bewegingen van de romp spelen echter ook een belangrijke rol in de meeste dagelijkse taken. Het reiken naar een doel ( het pakken van een glas water) vereist coördinatie van de romp met betrekking tot een strekkende arm en is een nogal complexe motorieke taak. Ook voor het handhaven van een stabiele lichaamshouding tijdens dagelijkse taken zijn rompbewegingen nodig.

Als vervolg op het Flextension project, werd het Symbionics project opgezet met als doel om aan het lichaam gebonden ondersteuningsmiddelen te ontwikkelen die actief hulp bieden aan mensen om de kwaliteit van hun leven te verbeteren door te concentreren op de handen, de romp, het hoofd en de voeten. Een sub project (2.1) spitste zich toe op het ontwikkelen van dynamische ondersteuningsmiddelen voor de romp en het hoofd, voor mensen met neuromusculaire afwijkingen, om hen te assisteren bij de uitvoering van hun dagelijkse activiteiten. Hierbinnen zijn drie sub projecten te onderscheiden, te weten onderzoek naar rompfunctie, naar een passieve rompondersteuning, en naar een actieve rompondersteuning. Rompfunctie van gebruikers betrof de interactie tussen de romp en de armen bij het uitvoeren van dagelijkse activiteiten. Een passieve rompondersteuning werd ontwikkeld en getest in een experimentele omgeving door gezonde mensen en mensen in een beginstadium van DMD. Naarmate DMD toeneemt, is meer ondersteuning nodig wat mogelijk geleverd kan worden door een actieve ondersteuning van de romp. Vandaar dat een actieve ondersteuning van de romp (wat de focus is van dit proefschrift) zich richt op de activering en aansturing van een passieve ondersteuning van de romp.

Het bedienen en beheersen van een actief ondersteuningsmiddel vereist een bedieningsmechanisme (control interface). De control interface is verantwoordelijk voor het omzetten van de voorgenomen beweging van de gebruiker in een beweging van het ondersteuningsmiddel. Er worden verschillende interfaces voorgesteld voor de bediening van ondersteuningsmiddelen, waarvan een joystick, kracht sensoren en sEMG (oppervlakteëlektromyografie of surface electromyography) de meest voorkomende zijn. We hebben hiervan de prestaties geëvalueerd of de bouw van een experimentele door de ge- 
bruiker te bedienen, rompondersteuning.

Het doel van dit proefschrift is derhalve de evaluatie van control interfaces voor een actieve rompondersteuning. Hiertoe werden enkele onderzoeksvragen geformuleerd en onderzocht:

I. Is er een alternatief voor het intuïtieve romp bedieningsmechanisme (intuïtive control interface) om de rompspieren aan te sturen?

Huidig onderzoek naar de bediening van orthotische ondersteuningsmiddelen die sEMG signalen gebruiken als aansturing spitsen zich overwegend toe op spieren die direct gelinkt zijn aan de uitgevoerde beweging (intutieve bediening of intuïtieve control). In sommige gevallen is het echter moeilijk om een juist sEMG signaal waar te nemen (bv. als er een aanzienlijk hoeveelheid vet aanwezig is). In het specifieke geval van EMG van de rompspieren bevinden zich ook ademhalingsspieren in de romp, die gemakkelijk het bedieningssignaal kunnen verstoren wat in een slechte bediening kan resulteren. Een manier om dit probleem te ondervangen is de introductie van andere nietintuïtieve vormen van besturing. We hebben een exploratieve, vergelijkende studie uitgevoerd naar het leergedrag van twee verschillende bedieningsmechanismen, een met sEMGs voor rompspieren (intuïtief) en n met sEMGs voor beenspieren (niet intuïtief) die potentieel kunnen worden gebruikt voor een actieve rompondersteuning. Zes gezonde proefpersonen kregen een 2-D Fitts law style taak uit te voeren. Hen werd gevraagd om de cursor naar mikpunten te bewegen in vijf richtingen die radiaal symmetrisch waren verspreid. We ontdekten dat:

- de proefpersonen hun taken konden leren en uitvoering in de loop der tijd konden verbeteren;

- de control interface voor de benen sneller was;

- de proefpersonen de bediening van een nietintuïtieve control interface met een grote nauwkeurigheid konden uitvoeren;

- een niet-intuïtieve bediening een geschikte oplossing kan zijn voor de bediening van een actieve rompondersteuning.

II. Welk bedieningsmechanisme past beter bij een actieve rompondersteuning?

Een haalbaarheidsstudie evalueerde de prestatie van bedieningsmechanismen (control interfaces) van een nieuw rompondersteuningshulpmiddel (Trunk Drive) voor volwassen mannen met Duchenne Spierdystrofie (DMD), namelijk de joystick, de kracht op het sternum (borstbeen), de kracht op de voeten en sEMG (elektromyografie of electromyography). Dit werd gedaan in de vorm van een stapsgewijze positie volgtaak. We bouwden een hulpmiddel rompondersteuning voor met een enkele graad van vrijheid dat op 10 gezonde mannen werd getest. Een op Fitts law gebaseerd experiment werd uitgevoerd voor de evaluatie. We ontdekten dat: 
- de kracht op de sternum en het joystick bedieningsmechanisme (joystick control interfaces) sneller waren dan de control interface die gebaseerd waren op de kracht op de voeten en het EMG;

- de kracht op de sternum de voor de deelnemers de meest vermoeiende interface was, en ze de voorkeur gaven aan de joystick;

- alle bedieningsmechanismen haalbare oplossingen bleken te zijn voor de bediening van een actieve rompondersteuning; elk had specifieke voordelen.

III. Welke ondersteunende admittantie-regeling presteert het beste in een 1-dimensionale Fitts law taak?

Deze studie werd gewijd aan de ontwikkeling en beoordeling van drie verschillende admittance control regelingen voor een romp ondersteunende robot: een regeling met constante parameters, een regeling met een toegevoegde kracht-voorwaartskoppeling en een regeling met variabele parameters. Een op Fitts lijkend experiment met 12 gezonde proefpersonen werd uitgevoerd om de regel strategieën te vergelijken. We ontdekten dat:

- de bewegingstijden voor de voorwaartskoppeling en variable regelaars lager waren dan wat met een standaard admittantie-regeling behaald kon worden;

IV. Genereren mensen met DMD bevredigende signalen die potentieel een actieve romp ondersteuning kunnen aansturen?

In een eerdere studie lieten we zien dat gezonde mensen in staat waren om een actieve rompondersteuning te bedienen met gebruikmaking van vier verschillende bedieningsmechanismen (gebaseerd op joystick, de kracht op de voeten, de kracht op de sternum en sEMG). Alle vier bedieningsmechanismen (control interfaces) hadden verschillende voor- en nadelen. Het doel van deze studie was om na te gaan welke van deze vier mechanismen kon worden gebruikt door mensen met DMD om een actieve rompondersteuning te bedienen. Drie proefpersonen met DMD participeerden in twee experimenten: een actief experiment met een actief rompondersteunend middel en een statisch experiment zonder de actieve rompondersteuning. De uitdaging bij beide experimenten was om de cursor naar een doel te sturen in een grafische gebruikersinterface, gebruikmakend van de signalen afkomstig van de verschillende bedieningsmechanismen. We ontdekten dat:

- de resultaten in beide experimenten afhankelijk waren van de proefpersonen;

- de joystick het meest veelbelovende bedieningsmechanisme (control interface) was in het actieve experiment; 
- De sEMG en de kracht op de voeten in het statisch experiment voor twee van de drie proefpersonen functioneerden;

- de control interfaces toegesneden moeten worden op iedere DMD proefpersoon.

We concludeerden dat, hoewel de niet-intutieve kracht-op-de-voeten een van de beste interfaces is voor mensen met DMD om een actieve romp ondersteuning te bedienen, sommige DMD patinten het gemakkelijker vonden om de EMG vanuit hun beenspieren te gebruiken. De joystick is het enige bruikbare intutieve bedieningsmechanisme (intuitive control interface) maar de functie van een hand moet dan worden opgeofferd. De beslissing over welke control interface het beste werkt moet per individu genomen worden. 


\section{CHAPTER 1}

\section{General Introduction}

\subsection{Symbionics project}

There are two main types of diseases that affect the muscle capacity in humans, which are neuromuscular diseases (NMD) and motor neuron diseases (MND) [1]. Most NMD and MND are progressive and people suffering from these diseases are treated with rehabilitation and medicine to decrease disease progression. Examples of NMD are Duchenne muscular dystrophy (DMD) and spinal muscular atrophy (SMA). Due to the fact that the reduced muscle capacity causes physical disabilities, people with DMD often have to rely on assistance with their activities of daily living (ADL), either from caregivers or assistive devices. Relying on professional caregivers increases the health care costs. In order to limit the number of caregivers, but at the same time maintain the same quality of life, assistive devices are needed. These devices are wearable passive or active (mechatronic) orthoses and are meant to improve the quality of life of people with disabilities.

The Symbionics project, a continuation of the Flextension project, was set up to enhance assistive technology development [2,3]. It was an umbrella project consisting of several sub-projects and collaborations between universities, companies and patient organizations (see 1.1). The common aim of each sub-project is to develop body-bounded devices that can actively support humans in order to improve their quality of life by focusing on the hand, trunk, head and foot. One sub-project (2.1) has been focusing on developing passive and active assistive devices to support the trunk and head of people with muscle weakness. This thesis is focused on control of an active assistive device for a 
trunk support.

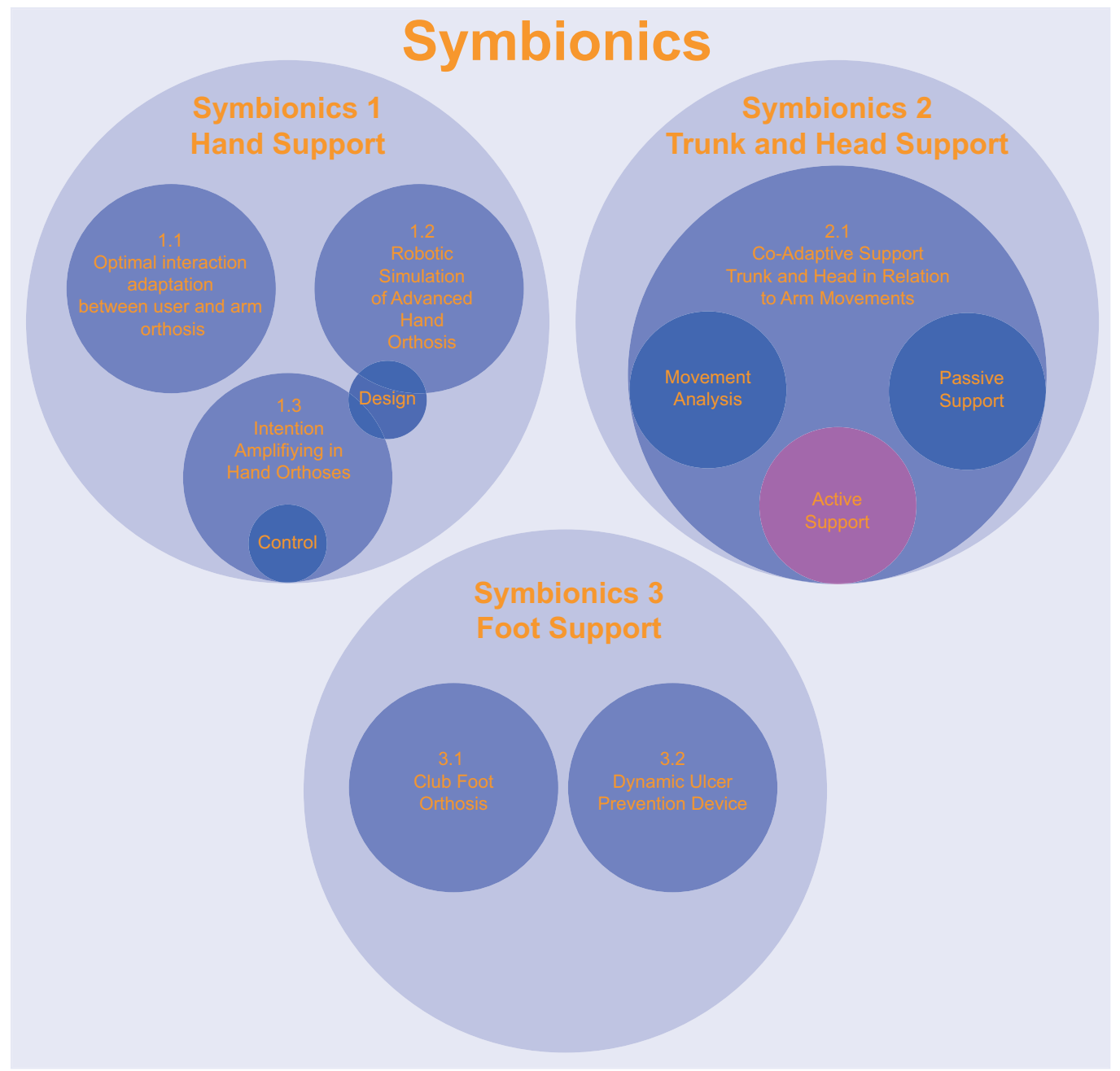

Fig. 1.1 Diagram of the Symbionics projects. Each sub-project, differentiated by a different number, is mainly carried out by 1-3 PhD and/or a PDeng student(s), and focuses on three main body segments: hand, trunk/head and foot. 


\subsection{Symbionics 2.1}

The aim of this project is to develop dynamic trunk and head supportive devices for people with neuromuscular disorders to assist them when performing daily activities. To achieve this goal, several Dutch universities (i.e., University of Twente, Vrije Universiteit Amsterdam and Radboud University Medical Center) participated, together with industrial partners (Focal Meditech, Baat Medical, Laevo, Summit Revalidatietechniek, Hankamp, Yumen Bionics) and patient organisations (Federation to eradicate Duchenne, Duchenne Parent Project, Parent Project Muscular Dystrophy and FSHD foundation).

This project was supported by the Netherlands Organisation for Scientific Research (NWO) (grant number 13524,13525$)$. The challenge in the project has been to develop devices (e.g., exoskeletons) close to the body, as inconspicuous as possible, which could integrate with the arm supportive device developed in the A-gear project. Potentially, the result would be an integrated comprehensive upper body assistive device to assist people with disabilities to perform ADL using the arm, trunk and head concurrently [3]. Both passive and active supportive devices are being developed. The passive devices assist in balancing the trunk or head by means of springs. The active devices can provide additional support, as muscle strength decreases further, through actuators and control strategies embedded in the passive designs.

The Radboud University Medical Center focused on the clinical perspective. Insight was gained on trunk and head function during seated arm tasks in the user groups to specify the requirements from the devices. The Vrije Universiteit Amsterdam was responsible for the design and development of the passive supportive devices. The University of Twente focused on the control interfaces and the active supportive devices.

(Note: The text above is identical in all the $\mathrm{PhD}$ theses written by the students in Symbionics 2.1.) 


\subsection{Duchenne Muscular Dystrophy}

Affecting 1 in 6000 live born males, DMD is the most common muscular dystrophy in humans and it is characterised by a gradual decrease in muscle strength [4]. The absence of the dystrophin protein is caused by a defective mutation in the dystrophin gene, resulting in muscle weakness. It mostly affects males. Females rarely have any symptoms but they can pass the mutation to their sons [1]. The gradual increase in muscle weakness results in the loss of gait function at the age of 12 and loss of upper body movement around the same age $[5,6]$.

Until now, there is no medication to prevent or cure DMD but it can increase the life expectancy of patients. In 1960, the life expectancy of people with DMD was 14 years but the use of Corticosteroids and nocturnal ventilation increased it to 25 years in 1990 and currently to 30 years [5, 7]. Despite the increase in life expectancy, studies have shown that the Health Related Quality of Life (HRQoL) still decreases for people with DMD due to low muscle strength, compared to healthy controls [8, 9]. As a consequence, people with DMD have to depend more and more on caregivers as the years go by. A possible improvement could be the development of assistive devices for people with DMD to perform ADL and as a result depend less on caregivers [10].

\subsection{Assistive devices for people with DMD}

Several assistive devices are being used by people with DMD, from scooters and night splints to Hoyer lifts and wheelchairs, all aiming to increase their quality of life and to maintain independence $[11,10]$. Passive arm supports have been tested by people with DMD with the benefits recorded as increased Range Of Motion (ROM) of the upper extremities and decreased time on ADL activities [12]. Research has shown that people with DMD can control an active elbow support with the use

of force based and sEMG (surface Electromyography) based control interfaces [13]. As the DMD progresses, more assistance is needed which could possibly be provided by an active trunk support (Fig. 1.2). According to Jansen et al., use it or lose it is a common saying that is applicable to people with DMD [14]. Hence, it was decided not to assist people with DMD with an active trunk support 
from the start, but to let them use their muscles as much as they can with a little support at first. As muscle strength decreases, extra support can be added as required.

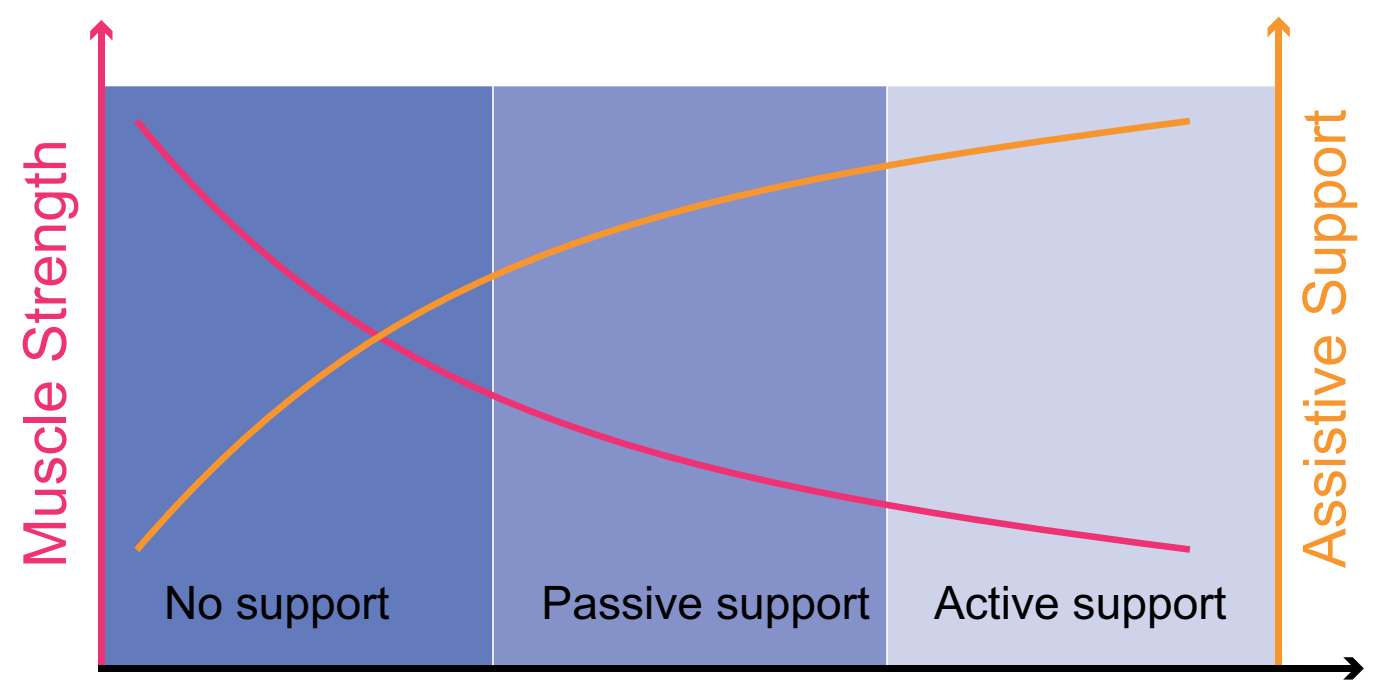

\section{Time}

Fig. 1.2 The muscle strength of people with DMD decreases with time. The aim of Symbionics 2.1 was to support the trunk of people with DMD by assisting the lessening muscle strength with external assistive devices. In the beginning, a passive support can compensate for the lost muscle strength and, as the muscle strength decreases further, assistance can be provided by an active trunk support.

\subsection{Importance of a Trunk Support}

Moving the trunk plays a significant role when performing daily tasks [15]. Reaching for a target (i.e., picking up a glass of water) requires trunk coordination with respect to the reaching arm and it is a rather complex motor task [16]. Also, trunk motion is needed for maintaining postural stability during daily tasks [17].

Symbionics 2.1 entailed three sub-projects: user involvement, passive trunk support, and active trunk support.

The user involvement project concluded that the interaction between the trunk and arm is essential for accomplishing daily tasks [18]. Consequently, when designing an assistive device for people with weak trunk muscles, such as for people with DMD, the key role of the trunk should be taken 
into account [19]. A benefit of trunk motion, in combination with arm support, is that the arm reaching distance can be increased [20]. Consequently, a trunk support device is needed in order to assist people with DMD to perform ADL. This contribution was taken into account when quantifying the design requirements of the research.

A passive trunk support was designed and tested in an experimental environment by people without and with early stage DMD. The main feature is gravity compensation of the upper body weight using springs. During the tests, it decreased the sEMG activity of the trunk muscles (Fig. 1.3) [21]. Thus, it can be used by people with DMD with decreased muscle activity in order to perform ADL tasks with less fatigue.

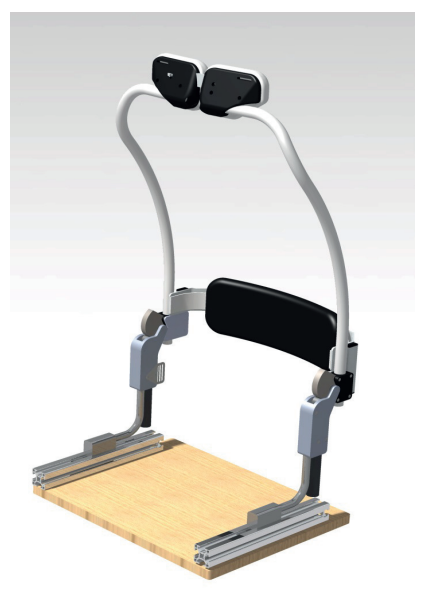

Fig. 1.3 Passive trunk support

The active trunk support was the focus of this thesis which concentrated on the actuation and control of the passive trunk support (Fig. 1.4).

\subsection{Control Interfaces}

In order to operate and control an active assistive device, a control interface is needed. The control interface is responsible for converting the intended movement into a device movement. Numerous control interfaces are available for controlling active support devices, such as brain-computer interface (BCI), force sensor, EMG etc. [22]. Evaluating all the possible control interfaces by experimental 


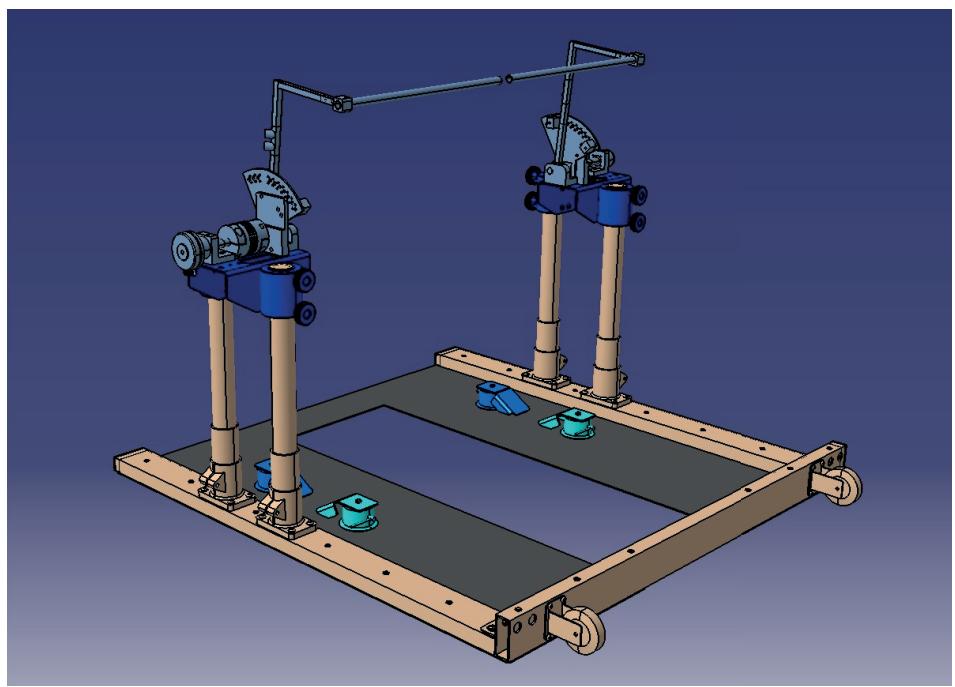

Fig. 1.4 Active trunk support.

procedures would be very time-consuming and expensive. Thus, we made an overview of the most suitable ones according to literature 1.1, and set some requirements that could narrow down the list of those control interfaces we should investigate. We scored each control interface from 1 to 10 based on subjective analysis from previous research. The requirements were:

- Intuitive: the user can use the control interface subconsciously without an enormous amount of mental effort. Hence, a BCI can be assumed to not fulfil this specification because it requires mental effort to generate the brain signals required to control the trunk support. In contrast, peripheral signals like force on sternum or EMG can be more natural and intuitive than BCIs.

- Independence (from other body parts): The control interface should not involve other body parts except for the one that is being supported.

- Robust: Several factors can influence the performance of the control interface, such as moving it during donning, different environmental conditions, external forces etc. All these factors may affect the activation of the sensor interface. Also, certain characteristics, such as the different body morphologies, short-term changes and long-term changes (i.e., daily fatigue and physiological changes), must not influence the performance of the control interface. 
- Autonomy: In an ideal world, assistive device users should not need any help from third parties with the preparation of the sensors, calibrating the system and donning and doffing the device. Sensors that are integrated into the assistive device have a clear advantage regarding the independence of the user. Also, simplifying the training procedure or minimising the time of training can increase the independence.

- Customizable: The sensor interface should be able to cope with the morphology of the body, physiological signals and pathology characteristics and has to be able to adapt to long-term and short-term changes with disease progression.

- Low price: Price will also play a vital role since the assistive device should cost less than 400 euros.

- Speed: the control interfaces should enable the subjects to move with a speed of 10 degrees/sec.

- Accuracy: the control interface should be accurate in terms of movement, to less than $3 \mathrm{~cm}$ accuracy, and following the subjects intentions.

After scoring each control interface (Table 1.1), we found that the ones with the highest total score were: sEMG from trunk muscles, force on feet, force on sternum and joystick. For convenience, joystick, force on sternum, force on feet and sEMG will be referred as (J), (FS), (FF) and (E) respectively in the rest of the thesis. To evaluate the performance difference of the control interfaces, we undertook several experiments to see which ones gave better requirement scores.

\subsection{Experimental Evaluation Methods for Control Interfaces}

Experimental evaluation methods are used for providing objective information about the effectiveness of different control interfaces. The information can be used to select the most appropriate control interface for the specific assistive device. The most common evaluation method uses a Graphical User Interface (GUI) with a target and a cursor. The target is controlled by the researcher and it is 
Table 1.1 Control interface scores of the pre-evaluation procedure.

\begin{tabular}{|c|c|c|c|c|c|c|c|c|c|c|c|}
\hline \multirow{2}{*}{$\begin{array}{c}\begin{array}{c}\text { Physiological } \\
\text { phenomena }\end{array} \\
\text { Sensor }\end{array}$} & \multicolumn{2}{|c|}{$\begin{array}{c}\text { Electric current } \\
\text { of muscle }\end{array}$} & \multicolumn{2}{|c|}{ Force } & \multirow{2}{*}{$\begin{array}{c}\begin{array}{c}\text { Movement } \\
\text { of small } \\
\text { body } \\
\text { segments }\end{array} \\
\text { Joystick }\end{array}$} & \multirow{2}{*}{$\begin{array}{c}\begin{array}{c}\text { Electric } \\
\text { current } \\
\text { of brain } \\
\text { activity }\end{array} \\
\text { EEG }\end{array}$} & \multicolumn{2}{|c|}{$\begin{array}{l}\text { Electric } \\
\text { current }\end{array}$} & \multirow{2}{*}{$\begin{array}{c}\text { Eye } \\
\text { motion }\end{array}$} & \multirow{2}{*}{$\begin{array}{c}\text { Tongue } \\
\text { motion }\end{array}$} & \multirow{2}{*}{$\begin{array}{l}\text { Speech } \\
\text { Mic. }\end{array}$} \\
\hline & sEMC & trode & $\begin{array}{r}\text { Force } \\
\mathrm{Se}\end{array}$ & & & & $\begin{array}{r}\text { Strain } \\
\text { wear } \\
\text { sen } \\
\end{array}$ & & & & \\
\hline $\begin{array}{c}\text { Signal } \\
\text { measured from }\end{array}$ & trunk & leg & feet & trunk & fingers & brain & trunk & $\begin{array}{l}\text { Other } \\
\text { limbs }\end{array}$ & $\begin{array}{l}\text { Corneal } \\
\text { reflection }\end{array}$ & $\begin{array}{c}\text { Contact } \\
\text { with } \\
\text { palate }\end{array}$ & Mouth \\
\hline \multicolumn{12}{|l|}{ Criteria } \\
\hline Intuitiveness & 5 & 2 & 2 & 5 & 5 & 2 & 5 & 2 & 2 & 2 & 2 \\
\hline Independence & 5 & 2 & 2 & 5 & 1 & 5 & 5 & 0 & 1 & 1 & 1 \\
\hline Robustness & 5 & 5 & 2 & 2 & 3 & 5 & 2 & 2 & 4 & 3 & 3 \\
\hline Autonomy & 5 & 4 & 4 & 5 & 5 & 1 & 1 & 1 & 0 & 0 & 0 \\
\hline Customizable & 5 & 5 & 4 & 4 & 5 & 2 & 3 & 3 & 5 & 5 & 5 \\
\hline Price & 5 & 5 & 5 & 5 & 5 & 1 & 5 & 5 & 1 & 1 & 1 \\
\hline Speed & 3 & 3 & 4 & 5 & 4 & 1 & 1 & 1 & 4 & 4 & 1 \\
\hline Accuracy & 3 & 3 & 4 & 4 & 5 & 1 & 1 & 1 & 1 & 1 & 1 \\
\hline Result & 4,50 & 3,63 & 3,38 & 4,38 & 4,13 & 2,25 & 2,88 & 1,88 & 2,25 & 2,13 & 1,75 \\
\hline
\end{tabular}

used as an excitation signal. The cursor is controlled by the subject with the aim to steer it towards the target.

One method of determining the performance of the (J), (FS), (FF) and (E) control interfaces is by carrying out position tracking task experiments, during which tracking error, information transfer rate, crossover frequency and effort are evaluated [23, 24]. A target, moving in a multi-sinusoidal manner, is tracked by a cursor operated by the subjects participating in the experiment.

As an alternative, a discrete approach can be used for the evaluation. In this method, a static target is displayed and the subject has to steer the cursor into the target as fast and as accurately as possible. The distance between the initial point of the cursor and the target, together with the width of the target, define the Index of Difficulty (ID) of the task. According to Fitts et al., the modelling of the speed-accuracy trade-offs when tapping or attaining the movements is linear [25, 26]. Fitts' law has been used as an evaluation method for comparing control interfaces, machine learning approaches to the interfaces, and different damping conditions in one or multiple dimensions $[27,28,29,30,31$, 32]. The most common performance metrics are time, throughput, path efficiency, reaction time and overshoot.

The current research applied Fitts' law as the evaluation method due to the fact that we assumed 
that discrete target tasks resemble the reaching movements of daily tasks rather than the multisinusoidal targets.

\subsection{Objectives and Research Questions}

To our knowledge, no active trunk support system exists that can be used by people with DMD. We hypothesise that an active trunk support can provide additional assistance and, as a consequence, improve the quality of life of people with DMD. As shown before, five potentially useful control interfaces were chosen for further experimental evaluation.

The goal of this dissertation is thus: "evaluation of control interfaces for an active trunk support for people with DMD”. In order to obtain this, four research questions were formulated: 


\section{Research Questions}

I. Is there an alternative to the intuitive trunk control interface to help the trunk muscles? One of the most common intuitive control interfaces is (E). The (E) signals, which come from the trunk muscles, can be used to control an active assistive device. However, it is hard to detect these signals in some cases (e.g., when there is a significant amount of fat concentrated in the abdomen area). A solution could be a non-intuitive control interface.

II. Which control interface performs better for an active trunk support? An active trunk support needs a control interface in order to function. We built an experimental setup to test the performance of different intuitive and non-intuitive control interfaces. The performance of the control interface is crucial when deciding which one is most suitable for people with DMD.

III. Which assistive admittance controller performs best in a 1-D Fitts's law task? The disadvantage of the admittance control, is that the values of the virtual mass, damping and inertia are fixed to a hypothetical optimal performance. Therefore, more sophisticated admittance control algorithms have to be used to achieve higher performance.

IV. Do people with DMD generate satisfactory signals which can potentially drive an active trunk support? The performance of the various control interfaces for an active trunk support can differ between people with and without DMD. Moreover, people with DMD may not attain the same performance level with the control interfaces as people without DMD. This leads to the conclusion that the control interfaces have to be optimised for people with DMD.

\subsection{Dissertation outline}

Fig. 1.5 depicts an outline of the thesis.

- Chapter 2 presents a first evaluation of two types of control interfaces using a screen-based one-dimensional position task. Movement time, path efficiency and throughput were assessed. 


\section{Chapter 1: \\ Introduction}

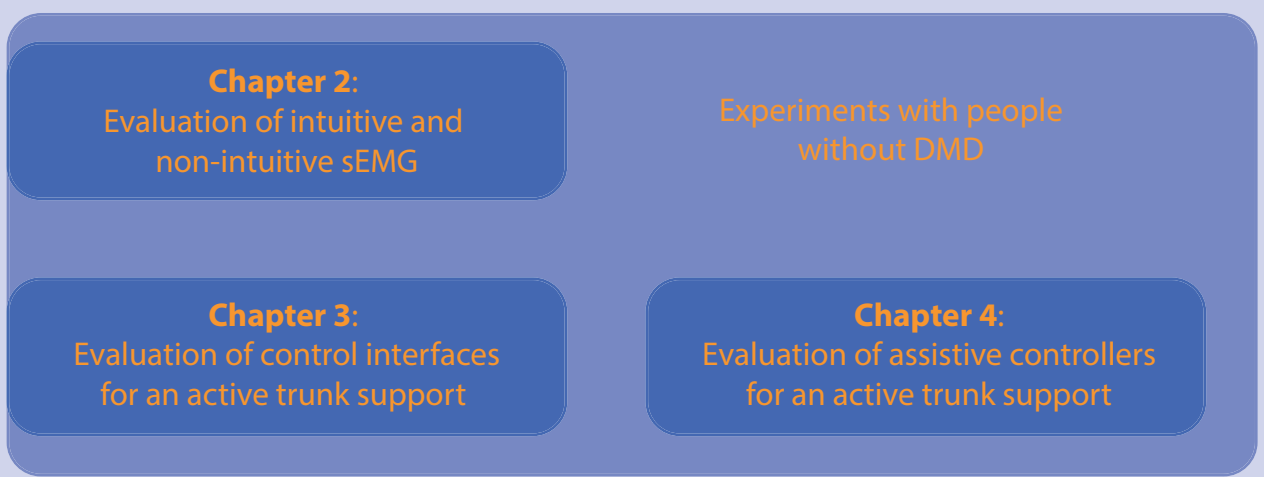

\section{Chapter 5:}

Exploring physiological signals

on people with DMD

\section{Chapter 6:}

Conclusions

Fig. 1.5 Thesis Outline.

The evaluation should show the potential feasibility of the non-intuitive controls.

- Chapter 3 presents a novel active trunk support assistive device and the evaluation of four control interfaces by 10 subjects without DMD. The interfaces that were evaluated with onedimensional position tasks using the leg muscles were the (J), (FS), (FF) and (E). Since nonintuitive control interfaces could be used as an alternative according to the previous chapter, (E) from leg muscles and force on feet were included as control interfaces in this experiment. The performance of the control interfaces was evaluated using the movement time, throughput, reaction time, path efficiency, overshoot and a questionnaire that was given to the subjects. 
- Chapter 4 presents the development and assessment of three admittance controllers. The disadvantage of an admittance control is that its virtual values have to be fixed through an experimental procedure to a hypothetical optimal value. We investigated several advanced admittance controllers in terms of higher performance, including the standard admittance, admittance with feedforward force and variable admittance. The performance of the controllers was evaluated using the movement time.

- Chapter 5 presents the experiments to explore the presence of physiological signals in people with DMD. One active and one static experiment were performed with 3 people with DMD.

- Chapter 6 includes the discussion section. This section answers the research questions and discusses the research on the topic of active trunk support.

All chapters of this dissertation (excluding the introduction and discussion) have been submitted to conferences or journal publications. 


\title{
Evaluation of intuitive trunk and
}

\section{non-intuitive leg sEMG control interfaces as}

\section{command input for a 2-D Fitts' law style}

\section{$\operatorname{task}^{1}$}

\begin{abstract}
Duchenne muscular dystrophy (DMD) is a muscular condition that leads to muscle loss. Orthotic devices may present a solution for people with DMD to perform activities of daily living (ADL). One such device is the active trunk support but it needs a control interface to identify the users intention. Myoelectric control interfaces can be used to detect the users intention and consequently control an active trunk support. Current research on the control of orthotic devices that use surface electromyography (E) signals as control inputs, focuses mainly on muscles that are directly linked to the movement being performed (intuitive control). However in some cases, it is hard to detect a proper (E) signal (e.g., when there is significant amount of fat), which can result in poor control performance. A way to overcome this problem might be the introduction of other, non-intuitive forms of control. This paper presents an explorative study on the comparison and learning behavior of two different control interfaces, one using (E) of trunk muscles (intuitive) and one using (E) of leg

\footnotetext{
${ }^{1}$ This chapter has been published as: Stergios Verros, Koen Lucassen, Edsko E.G. Hekman, Arjen Bergsma, Gijsbertus J. Verkerke, Bart F.J.M. Koopman, "Evaluation of intuitive trunk and non-intuitive leg (E) control interfaces as command input for a 2-D Fitts' law style task", PlosOne April 3, 2019.
} 
muscles that can be potentially used for an active trunk support (non-intuitive). Six healthy subjects undertook a 2-D Fitts' law style task. They were asked to steer a cursor into targets that were radially distributed symmetrically in five directions. The results show that the subjects were generally able to learn to control the tasks using either of the control interfaces and improve their performance over time. Comparison of both control interfaces demonstrated that the subjects were able to learn the leg control interface task faster than the trunk control interface task. Moreover, the performance on the diagonal-targets was significantly lower compared to the one directional-targets for both control interfaces. Overall, the results show that the subjects were able to control a non-intuitive control interface with high performance. Moreover, the results indicate that the non-intuitive control may be a viable solution for controlling an active trunk support. 


\subsection{Introduction}

Duchenne muscular dystrophy (DMD) is characterized by progressive skeletal muscle weakness and predominantly affects males with a prevalence of 1 per 6,000 [4]. Thanks to medication, the life expectancy of individuals with DMD has been increased and it is currently estimated to be over 30 years [7]. Loss of muscular activity leads to decrease in activities, participation and autonomy. Research has shown that Health Related Quality of Life (HRQoL) is significantly lower for people with muscular dystrophy when compared to healthy controls [9]. The increase of life expectancy with the decrease of muscle force consequently increases the dependency on caregivers.

Orthoses have the potential to assist people with DMD to perform activities of daily living. Some examples are arm orthoses that reduce gravity effects and assist the user in reaching tasks [12]. Those devices mainly provide passive support to overcome gravity, but research is being done on active arm orthoses for people with DMD [13]. In order to increase the reachable workspace, some level of trunk movement is important. Hence the Symbionics project was started with the aim to support trunk movements by orthotic devices. It was shown that that the movement of the trunk plays an important role in activities of daily living and that people with DMD can benefit from passive trunk support [33, 21]. However, with progressing DMD patients have less muscle capacitance and thus need additional assistance by an active support. Thus, part of the Symbionics project was dedicated to the development of an active trunk support. An extra benefit is an increase of the arm reach when an active trunk support is combined with an arm support [20]. To our knowledge, there is no active trunk assistive device yet.

To detect the users intention, (E) can be used [34],[35]. It has been shown that adequate signals can be measured in persons with DMD and there is a straightforward relationship between the (E) and the intended movement [22].

Using (E) signals from muscles that are related to the movement of the supported anatomy is considered to be most intuitive to control an orthotic device. However, there may also be challenges to measure a (E) on particular muscles. In the case of the trunk, one specific challenge is that respiratory muscles are located in the trunk as well and can easily disturb the control signal. Another is that 
muscles are often covered by fat, especially those in the abdomen, which consequently reduces the quality of the (E) signal.

One way of overcoming those problems could be to record the (E) from muscles that are not directly related to trunk movements (this is called non-intuitive in this article). The human brain has the ability to adapt to a certain level of non-intuitiveness [36]. It can form inverse models of space, optimize control strategies and learn new muscle synergies while completing physical tasks [37]. Furthermore, non-intuitive control interfaces have been used to drive a wheel chair [38]. The aim of this study was to evaluate the performance of an intuitive and a non-intuitive control interface for active trunk support. Regarding the non-intuitive control interface, we chose to record (E)s from the tibialis anterior and gastrocnemious, muscles in the legs, because those muscles can be contracted easily while sitting and are usually covered by less fat tissue than the trunk muscles. While the performance of an intuitive and a non-intuitive interface that controls a 2-D cursor using arm muscles has been studied before, no known study has compared control interfaces based on (E) signals from the legs and trunk [39].

To compare an intuitive control interface with a non-intuitive control interface, we designed and performed a 2-D experiment based on Fitts' law under isometric conditions. The information that a motor task can convey is finite and this limitation of information is a consequence of the effort required for performing a movement both as rapidly and as accurately as possible [40]. This speed/accuracy trade-off is known as Fitts' law and it holds for human motor tasks [28]. Moreover, it has been used for comparing different control interfaces [28].

The hypothesis is that the performance of the non-intuitive control interface is comparable to the intuitive one and thus can be used to control an active trunk support.

\subsection{Materials and methods}

\subsubsection{Participants}

Six healthy volunteers, without any prior experience of (E)-based control, were recruited after obtaining informed consent. The research was explorative and thus did not fall within the scope of the Dutch 
Medical Research Involving Human Subjects Act. The experiment consisted of a single session and did not pose any risks or burden to the subjects. The CMO Regio Arnhem-Nijmegen committee under Prof. Dr. P.N.R. Dekhuijzen had decided that the ethical approval is waived. Registration number: 2018-4933.

\subsubsection{Test set-up and signal acquisition}

The subjects sat on a mechanical frame that prevented any trunk or leg movement during the experiment (Fig. 2.1). Due to the fact that the subjects were lifting their legs during experiment $\mathrm{A}$ we decided to fix them. On the other hand, subjects did not move their trunk during experiment B so we let the trunk free. The experimental setup included a personal computer (PC) with an external monitor to present visual feedback to the subjects and an $\mathrm{xPC}$ target computer with a data acquisition card (PCI-6229; National Instruments Corp., USA, sampling at $1 \mathrm{KHz}$ ). The muscle activation signals were measured with wireless (E) sensors (Trigno Delsys, USA).

\subsection{3 (E) Signal processing}

In order to control a 2-D task, two pairs of antagonistic muscles were used for each of the two experiments. Each antagonistic pair of muscles controlled a 1-D movement. The cursor could also be controlled diagonally on the screen by a combination of the two antagonistic pairs. Regarding the trunk control interface, (E) sensors were placed on the rector abdominis muscle (placement: 1/2 of the line between the belly bottom and groin area) and the erector spinae muscle (placement: 2 fingers lateral of the spine at L1 level) to control the vertical movement whereas the left and right oblique muscles (placement: $17 \mathrm{~cm}$ from belly button) were used to control horizontal movement. Regarding the leg control interface, (E) sensors were placed on the left gastrocnemius muscle (placement: 1/3 of the line between the head of the fibula and the heel) and tibialis anterior muscle (placement: $1 / 3$ of the line between the head of the fibula and the tip of the medial malleolus) for vertical movement whereas the right gastrocnemius muscle and tibialis anterior muscle were used to control horizontal movement. 


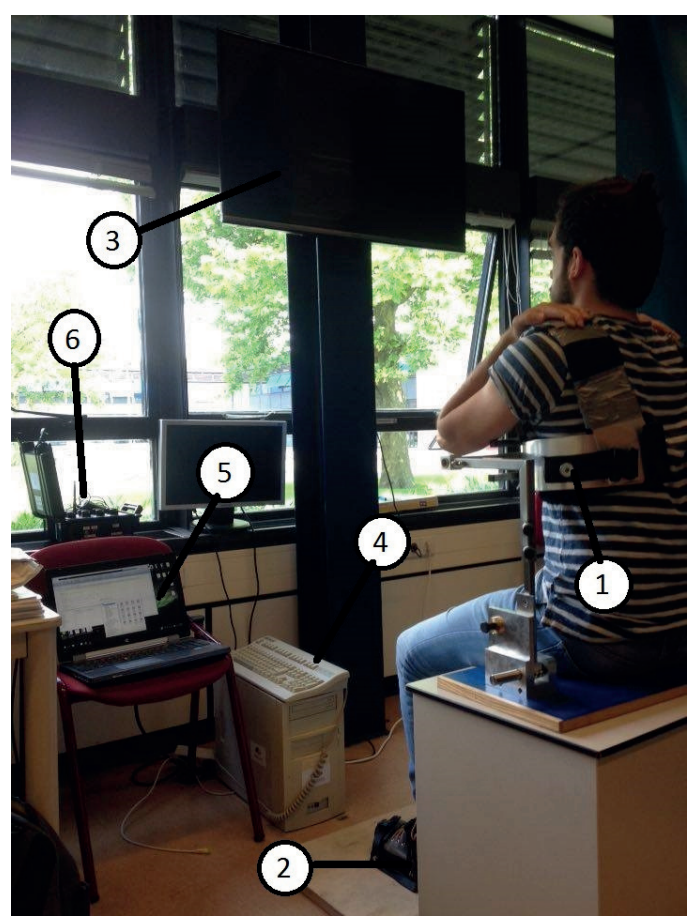

Fig. 2.1 Test setup. In experiment A (intuitive control using trunk muscles), the subjects were seated on a chair while their trunk (1) and feet (2) were fixed with straps to the mechanical structure. In experiment B (non-intuitive control using leg muscles), only the subjects feet were fixed with straps (2). The data from the (E) sensors were sent wireless to a base unit (6) that was connected to the xPC computer (4) which processed the data and sent the output to the PC (5). The screen (3) showed the cursor and the target to the subject.

The (E) data were filtered with a high pass filter (3rd order Butterworth: cutoff $40 \mathrm{~Hz}$ ), a rectifier function and subsequently, a low pass filter (3rd order Butterworth: cutoff $2 \mathrm{~Hz}$ ). The normalized EMG signals, $(E)_{n o r, k}(i)$ were obtained using Eq. (2.1).

$$
(E)_{n o r, k}(i)=\left(\frac{(E)_{e n v, k}(i)-(E)_{r e s, k}}{(E)_{\text {sub }, k}}\right)^{1.5}
$$

where subscript $\mathrm{k}$ represents the abbreviations of the control muscles, $(E)_{e n v, k}(i)$ denotes the processed (E) signal at the i-th time step. $(E)_{s u b, k}$ represents the submaximal contraction of the subject, $(E)_{r e s, k}(i)$ represents the average signal amplitude during rest. The normalized signal was limited to a value of one to prevent velocities higher than the maximum velocity. The sub-maximum contraction 
value of each subject was determined by 2 seconds of sub-effort. The subjects were asked to contract their muscles at a level that did not need the maximum effort. The power function made the control of small movements easier.

After normalization, the muscles were mapped into the corresponding direction. The mapping function $(Q)$ is a $2 \times 4$ matrix which maps the $4 \times 1$ vector $e$ of the normalized (E) amplitudes to a $2 \times 1$ vector CursorVelocity of control outputs. The first (last) two instances of the $e$ vector are the cursor velocities of one pair of antagonistic muscles that steer the cursor in the horizontal (vertical) axis. The mapping function for this control can be seen in Eq (2.2-2.4). MaxVelocity was set to the maximum fixed velocity of the cursor(400 pixels/s). The $(E)_{r e s, k}(i)$ was also integrated in order to have a velocity mapping. Compared to position mapping, velocity mapping has the advantage to help the subjects to keep the cursor into the target without contracting their muscles. Each set of muscles only maps one of the two control axes required for the task (Table. 2.1).

$$
\begin{array}{r}
\text { CursorVelocity }=Q * e * \text { MaxVelocity } \\
e=\left[\begin{array}{l}
(E)_{\text {nor }, 1}(i) \\
(E)_{\text {nor }, 2}(i) \\
(E)_{\text {nor }, 3}(i) \\
(E)_{\text {nor }, 4}(i)
\end{array}\right] \\
Q=\left[\begin{array}{cccc}
-1 & 1 & 0 & 0 \\
0 & 0 & -1 & 1
\end{array}\right]
\end{array}
$$

\subsubsection{Experimental procedure}

Each set of muscles only maps one of the two control axes required for the task [28]. The experiment included two tasks: an intuitive controlled task (A) and a non-intuitive controlled task (B) and in the experiments the order was randomized per subject. In both tasks, the subjects were asked to steer the cursor into the target on the screen as quickly and accurately as possible by contracting different sets 
Table 2.1 This table shows the mapping of muscle activation with movements of the cursor on the screen

\begin{tabular}{ccc}
\hline \hline Moving direction & Experiment A & Experiment B \\
\hline Right & Right external oblique & Right tibialis anterior \\
Left & Left external oblique & Right gastrocnemious \\
Up & Rectus abdominis & Left gastrocnemious \\
Down & Eroctor spinae & Left tibialis anterior \\
\hline
\end{tabular}

of muscles. According to Fitts' law, the Index of Difficulty (ID) is defined by Eq. (2.5), where D is the distance between the home position and the center of the target and $\mathrm{W}$ is the diameter of the target. In the current experiment, three different IDs were distinguished (2.3, 3.15 and 4.08). As the distance D was kept constant at 800 pixels, the differences in ID were only determined by the target widths of 200,100 or 50 pixels. Targets were spaced radially from the initial position in $0^{\circ}, 45^{\circ}, 90^{\circ}$, $135^{\circ}$ and $180^{\circ}$ directions, as shown in (Fig. $2.2 \mathrm{a}$ ).

A trial consisted of two movements: one center-out movement (home to target) was followed by a center-in movement (target to home), both with the same ID. At the start, the cursor (yellow) was at the home position. The center-out movement started when a target (red) appeared on the screen in one of the 5 possible locations. The subject had to steer the cursor into the target zone and keep it there for a dwell time of 2-s. As soon as this had been achieved, a new target appeared at the home position. To give this center-in target the same ID as the center-out target, the diameter was adjusted based on the instantaneous location of the cursor at the end of the center-out movement. Finally, the experiment was subdivided in 5 blocks of 15 trials each, after which a break was inserted.

$$
I D=\log _{2}\left(\frac{D}{W}+1\right)
$$

\subsubsection{Performance metrics}

The performance differences of experiments (A) and (B) were assessed by measuring Movement Time (MT), throughput (TP) and path efficiency (PE). 


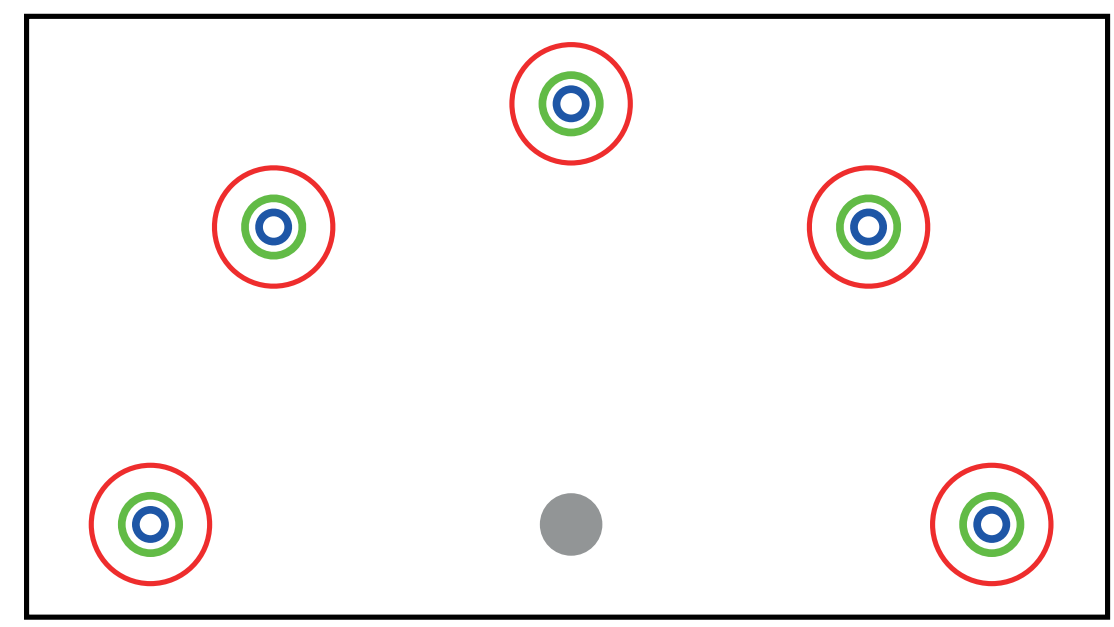

(a)

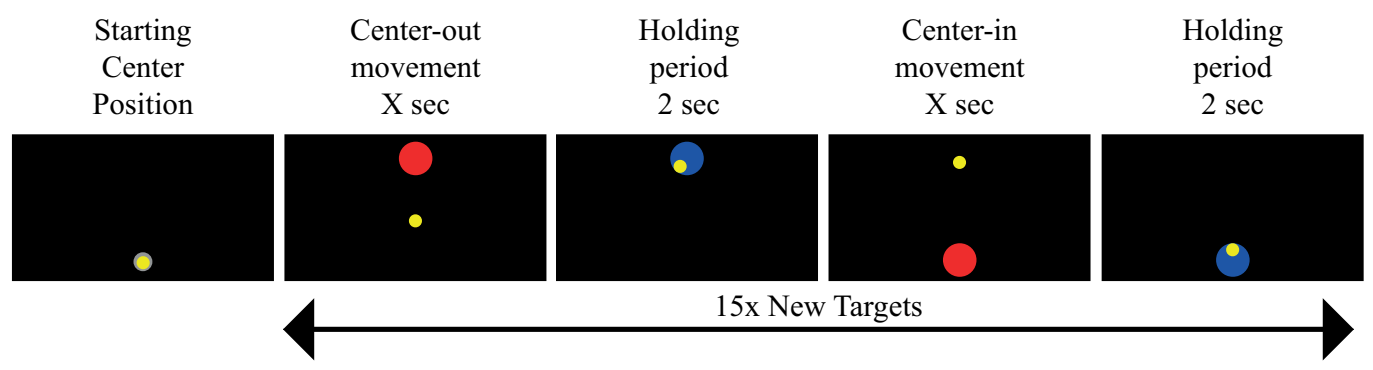

(b)

Fig. 2.2 Experimental layout. (a) Targets configuration; (b) Trial sequence. Subjects performed 15target center-out and center-in trials by controlling a cursor (yellow) from a starting area to one of the targets (red) shown on the screen.

The Movement Time (MT) is the time that is needed for a successful trial without the 2-s target dwell time. To calculate the linear regression we followed Eq. (2.6).

$$
M T=a \cdot I D+b
$$


Throughput (TP) is the information transfer rate and is a measure of the amount of information that the subject can process through a particular command source in relation to the task, in this case the cursor control [28]. The TP was computed using Eq. (2.7).

$$
T P=\frac{I D}{M T}
$$

Path efficiency (PE) is a measure of the straightness of the cursor path to the target. Path efficiency is computed by Eq (2.8), where the linear distance between the points is divided by the actually travelled distance.

$$
P E=\frac{\text { Linear Distance }}{\text { Actually Travelled Distance }} \times 100 \%
$$

Direction ratio shows the performance, TP and PE based on the direction. It is defined as the ratio of the average performance of each direction divided by the maximum performance.

Learning behavior is defined as the change of the performance of the throughput across the experimental blocks. A sigmoid function, Eq. (2.9), was used to fit the data points.

$$
f(x)=\frac{1}{1+e^{-a(x-c)}}+b
$$

\subsubsection{Data analysis}

The performance metrics described above were applied for the data analysis. The linearity between MT and ID was employed to check the consistency with Fitts' law. MT, TP and PE were used to evaluate the performance of the two tasks considering only the last 3 blocks. The average of every experimental block was calculated for every metric and for the MT per ID as well. For the learning behavior, statistical analysis was performed between the TP of the last 2 blocks of the experiment. The Kolmogorov-Smirnov test showed that the data were not normally distributed. Thus, a nonparametric test, the Wilcoxon Signed Rank-test, was used with a level of significance at $\mathrm{p}<0.05$. 


\subsection{Results}

Six subjects participated in the study. One subject did not complete experiment A (only three out of five blocks were completed). However, all the data of the six subjects were included in the analyses.

\subsubsection{Fitts' law}

The plots of the regression analyses of MT versus ID are shown on Fig. 2.3. The MT increases proportionally as the ID increases. The coefficient of determination for the non-intuitive control interface is higher $\left(R^{2}=0.746\right)$ than the intuitive control interface $\left(R^{2}=0.524\right)$.

\subsubsection{Movement Time}

There was no significant difference in movement time between the two control interfaces for the lowest ID (2.3), whereas the 3.15 and 4.08 IDs demonstrated a significant difference in movement time between the control interfaces, with the non-intuitive control interface being faster Fig. 2.4. 


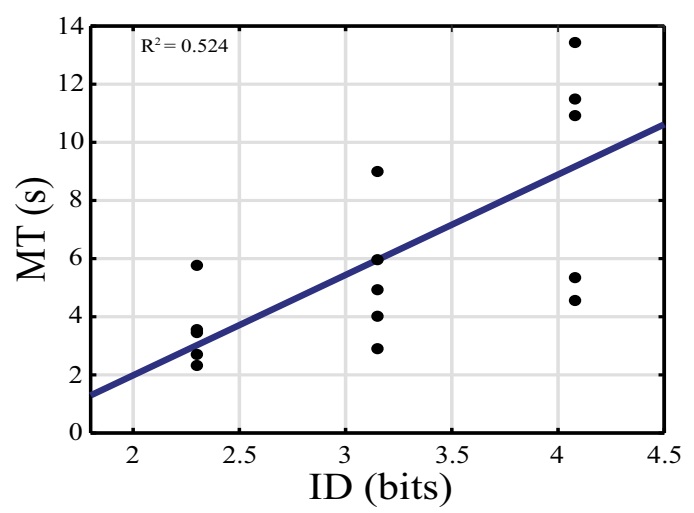

(a)

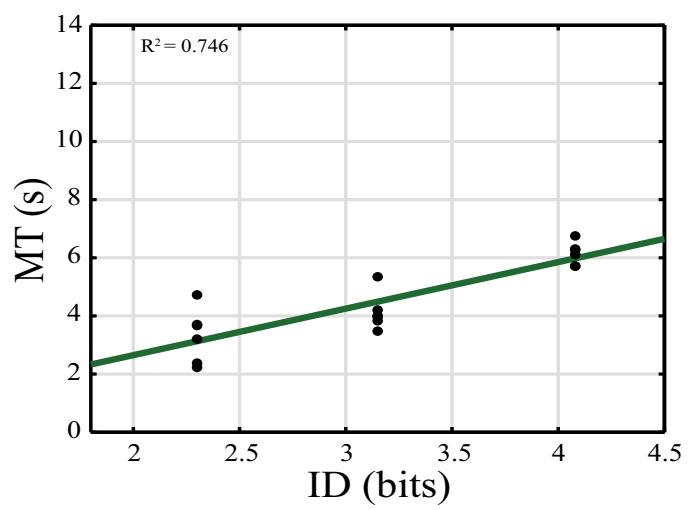

(b)

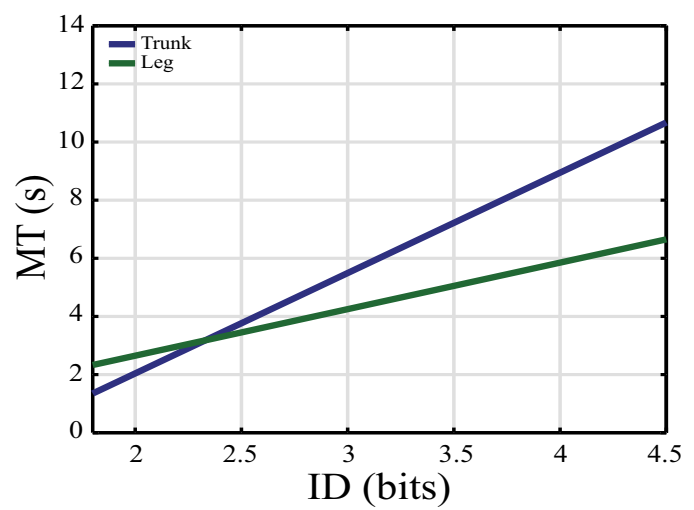

(c)

Fig. 2.3 The linear regression of ID in bits versus the movement time (MT) in seconds. (a) Linear regression of the intuitive control interface, (b) of the non-intuitive control interface and (c) their comparison. The mean of each subject for every ID and control interface is indicated with a circle. 


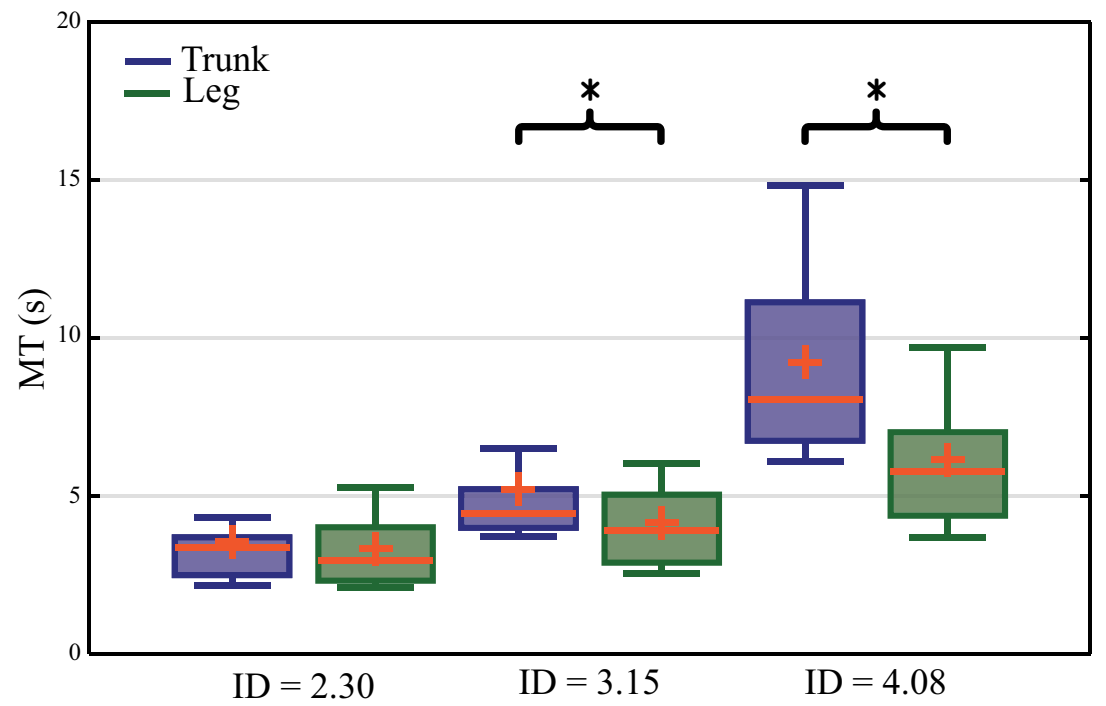

Fig. 2.4 Boxplots of movement times. Boxplots of the movement times (MT) of the trunk and leg control interfaces, for each of the three IDs. * represents a statistical difference $(\mathrm{p}<0.05)$.

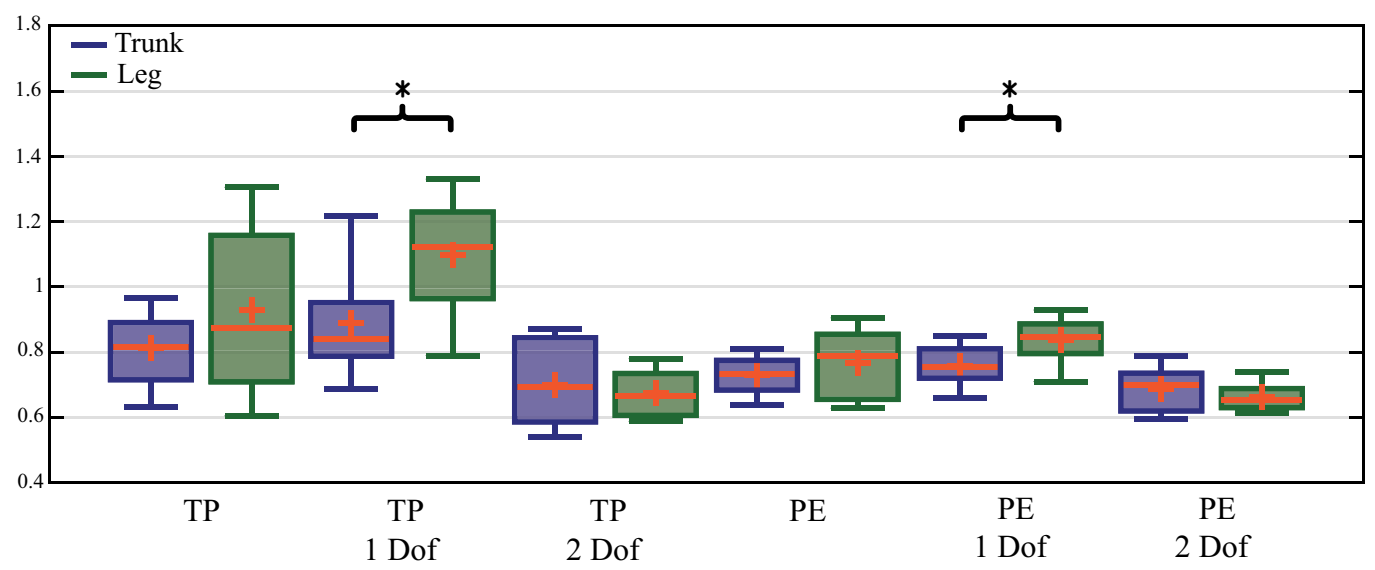

Fig. 2.5 Path efficiency and Throughput comparison boxplots. Comparison of intuitive and nonintuitive controlled interfaces for throughput and path efficiency. Overall performance stands for all movements combined, 1-Dof for movements that only required one pair of antagonistic muscles, 2-Dof for movements that needed two pairs of antagonistic muscles. 


\subsubsection{Path efficiency and Throughput}

The PE and TP performance metrics were analyzed for two conditions, one being independent of the target direction and the other being dependent on the target direction. The 1-Dof analyzed the movement whereby the subjects had to steer the cursor using only one pair of antagonistic muscles whereas the 2-Dof analyzed the subjects movement as they steered the cursor using two pairs of antagonistic muscles. Fig. 2.5 shows that there is no significant difference between the two control interfaces in the overall performance of PE and TP. On the 1-Dof, the non-intuitive control interface showed greater performance and significance than the intuitive control interface, both in PE and TP. No significant difference was obtained on the 2-Dof.

The direction ratio shows the normalized performance from the highest PE and TP target direction Fig. 2.6. Regarding the TP, the non-intuitive control interface performed the best in the left and right direction which was controlled by the right leg muscles. The lowest performance occurred in the diagonal direction where one muscle of each antagonistic pair was needed. The intuitive control interface showed the highest performance occurred with the backward and forward movements controlled by the rectus abdominis and the erector spinae. The diagonal targets performed the worst. Regarding the PE, both control interfaces performed highly in the single direction and less well in the diagonal directions.

\subsubsection{Learning Behaviour}

The results of the statistical analysis between the last tasks indicate that both the leg and the trunk approached their steady performance state at the end of the experiment. There was no significant difference in throughput between the two last tasks for both control interfaces (for trunk $\mathrm{p}=0.877$, for leg $\mathrm{p}=0.149$ ). Fig. 2.7 shows the Sigmoid fit together with the data points for both control interfaces individually and their comparison. 

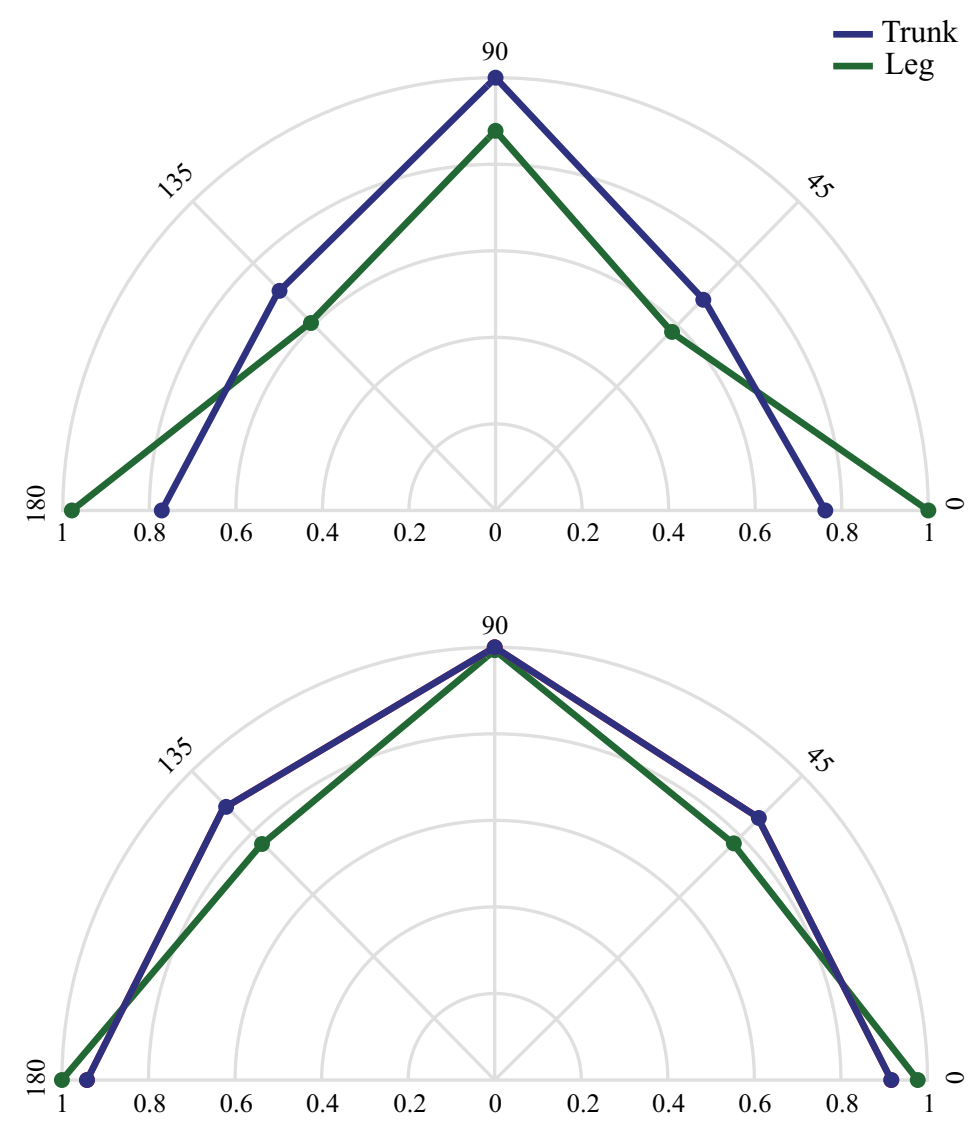

Fig. 2.6 Path efficiency and Throughput path direction ratio. Normalized target-direction performance of the performance metrics Throughput (a) and Path efficiency (b); Blue indicates the nonintuitive control and red indicates the intuitive control interface.

\subsection{Discussion}

Control interfaces based on (E) signals have the potential to control exoskeletons or orthotic devices. Intuitive control of an active trunk support based on (E) from trunk muscles can be insufficient so non-intuitive (E) control could be a valuable alternative solution. In this study, we compared the performance of two (E) based control interfaces which could be potentially used for an active trunk support. The control interface with (E) signals from trunk muscles was considered as intuitive whereas the control interface with (E) signals from leg muscles was considered as non-intuitive. 


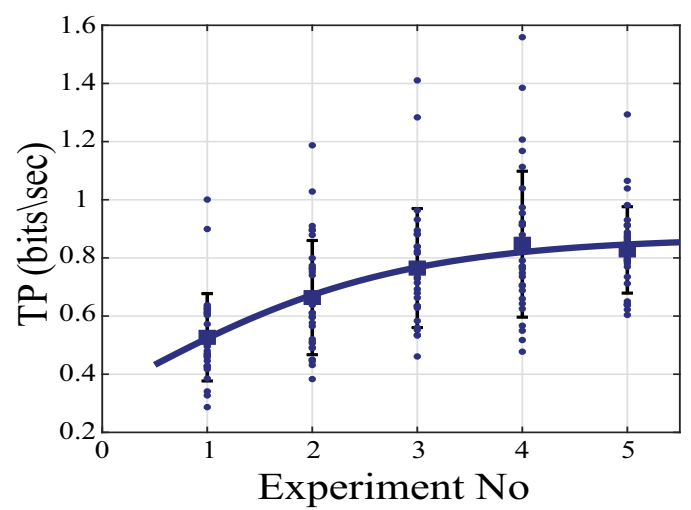

(a)

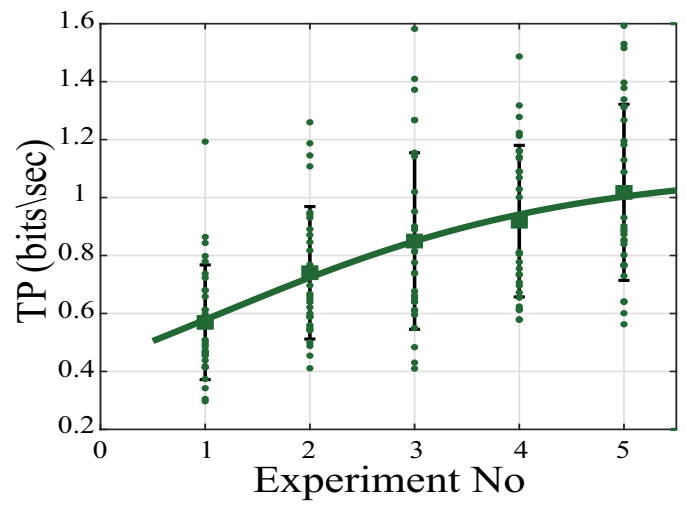

(b)

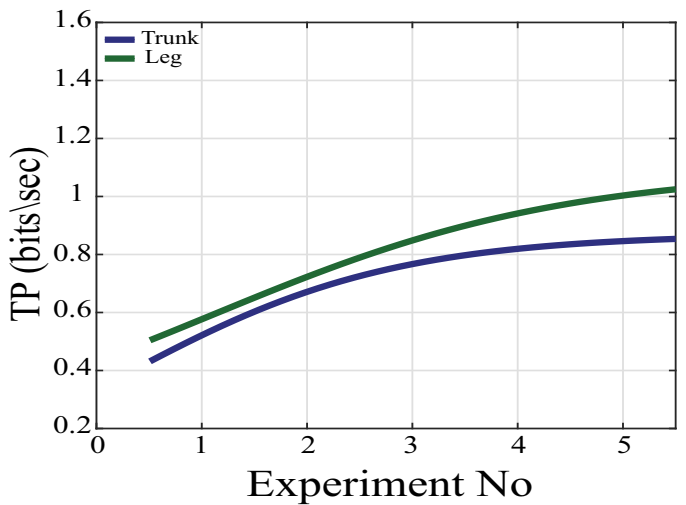

(c)

Fig. 2.7 Learning curve. (a) shows the learning curve for the intuitive control interface, (b) for the non-intuitive control interface and (c) the comparison. The mean of every target (for the 6 subjects) is shown as a square shape and the error bar indicates one standard deviation from the mean in both directions. 


\subsubsection{Fitts' law}

Fitts' law seems to hold for both control interfaces although the $\mathrm{R}$ values are lower than in other studies. The low $\mathrm{R}$ values can be explained by the fact that a) a steady state of the learning behavior was not reached b) dwell time was used instead of tapping or pressing a button c) the muscles that were involved in the tasks are not made to perform the same fine movement tasks as the hand. The regression plot for the trunk shows a high spread in average MT per ID. When comparing the regression coefficients, it can be concluded that the non-intuitive control interface has a tighter relationship between ID and MT based on the coefficient of determination. A note needs to be made that the targets in the experiment only varied in size and that the distance was kept constant, thus only the target size effect of Fitts' law was investigated.

\subsubsection{Performance Comparison}

The movement time shows that subjects can steer the cursor significantly faster with the non-intuitive leg control interface than the intuitive trunk control interface in relation to the 3.15 and 4.08 IDs. The sluggishness of the trunk control interface can be explained by the fact that the (E) signals from the trunk muscles are perturbed by respiratory muscle activity and the existence of body fat tissue.

The non-intuitive control interface of the 1-Dof direction performed significantly better in terms of TP and PE than the intuitive control interface. That can be explained by the fact that, despite the fact that the mechanical setup preventing any trunk or leg movement during the experiment, the subjects were still using their abdominal and back muscles to maintain an upright position. This muscle activation may have resulted in a disturbance that affected the performance. There are no significant differences in the 2-Dof due to the fact that both control interfaces needed one muscle from each pair of agonist/antagonist in order to complete the trial. There are no significant differences between the control interfaces for TP and PE but the non-intuitive control interface appears to be marginally superior.

It is notable from the path direction that the single direction targets were performed faster than the 
diagonal targets. This is a result of the fact that the subjects now had to activate two muscle groups simultaneously to perform the needed movement. This was significantly more difficult for the nonintuitive control mode. The poor initial performance of the intuitive control system was caused by the difficulty to activate specific muscle groups independently of each other. For example, the right and left oblique muscles are also tensed when contracting the abdominus rectus. When the subjects learnt to contract the muscles independently, they were able to control the cursor with high accuracy, resulting in a higher overall performance. The difficulty with the leg control is that it is a non-intuitive control system. When the subjects learned to associate the movement directions with the correct muscle contractions, high performance was achieved.

\subsubsection{Pattern recognition and abstract decoding}

Several methods for control could be used except for the direct control, like pattern recognition or abstract decoding $[41,42]$. The techniques of pattern recognition requires several (E) signals, which requires more time to be attached to the skin. Additionally, due to the fact that in this approach we used extrinsic muscles, abstract decoding could lead in unpredictable training time [42].

\subsubsection{Future work}

Even though we found in this study that the leg muscles have a better performance, the muscles of the trunk should be kept active otherwise they will be weakened even more. It would be useful then for the people with DMD to keep their muscle active through rehabilitation by playing a game with the same format as the experiment of this study. Alternatively, it is possible to combine the information of both muscles for better performance. For example, the muscles of the leg could only control the active trunk support if and only if the muscles of the trunk are activated. 


\subsection{Conclusion}

The non-intuitive control interface shows a tighter relation with the index of difficulty compared to the trunk and, performance is significantly higher with a higher index of difficulties. While trunk control is the more intuitive control interface, the non-intuitive leg control interface proves to be faster. Moreover, both control interfaces show similar behaviors in the learning phase. Therefore, non-intuitive control can be considered to be a viable control technique. As a result, to answer the research question, the non-intuitive control interface can be used for controlling an active trunk support. Future work will include a more elaborated analysis of both control interfaces with a higher diversity of targets, and a larger control group including people with DMD. 


\title{
Evaluation of Control Interfaces for Active
}

\section{Trunk Support ${ }^{1}$}

\begin{abstract}
A feasibility study was performed to evaluate control interfaces for a novel trunk support assistive device (Trunk Drive) namely, (J), (FS), (FF) and (E) to be used by adult men with Duchenne Muscular Dystrophy (DMD). The objective of this study was to evaluate the performance of the different control interfaces during a discrete position tracking task. We built a one degree of freedom flexion- extension active trunk support device that was tested on 10 healthy men. An experiment, based on Fitts' law, was conducted whereby subjects were asked to steer a cursor representing the angle of the Trunk Drive into a target that was shown on a Graphical User Interface (GUI), using the control interfaces mentioned above. The users could operate the Trunk Drive via each of the control interfaces. In general, the (J) and (FS) were the fastest in movement time (more than $40 \%$ ) without any significant difference between them but there was a significant difference between (FS) on the one hand, and (E) and (FF) on the other. All control interfaces proved to be feasible solutions for controlling an active trunk support, each of which had specific advantages.
\end{abstract}

\footnotetext{
${ }^{1}$ This chapter has been published as: Stergios Verros, Nauzef Mahmood, Laura Peeters, Joan Lobo-Prat, Arjen Bergsma, Edsko Hekman, Gijsbertus J. Verkerke, and Bart Koopman, "Evaluation of Control Interfaces for Active Trunk Support”, IEEE Transactions on neural systems and rehabilitation engineering, vol. 26, no. 10, October 2018.
} 


\subsection{Introduction}

The most common form of muscular dystrophy in humans is Duchenne muscular dystrophy (DMD), affecting 1 in every 3,500 boys [4]. DMD causes progressive degeneration of muscles, leading to progressive loss of muscle strength [43]. The mean life span used to be about 20 years of age but, due to improved health-care practices and ventilation, this has now increased to about 25-30 years [7], [44]. However, several studies have shown that people with DMD have lower Health Related Quality of Life (HRQoL) compared to healthy controls [9], [8]. As the dystrophy progresses over the years, impairments in body functions increases progressively. Thus, people with DMD become dependent on caregivers, especially with a reduction in arm function.

Several dynamic arm supports have been developed with the aim to increase the independence of people with decreased arm functions [45]. It has been shown that arm reach can be greatly increased when it is augmented with trunk motion [20]. Currently, there are no active trunk support devices and as DMD-patients have little voluntary trunk control in more advanced disease stages there is a demand for active trunk support. As a first step, we designed the Trunk Drive. The Trunk Drive is basically an experimental active trunk orthosis that supports and stabilizes flexion and extension of the trunk in a seated position.

Intention detection control interfaces are needed to operate active assistive orthotic devices, to provide the communication between the users intended motion and the device. Several control interfaces have been used to this end by others $[22,13,46,47,48]$. Force-based and electromyography control interfaces have been proposed as the most promising strategies to control an arm support for people with DMD [13]. Hand joysticks are used as control interfaces by people with disabilities in order to control powered wheelchairs and external robotic arms [46], [47]. Therefore, we decided to include $(\mathrm{J})$, force and $(\mathrm{E})$ based modalities in this study.

Two force-based control interfaces were tested. The first one measured the interaction force between the sternum and the Trunk Drive and the other one measured the interaction forces underneath the feet. The force between the sternum and the Trunk Drive can be changed by flexing or extending the trunk. The force underneath the feet can be changed by exerting isometric flexing or extending 
moments around the knees. To control a single degree-of-freedom (DoF), (E) signals from two muscles (usually an antagonistic muscle pair) need to be recorded [13]. We measured antagonistic pairs of leg muscles in subjects to obtain (E) control signals since it is shown that control tasks can be performed better using leg muscles than trunk muscles [49].

As a first step in the design of a trunk support prototype, which can be used in combination with an arm support to increase arm reach, we compared the performances of the four interfaces on the Trunk Drive. We were motivated from previous studies where it was shown that people with DMD with weaken muscles can control an arm exoskeleton using different control interfaces [13]. In this Fitts' law based experiment, we used 10 healthy volunteers as test subjects.

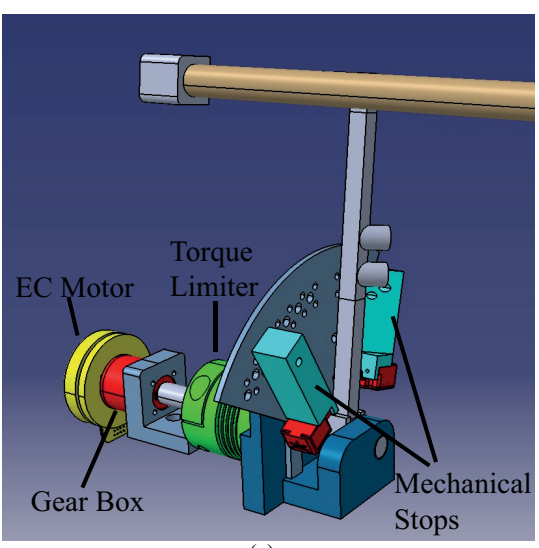

(a)

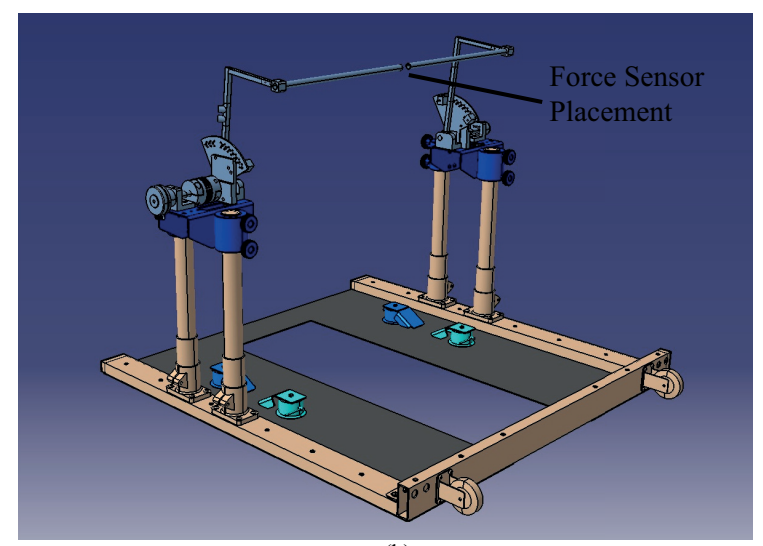

(b)

Fig. 3.1 Components of the Trunk Drive system. (a) Two EC motors with torque limiters are placed on the left and right at the L3 level of the spine to assist flexion and extension. Two mechanical stops ensure that the range of motion is between the allowable limits. (b) The rectangular structure is the floor plate and the subject sits between the vertical bars. The subject's trunk is attached to the horizontal bar with a plastic cup that encircles the trunk (not shown in the picture).

\subsection{Methods}

\subsubsection{Design and Actuation}

An experimental test set-up was designed (Trunk Drive) to investigate the four control interfaces when performing a simple movement, namely one DoF flexion and extension in a seated position (Fig. 3.1, 
3.2). The Trunk Drive consists of an aluminum alloy frame that encloses the trunk of the user from two sides on the frontal plane. The front horizontal bar interfaces at sternum level with the trunk of the user through a plastic pad. The two side bars are attached to two identical motor (Maxon EC 90, gearbox reduction 91:1) shafts that drive the flexion-extension movement through bearing and torque isolators to prevent frictional loss and misalignment of the shaft axes. The actuated rotational point of the Trunk Drive was kept aligned with the L3 level of the spine of the user by shifting the height of the Trunk Drive. The minimal flexion angle was set at $0^{\circ}$ (trunk oriented vertically) and the maximum angle was set at $40^{\circ}$ flexion. To prevent movements exceeding this range of motion, limit switches were used in conjunction with the mechanical stops.

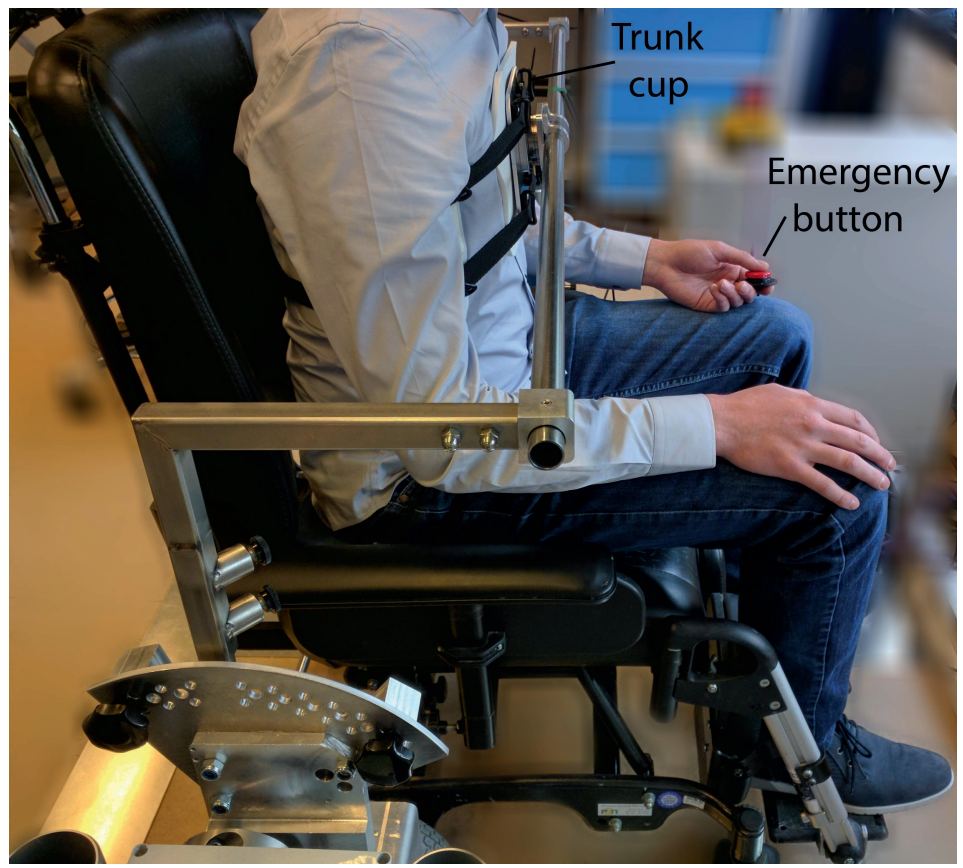

Fig. 3.2 Adult man using the Trunk Drive system at zero degree flexion angle. The trunk cup works as an adjustable connection mechanism between the Trunk Drive and the subject. The subject can operate an emergency button to stop the experiment in an unpleasant situation. 


\subsubsection{Sensors}

An optical encoder (Maxon Encoder MILE 512-64000 CPT, 2 channels) was used to measure the angular positions of the motors. The user's intention was detected by using either the signal from a (J), a force sensor at the sternum, a force sensor under the feet or a set of (E) electrodes. We used a 1-DoF $(J)$ whose spring stiffness could be adjusted. The force-based control interface on the sternum measured the interaction forces between the human and the device with a six DoF load sell (ATI mini45) located at the height of the sternum between the trunk cup and the metallic bar. Only the forces acting perpendicular to the sternum where taken into account. The force-based control interface under the feet measured the interaction forces between the feet and the ground. The feet where fixed to the force plate and only the horizontal forces in the forward and reverse direction, resulting from knee flexion and extension moments, were taken into account. Trunk flexion was coupled with the backward forces of the feet and vice versa. The reason behind this decision was to reflect standing up from a seated position. The flexion activation signals were measured from the lower tibialis anterior and the extension activation signals from the gastrocnemius. Two differential surface electrodes (Trigno, Delsys, USA) per muscle were placed parallel to the muscle fibers according to SENIAM recommendations [50].

\subsubsection{Signal Acquisition and Control Hardware}

The sensor signals were sent to a computer (xPC Target, MathWorks Inc., USA) by means of a data acquisition card (PCI-6229; National Instrument Corp., USA) which made analog-to-digital conversions with a sampling frequency of $1 \mathrm{KHz}$ and a 16-bit resolution. The controller was also connected to the computer and sent the calculated voltage to the motor driver (ESCON 90/50) through the same data acquisition card which then provided the appropriate current to the motor (Maxon EC 90 brushless). 


\subsubsection{Signal processing}

The real-time signal processing was adapted from Joan Lobo-Prat et al. [13]. The (J) was a simple potentiometer with a resistance of $1 \mathrm{k}$ and $5 \mathrm{~V}$-feed from the data acquisition card. The following equation describes the $(\mathrm{J})$ 's signal processing:

$$
\begin{gathered}
J_{v o l}(i)=J_{\text {sen }}(i)-J_{\text {res }} \\
u_{\text {joy }}(i)= \begin{cases}\frac{J_{v o l}(i)}{J_{m v i, f},} & \text { if } J_{v o l}(i)<0 \\
\frac{J_{v o l}(i)}{J_{m v i, e}}, & \text { if } J_{\text {vol }}(i)>0 .\end{cases}
\end{gathered}
$$

$J_{s e n}$ is the sensed intention of movement, $J_{r e s}$ is the average signal amplitude of a resting period of two seconds, $J_{v o l}$ is the voluntary movement and $u_{\text {joy }}$ is the $(\mathrm{J})$ control signal. $J_{m v i, f}$ and $J_{m v i, e}$ are the maximum voluntary inclination (MVI) of the $(\mathrm{J})$ when pushing the $(\mathrm{J})$ forward (flexion of trunk) and pushing the (J) backwards (extension of trunk) for two seconds, respectively. Finally, the (i) represents the $i^{\text {th }}$ time step of the signal.

Regarding the force-based control interface on the sternum, it is necessary to distinguish the voluntary forces of the user from external forces such as gravity or joint stiffness and to compensate for these. The external force is obtained before the actual measurement by measuring the sternum interface forces during a slow flexion of the trunk $(0.05 \mathrm{rad} / \mathrm{s})$ while the subject is fully relax. The compensated force $F_{c o m}(\theta)$ is a function of the trunk angle $(\theta)$ and it is subtracted from the sensed forced $F_{s e n}(i)$ to realize the intended movement as is shown in the following equations:

$$
\begin{gathered}
F_{\text {vol }, \theta}(i, \theta)=F_{\text {sen }}(i)-F_{\text {com }}(\theta)-F_{\text {res }} \\
u_{\text {force }}(i, \theta)= \begin{cases}\frac{F_{v o l}(i, \theta)}{F_{m v c, f},} & \text { if } F_{v o l}(i)<0 \\
\frac{F_{v o l}(i, \theta)}{F_{m v c, e}}, & \text { if } F_{v o l}(i)>0 .\end{cases}
\end{gathered}
$$


Where $u_{\text {force }}(i, \theta)$ is the force control signal, $F_{m v c, f}$ and $F_{m v c, e}$ are the two seconds abdominal (flexion) and iliocostalis (extension) maximum voluntary contraction (MVC), $F_{\text {res }}$ is the average signal amplitude of a resting period of 2 seconds and $J_{v o l}$ is the voluntary movement. The force plate signal processing can be described as:

$$
\begin{gathered}
F P_{\text {vol }, \theta}(i)=F P_{\text {sen }}(i)-F P_{\text {res }} \\
u_{\text {forceplate }}(i)= \begin{cases}\frac{F P_{\text {vol }}(i)}{F P_{\text {mvi }, f}}, & F P_{\text {vol }}(i)<0 \\
\frac{F P_{\text {vol }}(i)}{F P_{\text {mvie }}}, & F P_{\text {vol }}(i)>0 .\end{cases}
\end{gathered}
$$

Envelope detection was applied to the raw (E) signal with a high-pass Butterworth filter at $40 \mathrm{~Hz}$, a full wave rectifier and a low pass Butterworth filter at $2 \mathrm{~Hz}$ [51]. Furthermore, additional signal processing was performed to normalize the two signals from the agonist and antagonist muscles. In the following equation, $E_{n o r, k}(i)$ represents the normalized (E) and $u_{(E)}(i)$ the control signal:

$$
\begin{aligned}
& E_{n o r, k}(i)=\frac{E_{\text {env }, k}(i)-E_{r e s, k}}{E_{\text {mvic }, k}} \\
& u_{(E)}(i)=E_{n o r, t}(i)-E_{\text {nor }, g}(i)
\end{aligned}
$$

Subscript $k$ represents the abbreviation of the tibialis $(t)$ and gastrocnemius $(g)$ muscles. $E_{e n v, k}$ is the envelope of the raw (E), $E_{r e s, k}$ is the average of the signal amplitude in a rest period of two seconds, $E_{m v c_{k}}$ is the maximum value during 2 seconds of maximum voluntary isometric contraction.

\subsubsection{Control}

The control architecture consists of two levels: higher and lower level control. The higher level control is a second order admittance model with virtual mass A and virtual damping B where A, B were tuned with the different control interfaces in order to achieve low movement time and low overshoot. The values were kept constant between the subjects and they were chosen in such a way that the time 
to complete a task and the overshoot were minimized in a pre-experimental procedure with 2 subjects that were not included in the experiment. The admittance model generates the reference position from the intention detection signal. The position reference is followed by the lower level control. The lower level controls the position of the two motors using one PD controller for each motor. The PD values of the controller were tuned manually (Fig. 3.3, Table 3.1).

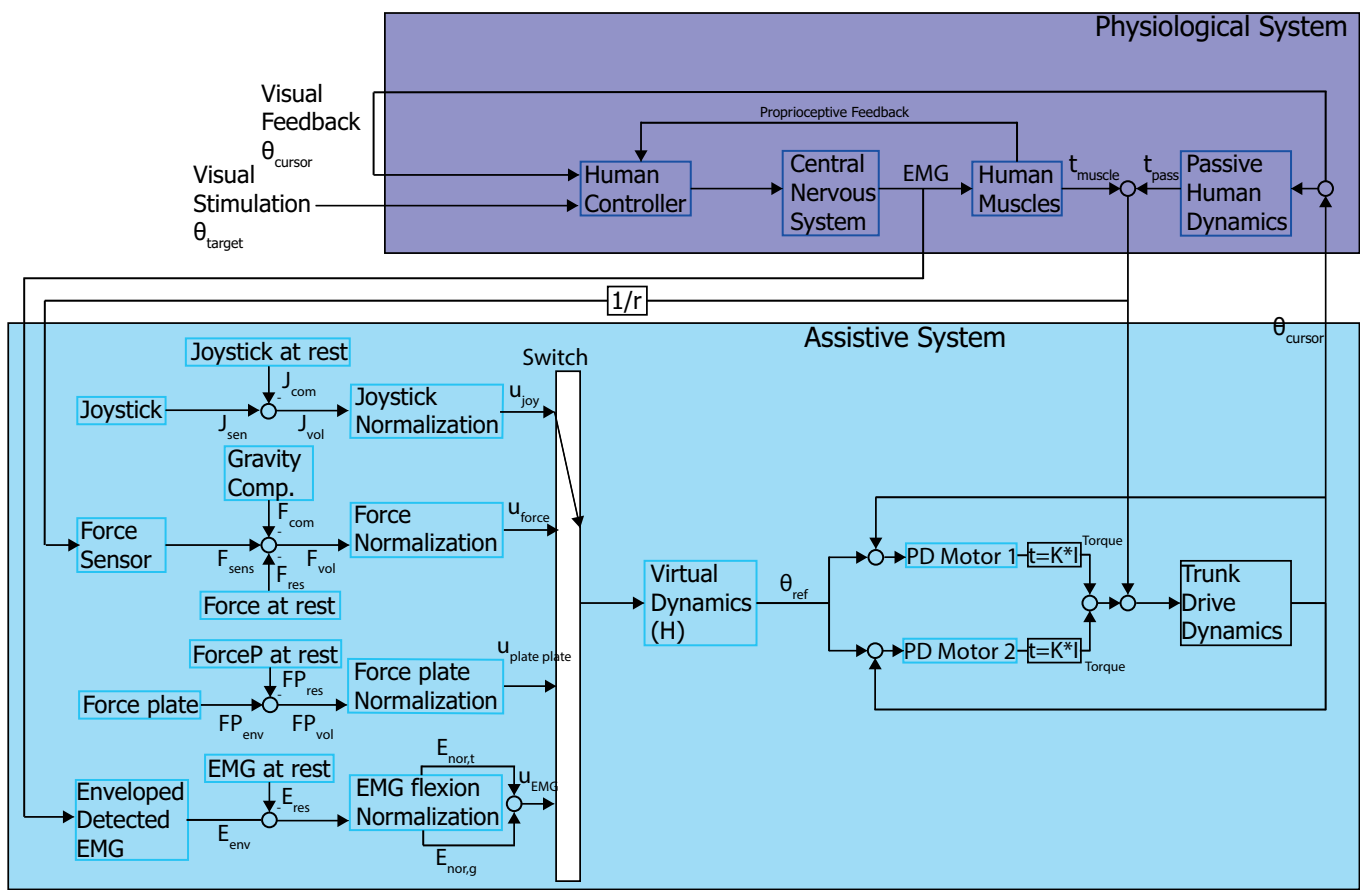

Fig. 3.3 Control Diagram of the Trunk Drive system with the physiological system. After the visual stimulation $\theta_{\text {target }}$, the subjects had to steer the $\theta_{\text {cursor }}$ into the target by using one of the four control interfaces. The $u_{\text {joy/force/forceplate/(E) }}$ created a reference angle $\theta_{\text {ref }}$ to be followed by the low level PD control.

\subsection{Experimental Design}

The experiment was based on the approach described by Fitts [25], who identified a predictive model describing human speed accuracy trade off in a tapping task. A one-dimension serial position-tracking task was presented to the subject by means of Python custom-made Graphical User Interface (GUI) 
Table 3.1 Admittance Control Parameters

\begin{tabular}{ccc}
\hline \hline Control Interface & Virtual Mass & Virtual Damping \\
\hline (J) & 0.3 & 1 \\
$(\mathrm{FS})$ & 0.1 & 0.5 \\
$(\mathrm{FF})$ & 0.3 & 1.5 \\
$(\mathrm{E})$ & 0.5 & 4 \\
\hline
\end{tabular}

on a $1050 \times 1680$ pixels display.

The user has to steer a cursor (yellow circle in Fig. 3.4) from a home position (blue circle) to a target (red circle). The cursor was coupled with the encoders of the left motor. The Index of Difficulty (ID, 3.9) from Shannon's form [52] was used to characterize targets. A target was presented at one of the three different locations at a distance of 395, 791 and 1583 pixels from the cursor starting position. The target diameter remained constant at 70 pixels plus 30 pixels for cursor correction [31]. The GUI is shown in Fig. 3.4.

$$
I D=\log _{2}\left(\frac{D}{R}+1\right)
$$

\subsubsection{Task}

After familiarization themselves with the device using the $(\mathrm{J})$ with their dominant hand, subjects were asked to perform flexion/extension movements by using the four different control interfaces. At initiation, the trunk was at zero degree flexion angle and the cursor was at the home position 1 at the bottom of the screen. To indicate the start of a trial, the word Go was displayed on the screen together with a target, and the subject had to move the cursor into the target and keep it there for two seconds. If the target movement was successful after a dwell time of two second, a blue target was shown at the top of the screen indicating home position 2 (permitted maximum flexion position). When the word Go appeared, the subject had to move the cursor again into a new target and remain there for a dwell time of two seconds to complete the extension trial. After the extension task was completed, the blue home position 1 appeared and a new flexion task was started. 


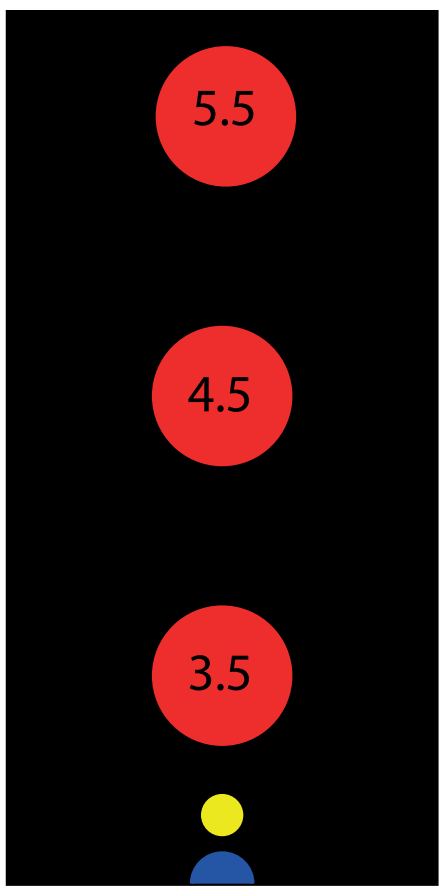

(a)

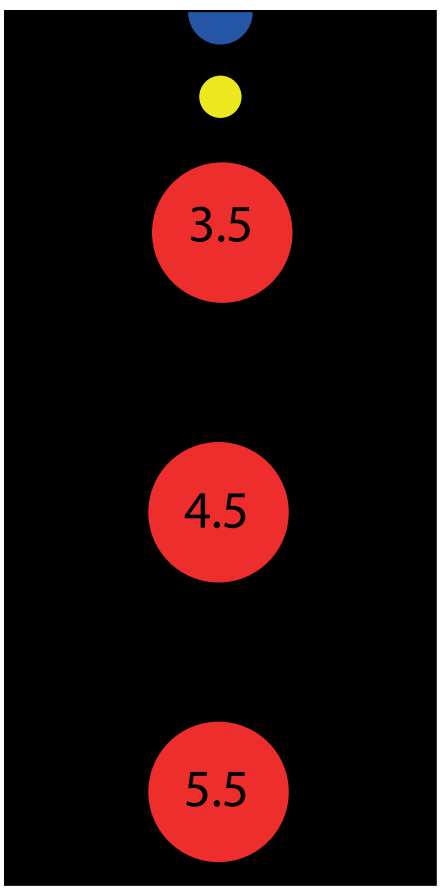

(b)

Fig. 3.4 Representation of the Graphical User Interface. A yellow cursor starts in the blue circle, ID increases with larger distances from the home position. The pixel/angle relation is 42 .

\subsubsection{Performance Metrics}

Performance metrics were used to assess the control interfaces by giving a more detailed picture of their advantages and disadvantages. The following performance metrics were used (Fig. 3.5):

Movement time (MT): the time needed to complete the task after the reaction time and without a dwell time.

Throughput (TP): also known as information transfer rate in bits/s, measures how much information can be conveyed from a subject through a particular command source; it was computed using (3.10).

$$
T P=\frac{I D}{M T}
$$


Reaction Time (RT): is the time counted between the appearance of the target and attaining $2 \%$ of the maximum speed of the trial.

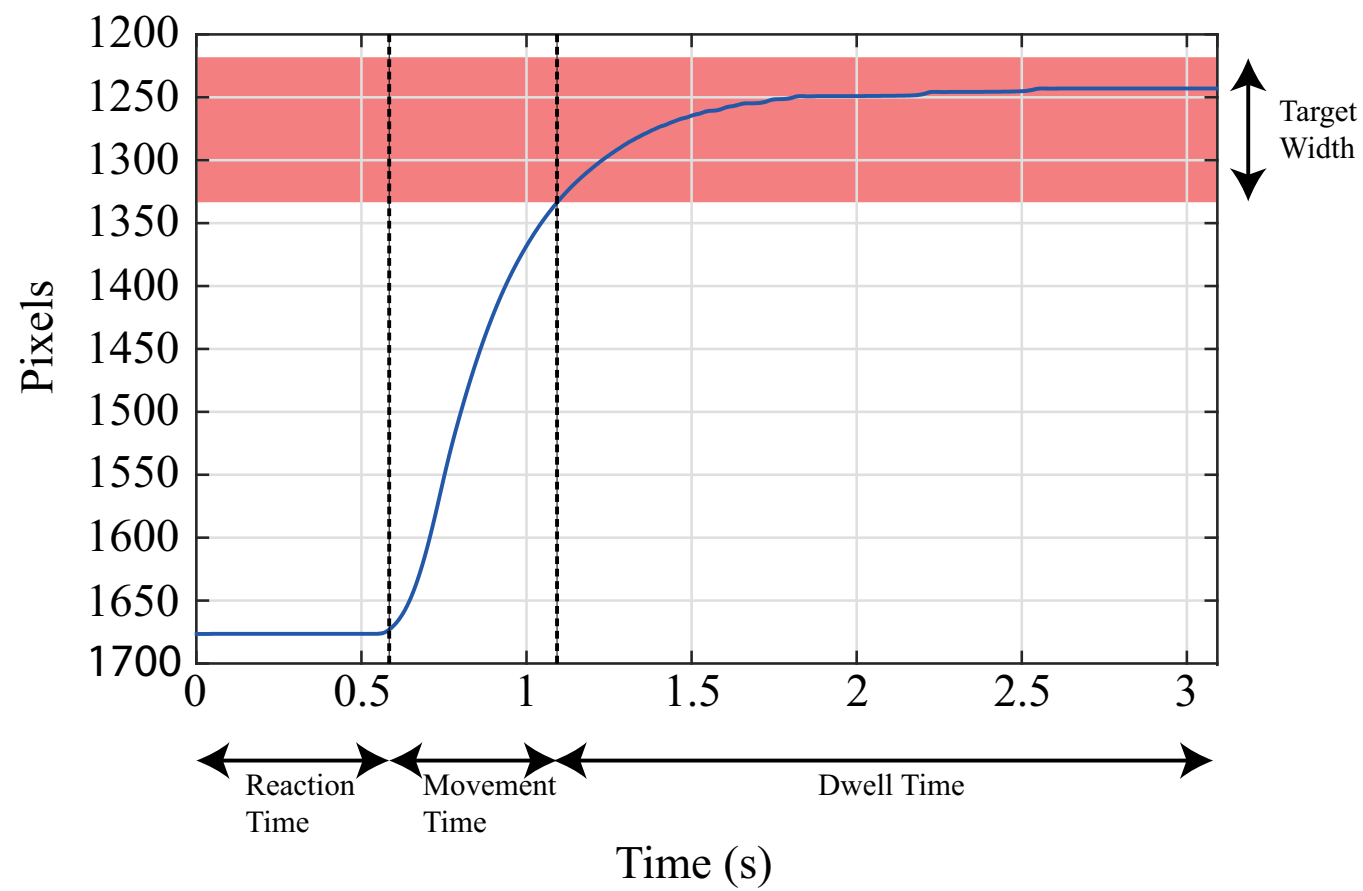

Fig. 3.5 Typical step like response of one trial with the (J) as control interface.

Path Efficiency (PE): measures the straightness of the cursor and it is computed as a percentage of the straight line.

$$
P E=100 \% \frac{\text { Straight_Distance }}{\text { Actual_Distance }}
$$

Overshoot (OS): indicates how many times the cursor left the target before the end of the dwell time of two seconds, whereby only the first time that the cursor left the target is counted and divided by the number of targets.

A questionnaire was administered at the end of the experiment to evaluate the users' experiences with the different control interfaces. The subjects had to evaluate the control interfaces by answering which control interface was: most accurate, fastest, easiest to control, most exhausting, easiest to install and, most comfortable. Finally, an overall preference had to be given. 


\subsubsection{Protocol}

After detailed explanation of the tasks, the subjects were placed into the Trunk Drive. The (J) was the first control interface to be tested (Fig. 3.6). The other three control interfaces were randomized for every subject. The subjects were given five minutes before an experiment was started to familiarize themselves with a new control interface. The subjects had to complete eight blocks consisting of nine trials of flexion and nine trials of extension (three for every target) in randomized order for each control interface. The first three blocks were for practicing and only the last five were analyzed. During the experiment, the subjects were instructed to move to the target as fast as possible without overshooting.

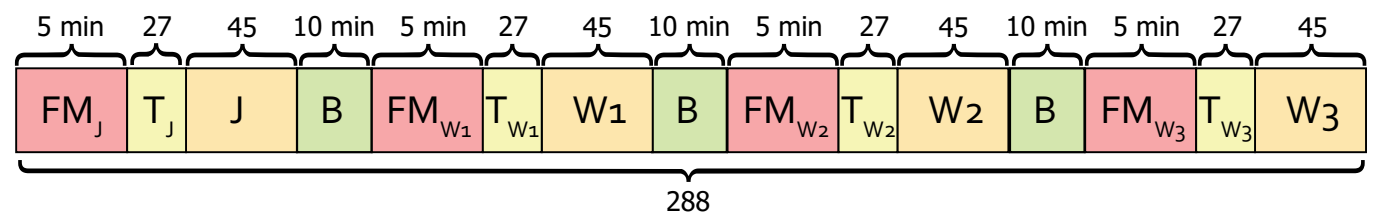

Fig. 3.6 Trial sequence of the experiment. $F M$ stands for familiarization, $T$ for training, $J$ for (J) and $B$ for break. $W 1, W 2, W 3$ represent the random force sequences on the sternum and the feet and the (E). $288 \times 2$ flexion and extension trials were performed.

\subsubsection{Participants}

In total, 10 healthy male subjects $(27.6 \pm 2.45$ years $)$ gave their informed consent and participated in this study. The medical Ethics Committee of Radboud University Medical Center approved the study and the design protocol (NL53143.091.15).

\subsubsection{Statistics}

Statistical analysis was performed between the control interfaces and, in the case of MT, each ID was also statistically analyzed. The average of each subject per control interface was calculated for every metric. Since not all the data were normally distributed, a Friedman test was performed. Post-hoc Wilcoxon signed rank with Bonferroni correction was followed by 6 pair-wise comparisons. A signif- 
icant level of $\mathrm{a}=0.0083$ and $\mathrm{a}=0.0017$ was indicated by $*$ and $* *$ respectively. The $\mathrm{r}$ values represent the square root of the coefficient of determination that was calculated on the linear regression.

\subsection{Results}

The following abbreviation will be used: $J$ for (J), $F_{s}$ for (FS), $F_{f}$ for (FF) and $E$ for (E). The MT results were analyzed per ID since there were differences between the control interfaces for each ID.

\subsubsection{Movement Time}

\subsubsection{Linear Relationship}

The mean MT was calculated per person per flexion and extension and it was plotted versus ID. The $\mathrm{r}$ values between ID and MT were above 0.814 for flexion and above 0.753 for extension (see Table 3.2 and Fig. 3.7).

Table 3.2 Regression coefficients of the ID versus movement time and the $r$ value. I, $S$ and $r$ stands for intercept, slope and $\mathrm{r}$ value respectively.

\begin{tabular}{ccccccc}
\hline \hline & $I_{\text {flexion }}$ & $S_{\text {flexion }}$ & $r_{\text {flexion }}$ & $I_{\text {extension }}$ & $S_{\text {extension }}$ & $r_{\text {extension }}$ \\
\hline$J$ & -0.5685 & 0.4206 & 0.833 & -0.2905 & 0.3574 & 0.753 \\
$F_{S}$ & -0.3045 & 0.3158 & 0.829 & -0.5368 & 0.3617 & 0.827 \\
$F_{f}$ & -1.6909 & 0.8272 & 0.814 & -0.8387 & 0.5577 & 0.819 \\
$E$ & -2.0397 & 0.9620 & 0.831 & -3.1751 & 1.2394 & 0.804 \\
\hline
\end{tabular}

\subsubsection{Comparison MT per ID}

Flexion: The Friedman test showed a significant difference in movement time between control interfaces in each ID $\left(p<0.001, n D O F=3, \chi_{I D=3.5}^{2}=22.68, \chi_{I D=4.5}^{2}=26.04, \chi_{I D=5.5}^{2}=24.12\right)$. When ID $=3.5$ (Fig. 3.8 and Table 3.3), the (J) was significantly faster than (E) and (FF). (FS) was also significantly faster than (FF) and (E). When ID = 4.5, (FS) was significantly faster than (J), (FF) and (E). The (J) was also significantly faster than (FF) and (E). Finally, when ID = 5.5, (FS) was significantly faster than (FF) and (E). The (J) was also significantly faster than (FF) and (E).

Extension: The Friedman test showed a significant difference in movement time between control 


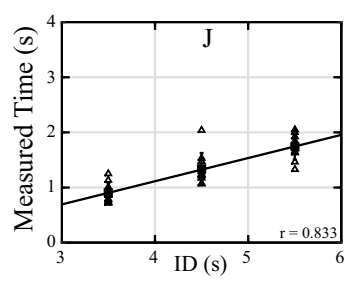

(a)

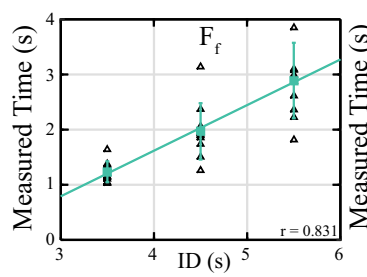

(c)

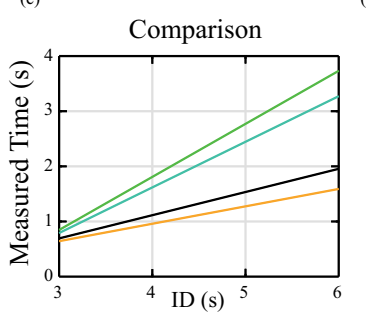

(e)
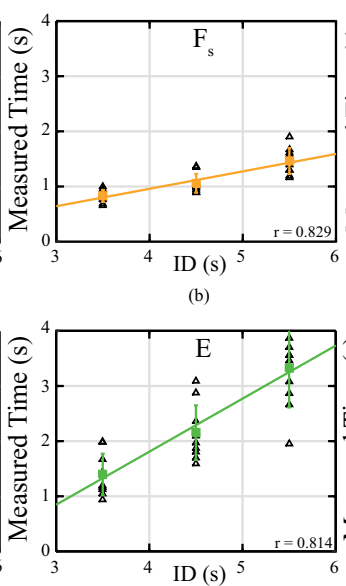

(d)

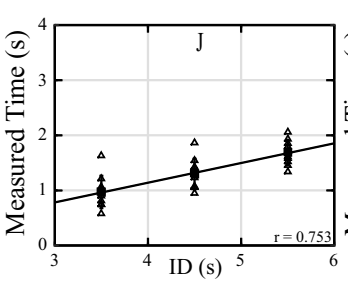

(f)

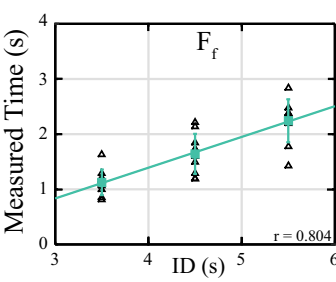

(h)

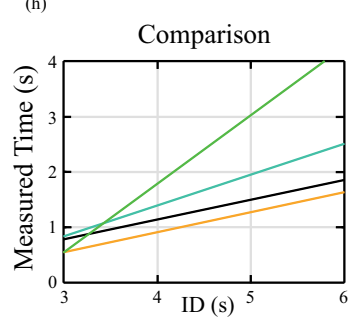

(j)

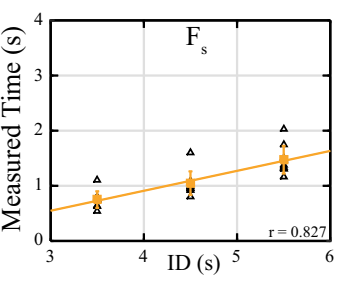

(g)

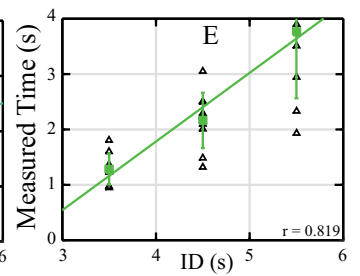

(i)

Fig. 3.7 Linear regression plots of the MT versus ID. (a) $J$ flexion (b) $F_{s}$ flexion (c) $F_{f}$ flexion (d) $E$ flexion (e) comparison flexion (f) $J$ extension (g) $F_{s}$ extension (h) $F_{f}$ extension (i) $E$ extension (j) comparison extension. Each triangle represents the average time per ID per subject. The error bars represent the mean per ID for 10 subjects with 1 standard deviation. The legend applies to all Figures.

interfaces in each ID $\left(p<0.001, n D O F=3, \chi_{I D=3.5}^{2}=16.2, \chi_{I D=4.5}^{2}=24.36, \chi_{I D=5.5}^{2}=24.36\right)$. When ID = 3.5 (Fig. 3.8 and Table 3.3), (FS) was significantly faster than (FF) and (E). When ID = 4.5, (FS) was significantly faster than (FF) and (E). Additionally, the (J) was significantly faster than (FF). Finally when ID = 5.5, (FS) was significantly faster than (FF) and (E). The (J) was significantly faster than $(\mathrm{FF})$ and $(\mathrm{E})$. Also, $(\mathrm{FF})$ was significantly faster than $(\mathrm{E})$.

Since the differences between the control interfaces on the following metrics were not momentous, the average of all IDs were taken into account. 


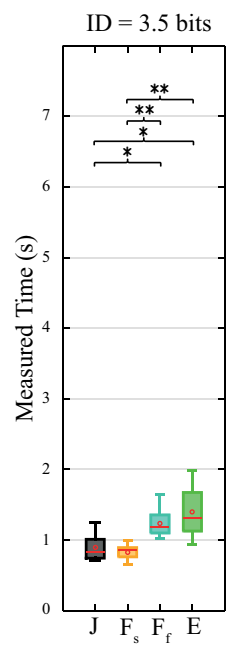

(a)

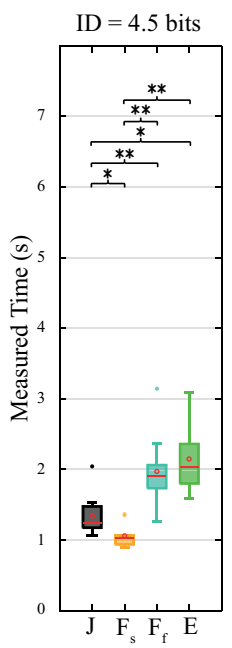

(b)

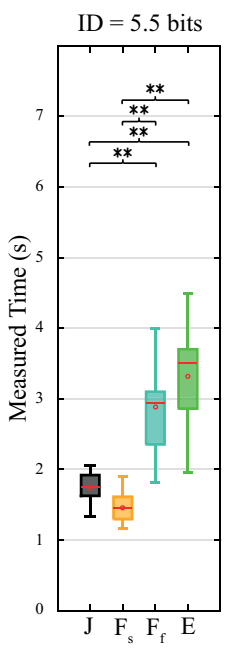

(c)

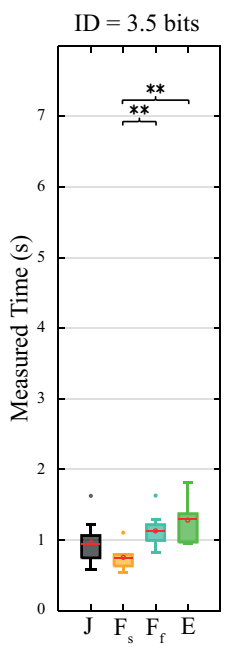

(d)

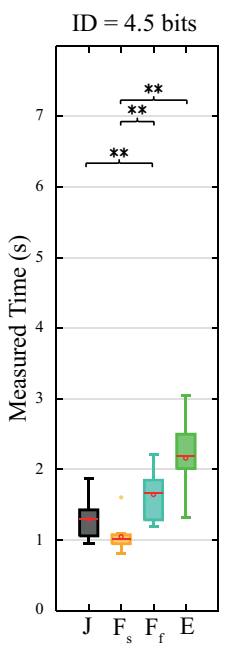

(e)

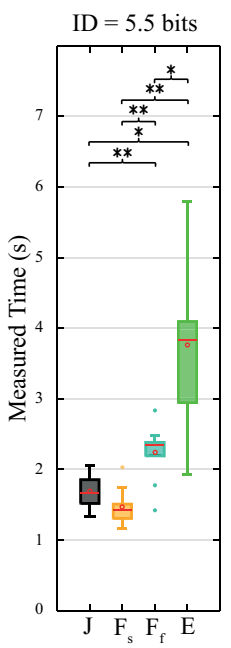

(f)

Fig. 3.8 Boxplots per ID statistics. $(*) p \leq 0.0083(* *) p \leq 0.0017$. Figures $a-c$ correspond to flexion and $d-f$ correspond to extension.

\subsubsection{Throughput}

Flexion: The Friedman test showed a significant difference in throughput $\left(p<0.001, n D O F=3, \chi^{2}=\right.$ 23.16). In the Post-hoc analysis (Fig. 3.9 and Table 3.4), the (FS) throughput was significantly greater than the (FF) and (E). The (J) throughput was also significantly greater than (FF) and (E). No significant difference was found between (J)-(FS) and force on feet-(E).

Extension: The Friedman test showed a significant difference in throughput $(p<0.001, n D O F=$ $3, \chi^{2}=24.36$ ). In the Post-hoc (Fig. 3.9 and Table 3.4), the (FS) throughput was significantly greater than (FF) and (E). (J) throughput was significantly greater than (FF). No significant difference was found between (J)-(FS), (J)-(FF) or (FF) and (E).

\subsubsection{Reaction Time}

Flexion: The Friedman test showed a significant difference in reaction time $(p<0.05, n D O F=$ $3, \chi^{2}=9.84$ ). In the Post-hoc analysis (Fig. 3.9 and Table 3.5), the only significant difference was found between (FS) and (FF) with (FS) being faster.

Extension: The Friedman test showed a significant difference in reaction time $(p<0.001, n D O F=$ 
Table 3.3 MT and standard deviation

\begin{tabular}{lcccc}
\hline \hline & $M T_{\text {flexion }}$ & $S D_{\text {flexion }}$ & $M T_{\text {extension }}$ & $S D_{\text {extension }}$ \\
\hline$J_{(3.5)}$ & 0.90 & 0.19 & 0.97 & 0.29 \\
$J_{(4.5)}$ & 1.34 & 0.29 & 1.30 & 0.28 \\
$J_{(5.5)}$ & 1.74 & 0.23 & 1.69 & 0.23 \\
$F_{S_{(3.5)}}$ & 0.83 & 0.11 & 0.75 & 0.15 \\
$F_{S_{(4.5)}}$ & 1.06 & 0.17 & 1.05 & 0.21 \\
$F_{S_{(5.5)}}$ & 1.46 & 0.23 & 1.47 & 0.25 \\
$F_{f_{(3.5)}}$ & 1.24 & 0.19 & 1.13 & 0.23 \\
$F_{f_{(4.5)}}$ & 1.97 & 0.51 & 1.64 & 0.36 \\
$F_{f_{(5.5)}}$ & 2.89 & 0.68 & 2.24 & 0.39 \\
$E_{(3.5)}$ & 1.40 & 0.38 & 1.28 & 0.28 \\
$E_{(4.5)}$ & 2.15 & 0.49 & 2.16 & 0.50 \\
$E_{(5.5)}$ & 3.32 & 0.71 & 3.76 & 1.18 \\
\hline
\end{tabular}

Table 3.4 TP and standard deviation

\begin{tabular}{ccccc}
\hline \hline & $T P_{\text {flexion }}$ & $S D_{\text {flexion }}$ & $T P_{\text {extension }}$ & $S D_{\text {extension }}$ \\
\hline$J$ & 4.00 & 0.59 & 3.97 & 0.64 \\
$F_{S}$ & 4.53 & 0.40 & 4.80 & 0.63 \\
$F_{f}$ & 2.76 & 0.50 & 3.14 & 0.54 \\
$E$ & 2.47 & 0.62 & 2.41 & 0.64 \\
\hline
\end{tabular}

$3, \chi^{2}=21.36$ ). In the Post-hoc analysis (Fig. 3.9 and Table 3.5), the (J) had a significantly faster reaction time than (FF). Also, (FS) had significantly faster reaction time than (FF). No other significant difference was found.

\subsubsection{Path Efficiency}

Flexion: The Friedman test showed a significant difference in path efficiency $(p<0.05, n D O F=$ $\left.3, \chi^{2}=12.6\right)$. The only significance in this metric was between $(\mathrm{J})$ and (FF)(Fig. 3.9 and Table 3.6).

Extension: The Friedman test showed a significant difference in path efficiency $(p<0.001, n D O F=$ $\left.3, \chi^{2}=22.68\right)$. The $(\mathrm{J})$ had a significantly greater path efficiency than (FS). (FS) had a significantly lower path efficiency than (FF) and (E) (Fig. 3.9 and Table 3.6). 

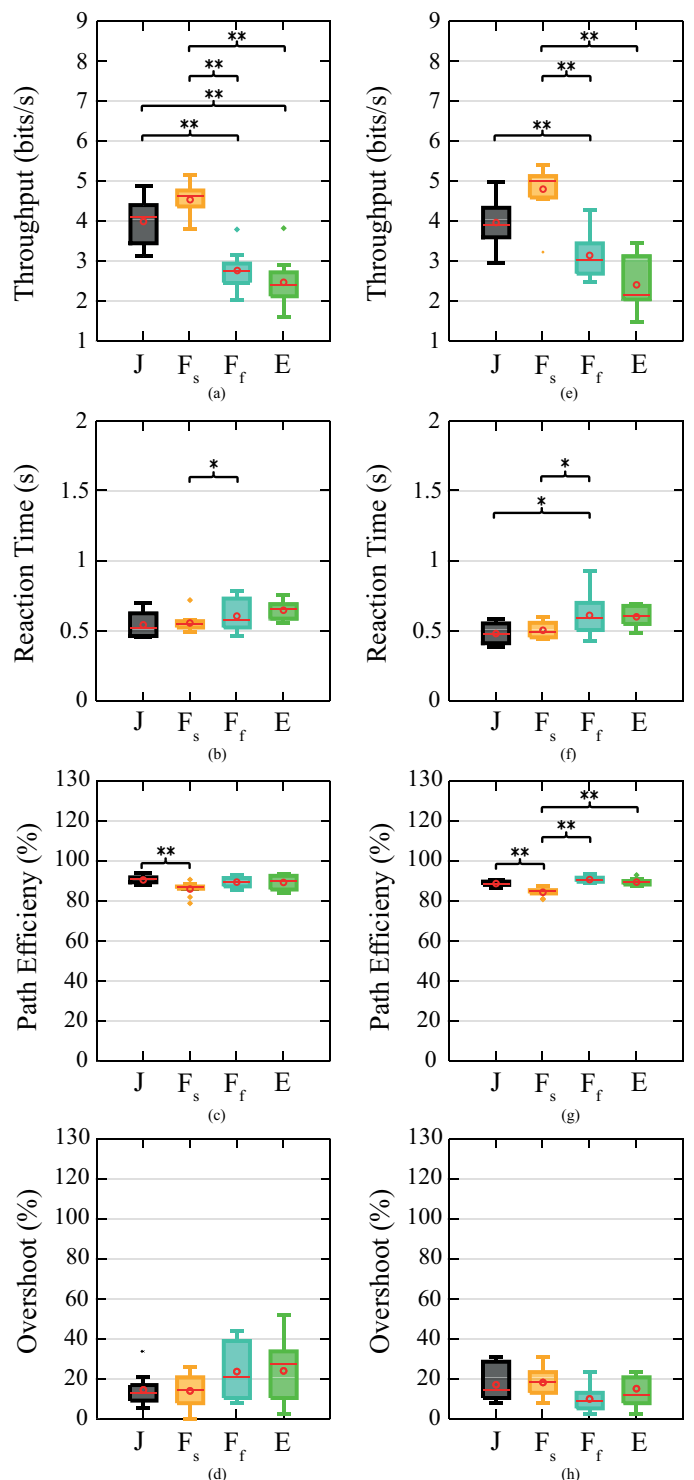

Fig. 3.9 Performance metrics statistics. Figures $a-d$ correspond to flexion and $e-g$ correspond to extension. 
Table 3.5 RT and standard deviation

\begin{tabular}{ccccc}
\hline \hline & $R T_{\text {flexion }}$ & $S D_{\text {flexion }}$ & $R T_{\text {extension }}$ & $S D_{\text {extension }}$ \\
\hline$J$ & 0.55 & 0.09 & 0.48 & 0.07 \\
$F_{S}$ & 0.56 & 0.06 & 0.50 & 0.05 \\
$F_{f}$ & 0.61 & 0.11 & 0.61 & 0.15 \\
$E$ & 0.65 & 0.06 & 0.60 & 0.07 \\
\hline
\end{tabular}

Table 3.6 PE and standard deviation

\begin{tabular}{ccccc}
\hline \hline & $P E_{\text {flexion }}$ & $S D_{\text {flexion }}$ & $P E_{\text {extension }}$ & $S D_{\text {extension }}$ \\
\hline$J$ & 90.59 & 1.93 & 88.70 & 1.32 \\
$F_{S}$ & 86.07 & 3.32 & 84.41 & 2.11 \\
$F_{f}$ & 89.40 & 2.70 & 90.72 & 1.51 \\
$E$ & 89.24 & 3.37 & 89.47 & 1.60 \\
\hline
\end{tabular}

\subsubsection{Overshoot}

In overshoot, the Friedman test showed that, for both flexion $\left(p=0.067, n D O F=3, \chi^{2}=7.17\right)$ and extension $\left(p=0.1236, n D O F=3, \chi^{2}=5.72\right)$, there was no significant difference between control interfaces (Fig. 3.9).

\subsubsection{Questionnaire}

Fig. 3.10 shows how the subjects replied to the questionnaire. The (FS) was the fastest (6 out of 10), easiest to install (6 out of 10), comfortable (6 out of 10) but also the most exhausting ( 9 out of 10). On the other hand (J) was most accurate (6 out of 10) and easiest to control (7 out of 10). Regarding the overall performance, subjects favoured the (J) (5 out of 10).

\subsection{Discussion}

This study investigated the performance of control interfaces on a novel active trunk support device. We designed and constructed a 1- DoF active trunk assistive device that can be controlled by four 


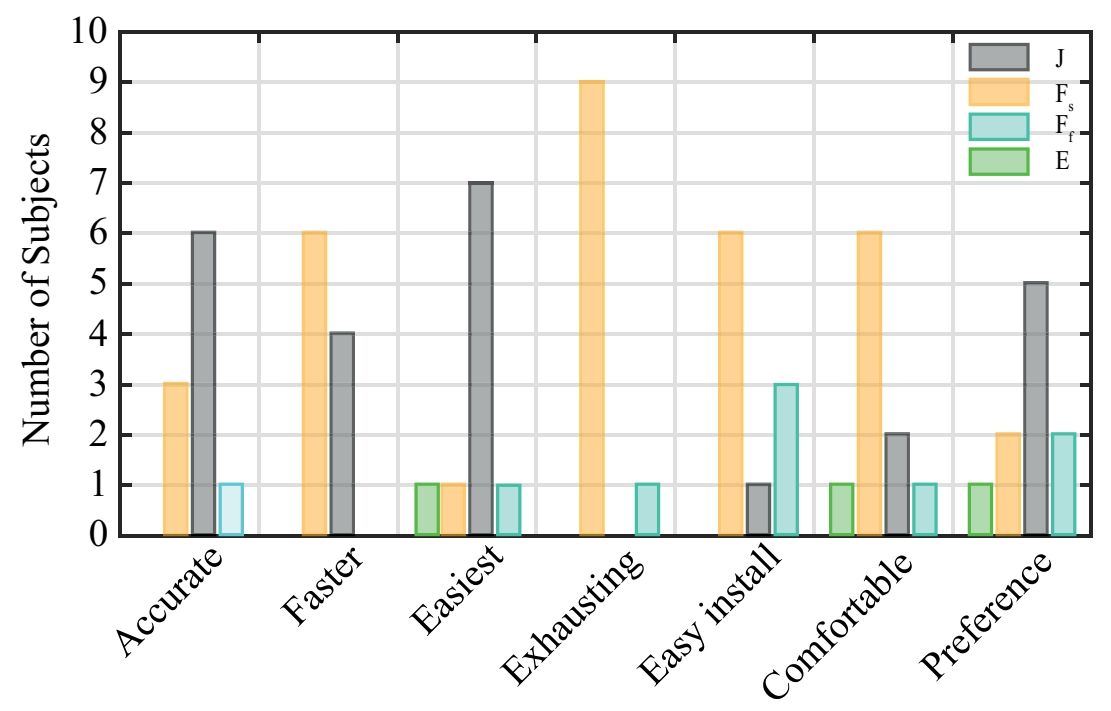

Fig. 3.10 Responses of the questionnaire.

control interfaces. The four control interfaces were compared with the Fitts' law style experiments on performance using healthy subjects.

\subsubsection{Performance Metrics and Acceptance}

To evaluate the control interfaces, we considered time as an important factor because performing a task in a short amount of time indicates that the user has adapted to the control interfaces. Furthermore, accuracy performances such path efficiency and overshoot, compare the movement performance across the different control interfaces. Finally, the questionnaire gave a better insight into the control interfaces from the user perspective. The subjects did not have any previous experience with controlling assistive devices and were able to complete a series of trials with all the proposed control interfaces. These led us to the conclusion that the proposed control interfaces can be used for controlling a trunk support prototype. 


\subsubsection{Fitts' Law}

Following Fitts' law, movement within the human can be described as an ID vs MT relationship. We used Fitts' law to investigate if the physical man-machine augmentation will disturb this relationship. $\mathrm{R}$ values higher than 0.5 would indicate a strong relation between ID and MT. Based on our r-values, it can be concluded that all four control interfaces follow this relationship between ID and MT. However, the regression coefficients of this study are lower than the ones found by others $(<0.9)[53]$. There are two possible reasons for this. First, the dwell time of the current experiment was used to identify the completion of the trial instead of tapping or pressing a button which changes the outcome of the experiment. Second, the control interfaces were used to flex and extent the human trunk which is not the same as performing fine movements with the hand.

\subsubsection{Overall Performance}

Based on the results of the MT, we can conclude that (FF) and (E) were slower than (FS) and (J) for all IDs indicating that the subjects could achieve faster flexion and extension movements (attaining more than $70 \%$ in some cases). The MT results are in agreement with the performance of throughput where (FS) and (J) have a larger transfer rate than (FF) and (E). This result can be explained by the fact that the motion of the trunk can be controlled more intuitively by the (J) and the (FS). In contrast, (FF) and (E) from the leg muscle are considered to be less intuitive. The RT, PE differences were small ( $<$ 0.2 seconds, $4 \%$ respectively) which indicates only a marginal performance difference. Finally, there were no significant differences for the OS.

According to the subjects' responses to the questionnaire, the $(\mathrm{J})$ was the easiest to control and the more accurate which contradicts with the results of the PE and OS metrics. The (FS) was the fastest which is in line with the experimental results. On the other hand, the subjects found the (FS) the most exhausting compared to the other 3 due to the fact that force signal contains both dynamic and static components of the upper body . Finally, the users' overall preference was the (J) which is not surprising because it is a very common control interface in, for example, video games. 


\subsubsection{Control Interfaces}

The $(\mathrm{J})$ was the first control interface to be used to allow the subjects to familiarize themselves with the system's dynamics. Hand- (J)s are commonly used as control interfaces for assistive devices (e.g., electrical wheelchairs) by individuals with muscular weakness and this was considered the easiest and most straightforward method to control an assistive device. Indeed, the ( $\mathrm{J}$ ) performed similarly to (FS) although it was always the first control interface. The major drawback of using a (J) is that one hand's function is sacrificed whenever a person intents to move the trunk since it is a parallel system.

The (FS) control interface was considered the most intuitive one. However, gravity compensation complicates matters as it acts on the upper body. Participants had difficulties in fully relaxing their muscles, which is important to achieve proper gravity compensation. Additionally, the interface was sensitive to respiration, which resulted in small oscillatory movements during the dwell time when the subjects were trying to keep their trunk at a certain angle.

The (FF) control interface was slower than the one using a sensor at the sternum, but gravity compensation was not necessary and the placement of the sensor not very critical. Although it is a parallel system requiring slight movements of the feet and it is slightly slower than the other control interfaces, it may be a solution for people who are seated in a wheelchair, because using the feet to control trunk movement is not a functional sacrifice.

(E) control performance was strongly dependent on where the sensor was placed on the muscles. It was easier to get a signal from the tibialis muscle to control the device. It was more difficult to find the right sensor location on the gastrocnemius so that the subject could control the device with ease. It should be mentioned though that at the beginning, the subjects needed some familiarization time to get used to the fact that they had to move their trunk by contracting their legs muscles. However, all the subjects were able to adapt to that procedure within minutes.

\subsubsection{One-DoF vs multi-DoF}

The Peeters et-al study showed that the contribution of the trunk to achieve flexion tasks is divided equally between different segments (pelvis, lower lumbar, upper lumbar, lower thoracic, upper tho- 
racic) [18]. As a consequence, an active trunk support should also be able to provide multi-DoF support, resembling natural reaching movements. Since no active trunk assistive devices exist, we decided to investigate the control capabilities of a relatively simple system before investigating a more complex assistive device. The DoF has to be increased for lateral bending as the current design restricts it.

An increase in DoF will introduce complexity not only to the mechanical design but also to the control. The mentioned control interfaces would have performed differently if the complexity of the control task had been increased.

\subsubsection{Limitations}

The first limitation is the setting of the admittance values which were tuned based on the performance on a pre- experiment with 2 subjects (not included in the results). The purpose of this pre-experiment was to find the optimal values of virtual mass and damping for each of the control interfaces. Even though the values of the virtual masses are close, the values of the virtual damping differ noticeably. This is due to the nature of the input signal in the admittance model. Control interfaces such as (E) need a bigger virtual damping value to attenuate the high input in the admittance model. Reducing the virtual damping value would result in a higher overshoot.

Second, the gear ratio backlash and the electronics of the motor resulted in mechanical play, giving 0 to 20 pixels in the GUI. Thus, not all the trials started at 0 or 1680 pixels (starting points for flexion end extension respectively), even though the subjects were asked to move the device to the mechanical end stops. We did not compensate for this non equality between trials since we considered it to be negligible.

\subsection{Conclusion}

We investigated the performance of four different control interfaces on an experimental active trunk support device. The (FS) and the (J) control interfaces were faster than the ones based on force underneath the feet and (E). Regarding path efficiency, overshoot and reaction time, significant differences 
were found between the control interfaces but the differences in absolute values are negligible. (FS) was experienced as the most fatiguing interface by the participants, and they preferred the (J). From the above results, we can conclude that all four control interfaces can be potentially used to control an active trunk support with different advantages and disadvantages. Further research on the performance of the control interfaces will be done with people with DMD. 


\title{
Comparing Assistive Admittance Control
}

\section{Algorithms For A Trunk Supporting Exoskeleton $^{1}$}

\begin{abstract}
Duchenne muscular dystrophy leaves patients with severe dependency on health care. In an effort to increase independence and quality of life, active exoskeletons are developed to support activities of daily living. This study is dedicated to the development and assessment of three different admittance control algorithms for a trunk supporting robot; a law with constant parameters, a law with added feed-forward force, and a law with variable parameters. A Fitts'-like experiment with 12 healthy subjects was performed to compare the control laws. The results show decreased movement times for the feed-forward and variable admittance controllers with respect to the standard admittance.
\end{abstract}

\footnotetext{
${ }^{1}$ This chapter has been published as: P.G. van Lenthe*, S. Verros*, E.E.G. Hekman, R. Carloni, H.F.J.M. Koopman, "Comparing Assistive Admittance Control Algorithms For A Trunk Supporting Exoskeleton", IEEE 2018 IEEE International Conference on Robotics and Automation (ICRA) May 21-25, 2018, Brisbane, Australia. (*: both first authors contributed equally.)
} 


\subsection{Introduction}

Duchenne Muscular Dystrophy (DMD) is a genetic disorder manifesting in progressive muscle degeneration. DMD is found predominantly in males, as the disease is linked to the X-chromosome. One in 3300 new-born boys were found to be affected by DMD [54]. In exceptional cases, also women carriers can show symptoms of muscular dystrophy [55].

Improvements in health care have increased the life expectancy of DMD patients, leading to an increased demand for advances in quality of life [7]. The Symbionics project aims to develop exoskeleton technology to support activities of daily living of people with DMD to improve self-reliance and keep patients active [2].

Along with loss of strength in the extremities, DMD patients suffer degeneration of the trunk and neck muscles. This leads to instability of the upper body, which further impedes controlled arm movements. The Flextension project has already developed robotic devices for arm support [56]. These devices could be more effective if the trunk is also supported, since it increases range of motion and stability of arm orthoses [20]. Therefore, a novel trunk supporting exoskeleton is currently under development.

\subsubsection{Mechanical Design}

To explore different control algorithms, an experimental setup of one degree of freedom was built (Trunk Drive (TD)). The TD consists of an aluminum alloy frame with the only interaction point at the sternum of the subject. The frame is connected from both sides to two identical Maxon EC 90 motors. The rotational point of the motors is aligned with the physical rotation point of the trunk.

\subsubsection{Control Interfaces}

To grant users intuitive control over an exoskeleton, a suitable interface between human and machine must be selected. Different interfaces have been used in the past for exoskeleton devices. The most used interfaces are (E) based [57], [51] and force based [58]. Both (E) and force are directly linked to 
the movement intention and might, therefore, offer intuitive control.

In other studies it was proven that force-based control interfaces allow less fatiguing control and higher information transmission rates for healthy subjects in a position tracking task [22]. Therefore, force was chosen as control interface for the remainder of this study. The assumption that the optimal control for healthy subjects is also optimal for people with DMD needs yet to be verified.

\subsubsection{Control algorithms}

Literature on control algorithms contains a vast landscape of different applications for control. In the field of rehabilitation robotics, the control design is focused around assisting users in relearning normal human movement trajectories. The literature revolves around trajectory tracking. This is done in several ways, among which 'assist-as-needed' is a high profile paradigm. Usually, this involves a known ideal trajectory the user is expected to follow [59].

On the other hand, in the field of assistive robotics meant for daily use, the goal is not to re-learn movements, but to support users independently of their strength and activities. To design an active orthosis capable of assisting during a wide range of activities, either a large database of ideal trajectories for every possible task combined with intention detection must be used, or the assistive part must be reduced to force amplification instead of trajectory assistance. The latter was chosen for this work. This excludes the availability of a position error signal to control the amount of assistance given, since there is no known ideal trajectory. With a regular admittance model the parameters are fixed to a hypothetical optimal performance. However, different control variations may offer higher performance without fixing gains or use other means of extra support and, in the same, time guarantee the stability. Therefore, this study aims to test different variations on admittance control algorithms, with upper body flexion and extension forces as inputs. The three control architectures are an admittance law, an admittance law with added feed forward force, and a variable admittance law. 


\subsection{Methods}

\subsubsection{Prototype Trunk Drive}

Two Maxon motors EC90 flat with gear boxes (Planetary Gearhead GP 52 C, 91:1 ratio) drive the orthosis together. They are installed in line and connected to the orthosis via torque couplings to provide robustness against potential misalignment. The motors are mounted on a large steel frame, see Fig. 4.1.

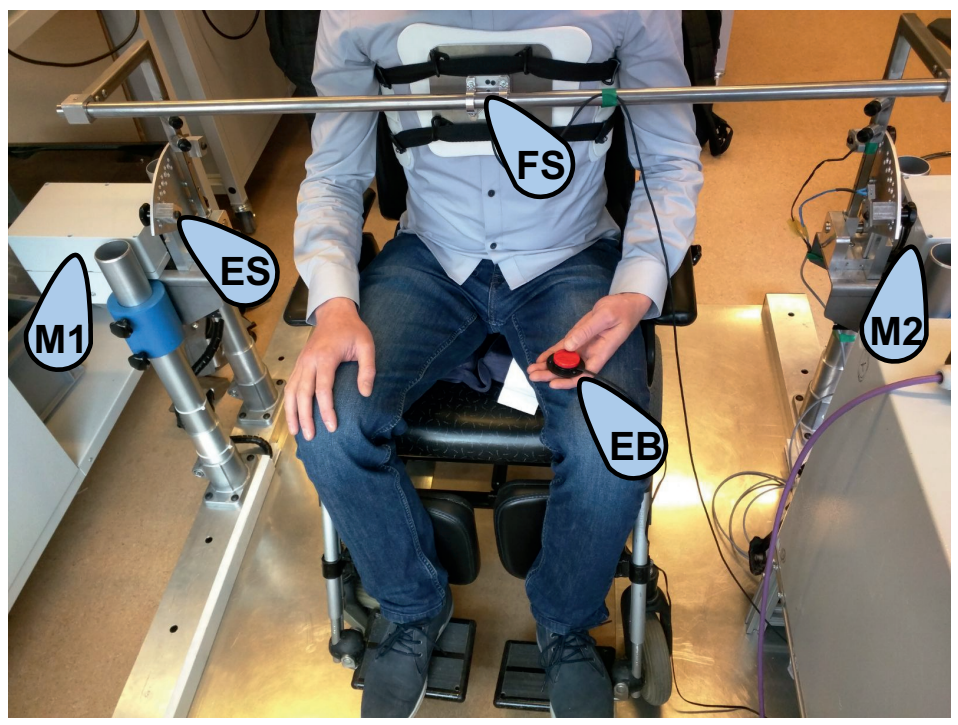

Fig. 4.1 Setup of the Trunk Drive. M1-2 are the motor locations, FS the force sensor, EB are emergency buttons, ES is a passive emergency stop.

The subject is seated in a wheelchair, which can be placed within the steel frame. The subject is wearing a harness with fastening straps around the torso which is rigidly connected to a force sensor [60]. The force sensor is connected to the orthosis and is the only physical point of interaction between subject and the orthosis.

The TD is controlled using XPCtarget software in combination with Simulink (MathWorks, USA). This allows real time application at $1000 \mathrm{~Hz}$. 
The TD is equipped with two emergency buttons. One can be operated by the researchers, the other by the subject. Pressing an emergency button at any time during operation results in a power-off for the motors.

\subsubsection{Basic Control Design}

The different control algorithms for TD are all founded on the same architecture, shown in Fig. 4.2. Each block is discussed in details hereafter.

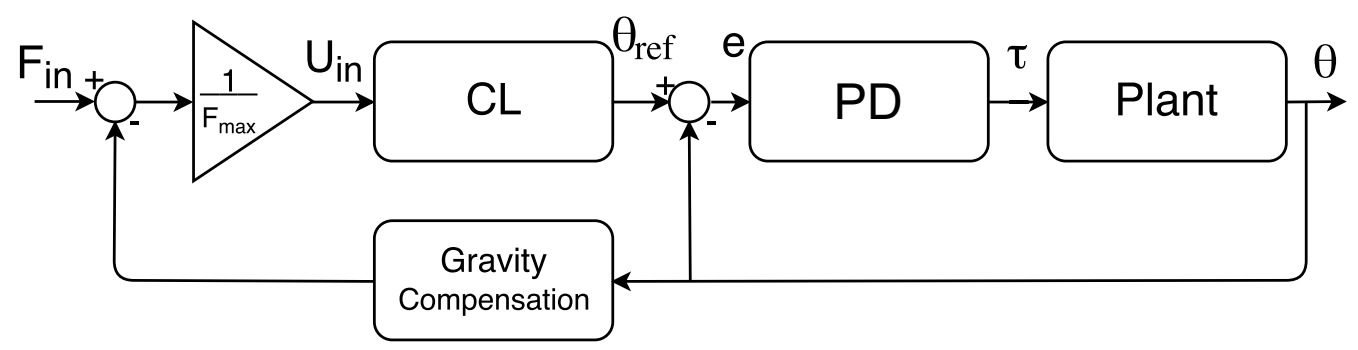

Fig. 4.2 Block diagram of the Trunk Drive.

\subsubsection{Maximum Voluntary Force}

$F_{\text {max }}$ is the maximum voluntary force (MVF) of the subject. It is recorded during an initial calibration. The subject is asked to perform a maximal contraction flexion and extension movement, which is used to normalize the input force so $-1 \leq u_{\text {in }} \leq 1$.

$$
\begin{gathered}
u_{\text {in }}=\frac{F_{\text {in }}-F_{\text {gravity }}}{F_{\text {max }}} \\
F_{\text {max }}= \begin{cases}\mid F_{\text {max }- \text { flexion } \mid,} & \text { if } F_{\text {in }}>0 \\
\left|F_{\text {max-extension }}\right|, & \text { if } F_{\text {in }}<0\end{cases}
\end{gathered}
$$

in which $F_{\text {in }}$ is the measured force, $F_{\text {max-flexion }}$ the MVF measured during flexion and $F_{\text {max-extension }}$ during extension. 


\subsubsection{CL}

Represent different variations of control architecture or control laws, as described in 4.2.3.

\subsubsection{PD control}

The plant is controlled by means of a proportional-derivative controller to track the position output of each control law. The PD values, obtained by manual tuning, for $P=300$ and $D=30$ (and $I=0$ ).

\subsubsection{Plant description}

The plant block represents all physical parts that are subject to displacement. This includes the motor shafts, gearboxes, robot masses, and human upper body.

\subsubsection{Gravity Compensation}

To provide the trunk with a basic supportive function, a gravity compensation algorithm was developed. The user's passive body force, i.e. upper body weight, is measured during slow forward motion through the total range of motion of 0.6 radians. A first order regression model of this data is used to determine an appropriate weight compensating force during operation, i.e,

$$
F_{g}=a_{g}+b_{g} \cdot \theta
$$

in which $a_{g}$ is the intercept, $b_{g}$ the slope of the linear regression model and $\theta$ is the forward angle of the robot in radians.

In static conditions, the gravity compensation ensures no muscle activity is required to remain stationary at any given angle within the range of motion.

\subsubsection{Control Laws}

\subsubsection{Admittance Control(ADM)}

In this architecture, the function function from $u_{\text {in }}$ to $\theta_{\text {ref }}$ is following a standard admittance control algorithm with fixed parameters, i.e., 


$$
\theta_{r e f}=\frac{1}{M s^{2}+B s+K} \cdot u_{i n}
$$

where the relative mass $M=0.3$, the relative damping $B=0.1$, and the relative stiffness $K=0$, because the gravity compensation already acts as a stiffness term in the overall system. $\theta_{\text {ref }}$ is the reference angle in radians.

\subsubsection{Admittance control with feedforward force (FF)}

This control law is an adaptation of the one presented in [61], where the user's joint torque is estimated based on the measured force and a feedforward torque is calculated based on the amplitude of this force. Instead of estimating the user's joint torque, it uses $u_{\text {in }}$ as dependent parameter. The control law adds a force to the user input when $u_{\text {in }}$ passes a certain threshold. This means that for increased measured input force, the assistance will be greater. For input forces under the threshold, no assistance is given. It assumes a user needs no extra assistance for small or slow trajectories.

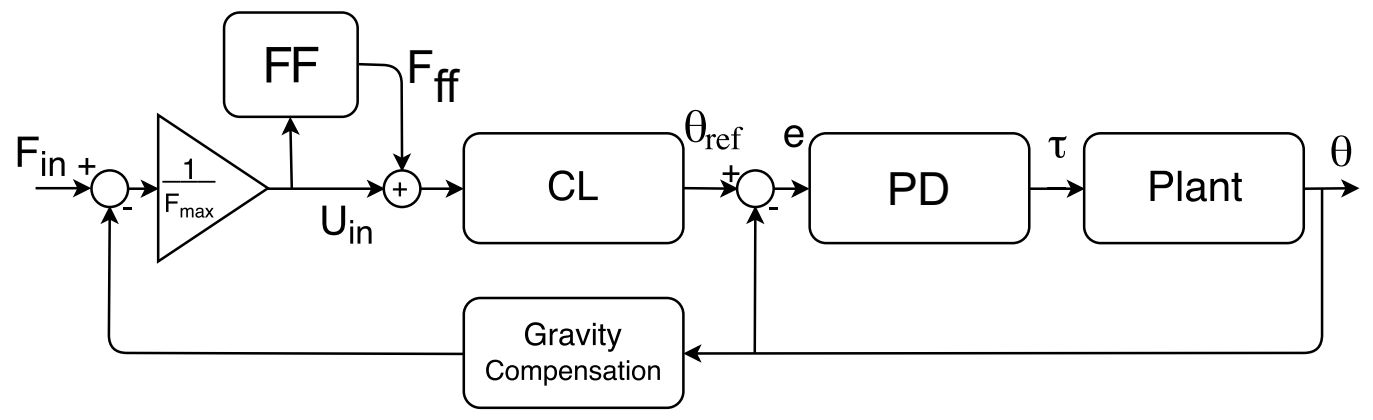

Fig. 4.3 Block diagram of the FF architecture.

In this admittance, the transfer function from $u_{\text {in }}$ to $\theta$ is:

$$
\theta_{r e f}=\frac{1}{M s^{2}+B s+K} \cdot\left(u_{i n}+F_{f f}\right)
$$




$$
F_{f f}= \begin{cases}0, & \text { if } \sigma_{l} \leq u_{i n} \leq \sigma_{u} \\ \beta\left(u_{i n}-\sigma_{l}\right), & \text { if } u_{i n}<\sigma_{l} \\ \beta\left(u_{i n}-\sigma_{u}\right), & \text { if } u_{i n}>\sigma_{u}\end{cases}
$$

where $-\sigma_{l}=\sigma_{u}=0.1$, which means that the assistance is triggered at $10 \%$ of the MVF. $\beta=1.5$, which regulates the amount of assistance given. This value was chosen arbitrarily and is fixed.

\subsubsection{Variable admittance (VADM)}

The last control law is an adaptation of the one presented in [62]. An intention detection algorithm classifies the user's intention into two possible categories; the first is acceleration (acc), the second deceleration $(\mathrm{dec})$. Based on the intention of the user, the admittance parameters are changed. For acceleration, the parameters are lowered, making it easier to move the robot. Different from [62], for deceleration, the damping is increased while mass is decreased, actively helping the user to slow down and perform more accurate movements.

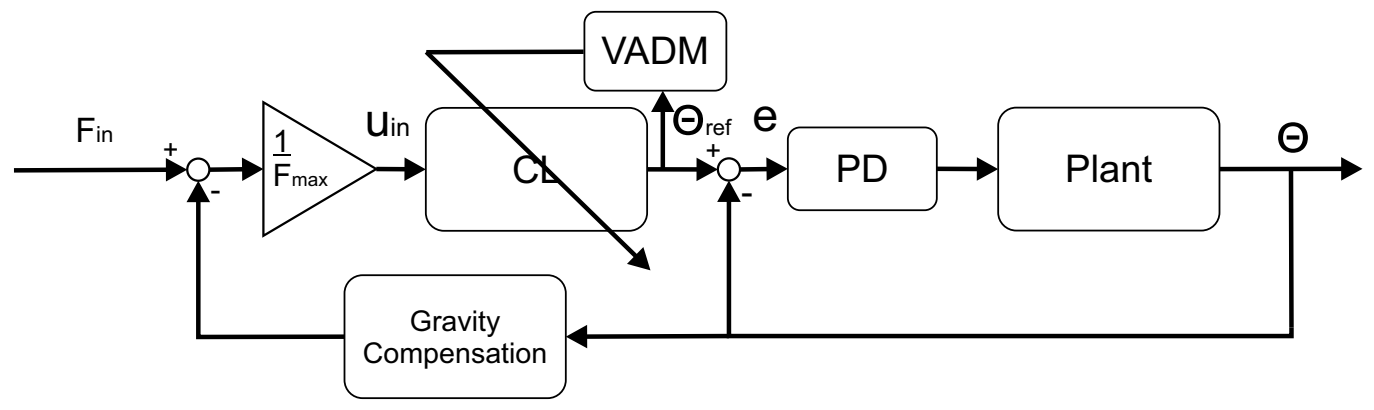

Fig. 4.4 Block diagram of the VADM architecture.

In this admittance, the transfer function from $u_{\text {in }}$ to $\theta$ is:

$$
\theta_{\text {ref }}=\frac{1}{M_{v} s^{2}+B_{v} s} \cdot u_{\text {in }}
$$




$$
\begin{aligned}
& \text { Intention }= \begin{cases}\text { acc, } & \text { if } \operatorname{sign}\left(\ddot{\theta}_{r e f}\right)=\operatorname{sign}\left(\dot{\theta}_{r e f}\right) \\
\operatorname{dec}, & \text { if } \operatorname{sign}\left(\ddot{\theta}_{r e f}\right) \neq \operatorname{sign}\left(\dot{\theta}_{r e f}\right)\end{cases} \\
& B_{v}= \begin{cases}B_{f}-\alpha_{a}\left|\ddot{\theta}_{r e f}\right|, & \text { for acc } \\
B_{f}+\alpha_{d}\left|\ddot{\theta}_{r e f}\right|, & \text { for dec }\end{cases}
\end{aligned}
$$

where $B_{v}$ is the actively used damping, $B_{f}=0.1$ the base damping. The parameters $\alpha_{a}=0.05$ and $\alpha_{d}=0.2$ were tuned manually and control the rate of change of $B_{v}$. The actively used mass $M_{v}$ is:

$$
M_{v}= \begin{cases}\frac{M_{f} B_{v}}{B_{f}}, & \text { for acc } \\ \frac{M_{f}\left(B_{f}-\alpha_{a}\left|\ddot{\theta}_{r e f}\right|\right)}{B_{f}} & \text { for dec }\end{cases}
$$

where $M_{f}=0.3$ is the base mass.

To ensure safety, $B_{v}$ and $M_{v}$ are limited to positive numbers.

\subsubsection{Experiment}

To evaluate the relative performance of the algorithms an experiment was conducted with 12 healthy subjects. Since the goal of the project is to create robots that assist users in performing activities of daily living, the experiment is designed as a series of reaching tasks, i.e., a commonly performed activity.

\subsubsection{Task}

A target is drawn on a graphical user interface on a sideways turned 1680x1050 pixels monitor. Locations of the targets are based on Fitts' law, using an index of difficulty $I D=[3.5,4.5,5.5]$ with fixed width $W=70$ pixels [25]. The $I D$, a dimensionless number representing the difficulty of a target, and MT, the movement time(s) are given by:

$$
M T=a+b \cdot I D
$$




$$
I D=\log _{2} \frac{D}{W}+1
$$

where $a$ and $b$ are linear parameters to be determined, $I D$ the index of difficulty in (bits), $D$ is the target distance in pixels and $W$ the target width in pixels. The targets are defined in terms of pixel distance $D$ from the home position, see Table 4.1 .

Table 4.1 Target Specifications

\begin{tabular}{cccc}
\hline \hline ID (bits) & 3,5 & 4,5 & 5,5 \\
\hline Pixel distance & 396 & 792 & 1584 \\
Angle (deg) & 8,1 & 16,2 & 32,4 \\
\hline
\end{tabular}

A yellow circle-shaped cursor (C) with a width of 30 pixels moves according to the angle of the robot and is directly controlled by the user. Due to the size of the cursor, the calculated target widths are corrected by adding the cursor width, resulting in $W=100$ pixels. The range of motion of the device is restricted to $0,6 \mathrm{rad}$ or $34,4^{\circ}$ to prevent collisions with the surroundings. Fig. 4.5 shows a representation of the graphical user interface. For flexion (Fig. 4.5, left), a home position is displayed as a semi-circle on the lower edge of the screen. The target is displayed consecutively in the area above the home target. For extension trials (Fig. 4.5, right), the home is placed on the upper edge. The cursor represents the angle of the robot with $0 \mathrm{rad}$ at the bottom of the screen and $0.6 \mathrm{rad}$ the upper edge of the screen.

\subsubsection{Protocol}

The experiment begins with a calibration phase to determine the required gravity compensation torque. Subjects are asked to relax and put their full weight on the robot. The robot then moves from $0 \mathrm{rad}$ to approximately $0.6 \mathrm{rad}$ in forward direction to calibrate the range of motion. Subsequently, the robot returns to an upright state and repeats the same trajectory, now measuring the angle and force. After this, subjects perform an isometric force measurement to capture the MVF.

After calibration, the first familiarization block starts. Within the familiarization periods (F1-3) subjects perform the task in the same way as in the following CL-block to familiarize themselves with 


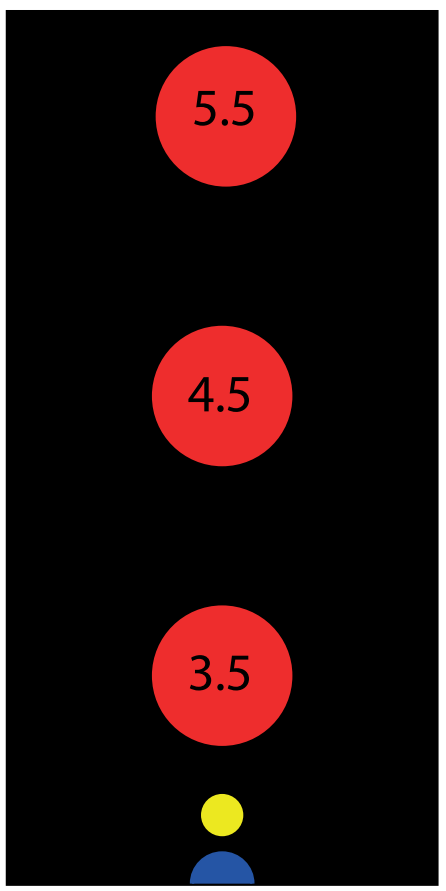

(a)

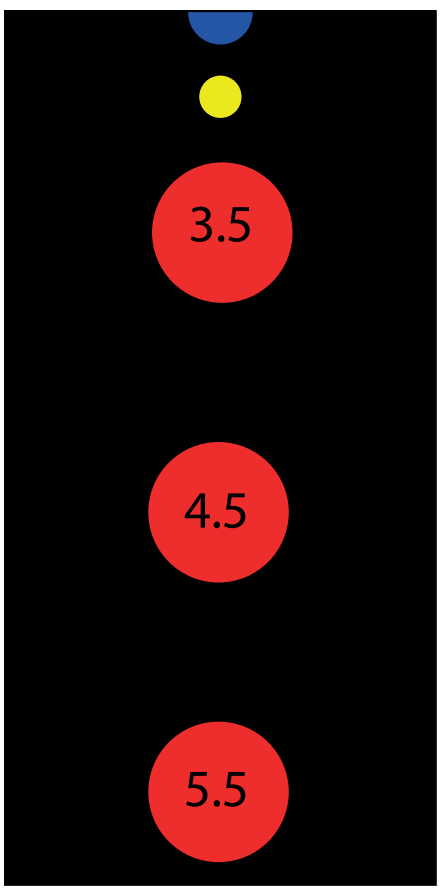

(b)

Fig. 4.5 Schematic overview of the user interface. Left and right represent flexion and extension respectively. $\mathrm{H}$ is the home position, $\mathrm{T}$ the target position, and $\mathrm{C}$ the cursor position.

the task and assigned control law. F2-3 are also used as wash out from previous control laws. After familiarization a CL-block starts immediately. The order in which the control laws are presented to subjects are blindly assigned to each subjects so every possible permutation is performed by two subjects. In between measurements, subjects are required to take a break of approximately 10 minutes (BR1-2). After CL3, subjects fill out a questionnaire, stating which control law they prefer.

The familiarization block consists of four sequences, each containing a randomized array of three times the targets specified in Table 4.1. Each sequence thus contains 9 trials. This means that the familiarization blocks consist of 36 trials. Each measurement block CL1-3 contains eight sequences, for a total of 72 trials per block.

A trial started with the requirement to remain stationary within the home position for a randomly chosen amount of time (1 to 5 seconds), after which a target appeared. Subjects were instructed to 
move toward the target as fast and accurate as possible. A target is reached when the user is able to hold the cursor within the target diameter for $0.5 \mathrm{~s}$. This time is called the dwell time. Dwell time was chosen as threshold for success to enforce a controlled deceleration toward an stationary behaviour within the target area.

\subsubsection{Subject Information}

12 healthy male subjects were recruited to participate in the experiment, see Table 4.2 to review their characteristics. All subjects read and signed an informed consent form. Subject 1 performed the experiment twice, but only his second run was recorded.

Table 4.2 Subject Characteristics

\begin{tabular}{cc}
\hline \hline Characteristic & 100\% male $(n=12)$ \\
\hline Age $[\mathrm{y}]$ & $23 \pm 2,8$ \\
Body Height $[\mathrm{cm}]$ & $186 \pm 3,3$ \\
Body Weight $[\mathrm{kg}]$ & $74 \pm 8,1$ \\
\hline
\end{tabular}

\section{4 trials, $\pm 120 \mathrm{~min}$}

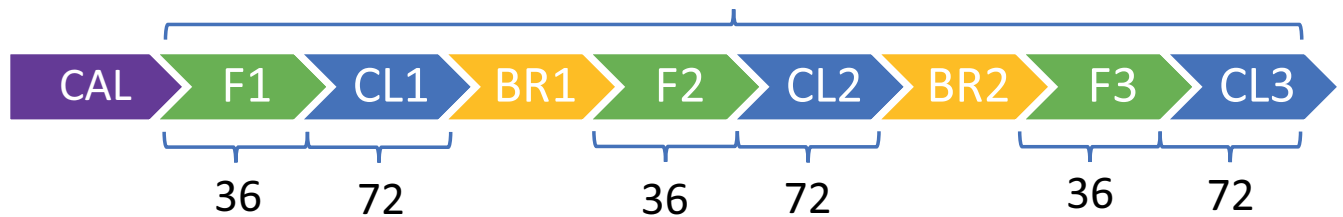

Fig. 4.6 Experiment flow. CAL: Calibration. F1-3: Familiarization period. CL1-3: Testing period for the control laws; BR1-2: Break. The numbers at the curly brackets represent amount of trials within that block.

\subsubsection{Quantitative Measures}

To assess performance, several parameters are calculated from the measured data. During the experiments, the cursor and target locations are saved in combination with timestamps at $1000 \mathrm{~Hz}$. Flexion and extension are investigated separately, since different muscle groups are involved in the major movements. The movement time is studied and is defined as the total time between the appearing of a target and reaching that target minus the reaction time and dwell time. The reaction time is defined 
as the time from the appearing of a target until the cursor has reached $2 \%$ of its maximum velocity for that trial.

\subsubsection{Statistical Analysis}

A non parametric Friedman test followed by a post-hoc Wilcoxon sign rank test with Bonferroni correction is done to determine the source of found significant differences. For the Friedman test, $\alpha=0.05$ and, for Wilcoxon's signed rank test with Bonferroni correction, $\alpha<\frac{0.05}{3}=0.017$, because three hypotheses are tested for in parallel.
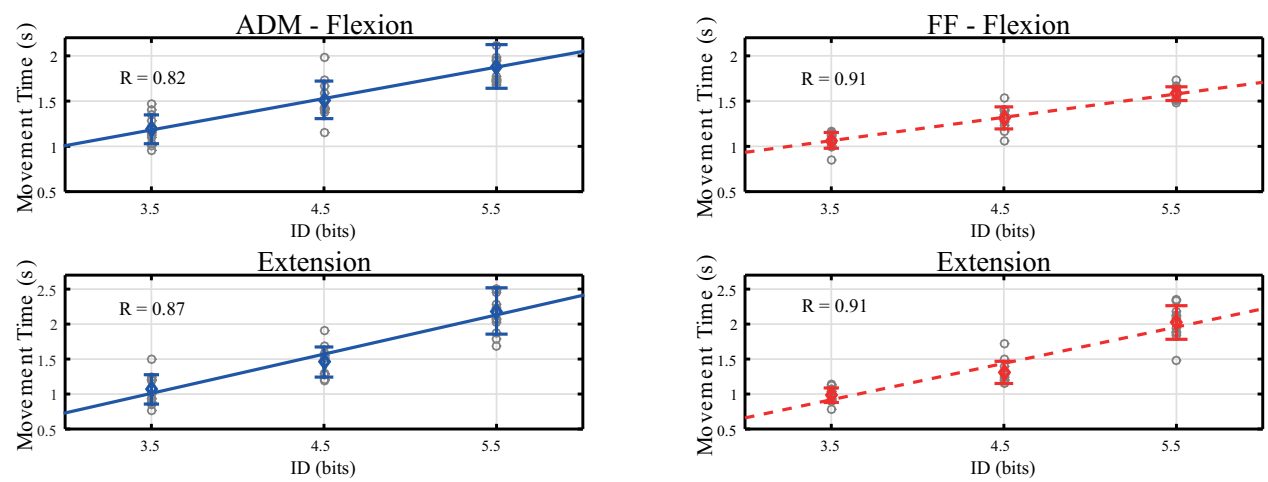

(a) Standard Admittance Law

(b) Feedforward Force Law
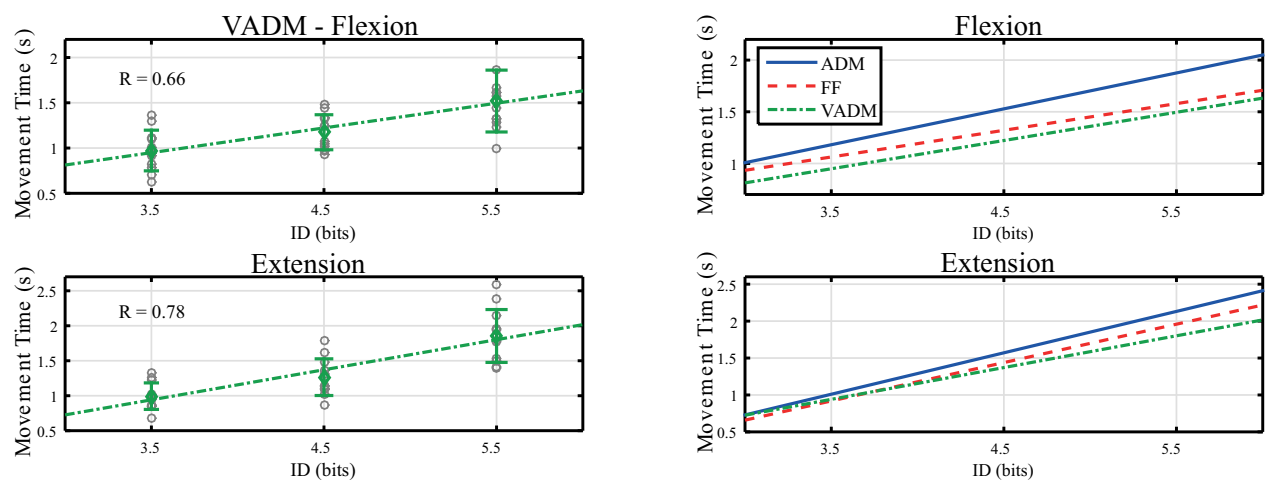

(c) Variable Admittance Law

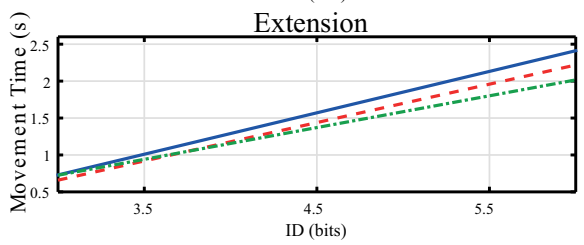

(d) Comparison

Fig. 4.7 Linear Regression on measured data. In (a-b-c) the average movement time per subject is plotted as grey circles. 
Table 4.3 Statistical analysis of movement time(F. and W. stand for Friedman and Wilcoxon respectively).

\begin{tabular}{lccccccc}
\hline \hline & & \multicolumn{3}{c}{ Flexion } & \multicolumn{3}{c}{ Extension } \\
\hline & ID & 3,5 & 4,5 & 5,5 & 3,5 & 4,5 & 5,5 \\
\hline F. $\chi^{2}$ value & & 7,17 & 16,67 & 12,67 & 0,5 & 6,5 & 3.5 \\
F. p-value & & 0,0278 & 0,0002 & 0,0018 & 0,7788 & 0,0388 & 0,1738 \\
W. p-value & ADM - FF & 0,1099 & 0,0068 & 0,0005 & 0,1099 & 0,0210 & 0,3013 \\
W. p-value & ADM - VADM & 0,0068 & 0,0005 & 0,0049 & 0,4238 & 0,0342 & 0,0210 \\
W. p-value & FF - VADM & 0,0640 & 0,0342 & 0,4238 & 0,9097 & 0,3394 & 0,3804 \\
\hline
\end{tabular}
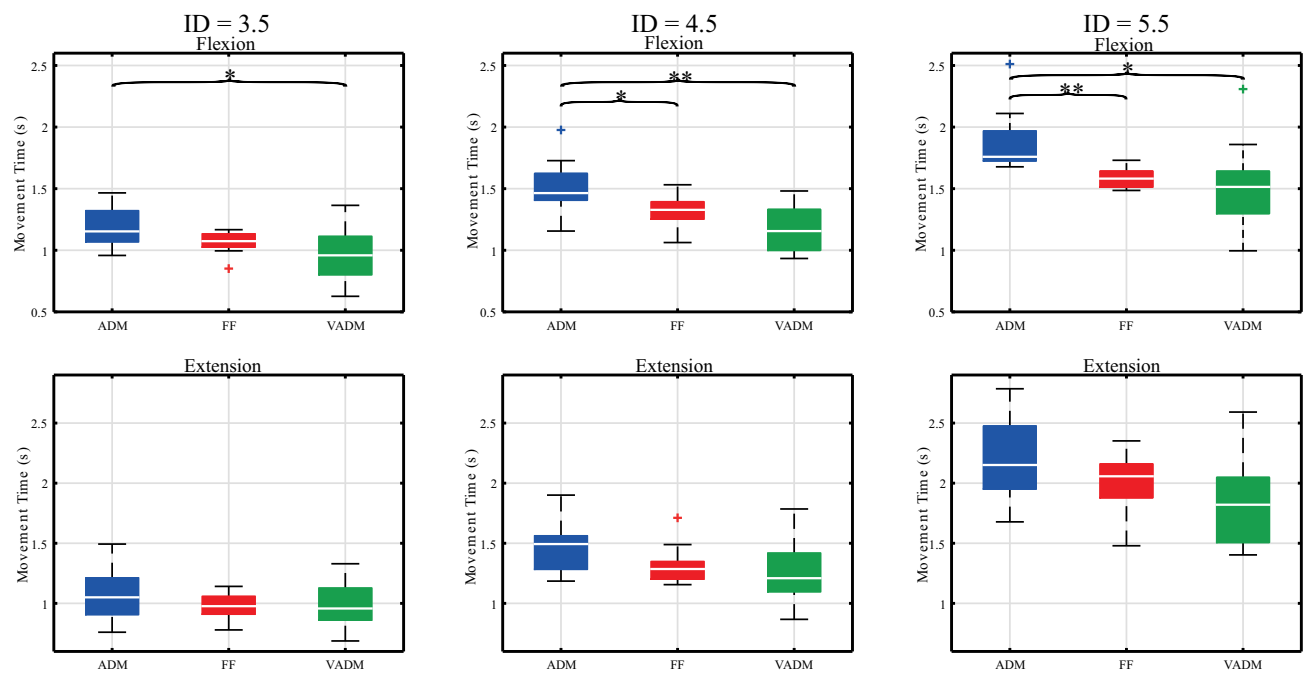

(a)

(b)

(c)

Fig. 4.8 Average Movement Time per Index of Difficulty. ${ }^{*} p<0.017,{ }^{* *} p<0.0017$.

\subsection{Results}

\subsubsection{Movement Time}

The movement time was extracted from the data for all trials. This data was averaged over subjects and plotted per ID see Fig. 4.7.

For flexion, strong evidence was found that the different conditions (control laws) affected the MT $(p<0.05)$ on all ID's using a Friedman test. For extension, evidence was only found for $I D=4.5$. 
Table 4.4 Linear Model parameters. (*) $0.05<p<0.1$, (**) $p>0.5$.

\begin{tabular}{ccccc}
\hline \hline \multicolumn{5}{c}{ Flexion } \\
\hline Control Law & $a[s / b i t s]$ & $b[s]$ & $R_{a}$ & $R_{s}$ \\
\hline ADM & 0,35 & $-0.03^{* *}$ & 0,82 & 0,43 \\
FF & 0,26 & $0,16^{*}$ & 0,92 & 0,36 \\
VADM & 0,27 & $-0.01^{* *}$ & 0,66 & 0,36 \\
\hline \multicolumn{6}{c}{} \\
\hline Extension \\
\hline Control Law & $a[s / b i t s]$ & $b[s]$ & $R_{a}$ & $R_{s}$ \\
\hline ADM & 0,56 & $-0,95$ & 0,87 & 0,57 \\
FF & 0,52 & $-0,90$ & 0,91 & 0,53 \\
VADM & 0,43 & $-0,56$ & 0,78 & 0,47 \\
\hline \multicolumn{7}{c}{}
\end{tabular}

A post-hoc Wilcoxon signed rank test was done to find between which conditions the differences occurred. In flexion, significant differences were found between ADM and FF $(P<0.017)$ for $I D=$ $[4.5,5.5]$, and between ADM and VADM for all ID values $(P<0.017)$. Between laws FF and VADM, no significant differences were found. For extension, no significant differences were found between specific conditions for any ID, see Fig. 4.8.

Following Fitts' law, linear regression was performed on these averages. The regression coefficients are noted in Table 4.3, based both on the averaged data points per subject $\left(R_{a}\right)$ and on all separate trial data $\left(R_{S}\right) . R_{S}$ is lower due to higher variance in the separate data. In both flexion and extension, the $R_{a}$ of VADM is the lowest, followed by ADM and finally FF.

\subsubsection{Questionnaire}

By $67 \%$ of the subjects VADM was chosen as the preferred control law, followed by FF (25\%) and ADM (8\%). Subjects indicated that although VADM was the hardest to learn, it offered the best support. 


\subsection{Discussion}

\subsubsection{Movement Time and Fitts' law}

Using the FF control law or the VADM control law reduces the average movement time for trunk flexion. Between FF and VADM, no distinction could be made in terms of quantitative performance.

It seems that Fitts' law holds for the measured data, since linear regression coefficients over the averaged MT is close to those given in the literature for comparable experiments [31]. Increased variance may have been caused by the usage of dwell time as a marker for the success of a trial. Deviation from the target before the dwell time was completed reset the timer, so time spent within the target area before a full dwell time was reached is counted as movement time. Another reason might be found in that human trunk motion does not require precise movements in daily life. The endpoint for activities involving trunk motion is usually covered by a limb such as the arms. Therefore, humans might not be inclined to perform fine trunk movements.

The lower regression coefficient of $\operatorname{VADM}\left(R_{a}=0.66\right)$ might be explained by subjects comments. Subjects noted during measurements that although they preferred VADM above the other algorithms, it is the hardest to learn. This indicates that larger errors may have been made in the earlier trials resulting in a larger variance.

\subsubsection{Flexion vs. Extension}

Significant results mostly show in the data for flexion movements. This could have been caused by the gravity compensation algorithm. This algorithm provided a backward directed force to compensate the body weight dependent on the angle within the range of motion. The amplitude of this force is large with respect to the extra force generated by the FF or VADM and is thus the main contributor to the extension movements. This could mean that subjects generally learned how to use the gravity compensation for trunk extension, disregarding the smaller contributions of different control laws. For flexion, the gravity compensation force is counter-assistive and does not contribute to the flexion movements, so all flexion assisting forces were generated by the control laws, forcing subjects to 
learn how to control and use their beneficial effects to improve task performance.

\subsubsection{Comparison}

The control laws FF and VADM showed smaller movement times compared to the ADM. This indicates that the regularly used standard admittance can be improved easily by adding feed forward forces or using a simple intention detection algorithm to modify the admittance parameters. Subjects feel more supported and show that they improve motor skills using the extra given support.

\subsection{Conclusion}

Three assistive admittance control algorithms were developed for the Trunk Drive exoskeleton. A Fitts' law experiment was setup and performed with twelve subjects. Movement Time for a 1-DOF reaching task of the trunk using the TD exoskeleton holds to Fitts' law. FF and VADM show decreased movement times for flexion and are valued over ADM by subjects. Based on the results, it is hard to differentiate between FF and VADM in terms of performance. Based on subject preferences, VADM is the most promising control law.

In the future, experiments will be done to evaluate the use of (E) as input device as opposed to force, as this may be more convenient for people with DMD. 


\title{
CHAPTER 5
}

\section{Exploring physiological signals on people with Duchenne muscular dystrophy for an} active trunk support: A case study ${ }^{1}$

\begin{abstract}
Arm support devices are available to support people with Duchenne muscular dystrophy (DMD), but active trunk support devices are lacking. An active trunk support device can potentially extend the reach of the arm and stabilize the unstable trunk of people with DMD. In a previous study, we showed that healthy people were able to control an active trunk support using four different control interfaces (based on (J), (FS), (FF) and (E)). All four control interfaces had different advantages and disadvantages. The aim of this study was to explore which of the four inputs is detectably used by people with DMD to control an active trunk support. Three subjects with DMD participated in a study aimed at identifying the best way of controlling an active trunk support. Two experiments were performed for that reason: an active experiment with an active trunk support assistive device and a static experiment without the active trunk support. The challenge in both experiments was to steer the cursor into a target of a graphical user interface using the signals from different control interfaces. The results were subject-dependent in both experiments. In the active experiment, the $(\mathrm{J})$ was the most promising control interface. Regarding the static experiment, (E) and (FF) worked for two out

\footnotetext{
${ }^{1}$ This chapter has been published as: Stergios Verros, Laura Peeters, Arjen Bergsma, Edsko E.G. Hekman, Gijsbertus J. Verkerke and Bart F.J.M. Koopman, "Exploring physiological signals on people with Duchenne muscular dystrophy for an active trunk support: A case study", BMC Biomedical Engineering.
} 
of the three subjects. To our knowledge, this is the first time that people with DMD have engaged in a control task using signals other than those related to their arm muscles. According to our findings, the control interfaces have to be customised to every DMD subject. 


\subsection{Background}

People with Duchene muscular dystrophy lose their muscle functions progressively [8]. It affects one out every 6000 boys [63].The current life expectancy has increased to about 30 years of age due to, among others, the use of corticosteroids which slow down disease progression [64]. However, the Health Related Quality of Life (HRQoL) for people with DMD is lower than healthy people [9].

Passive trunk support can increase the range of motion, stabilise the trunk, and reduce trunk muscle activation $[20,21]$. However, as the DMD progresses, the patients muscle capacities decrease and additional assistance is needed by means of an active trunk support. To operate an active device, intention detection control interfaces are needed. Several control interfaces have been used to control active assistive devices [13]. Hand joysticks are useful for people with disabilities to control powered wheelchairs and external robotic arms $[46,47]$. Also, force-based control and electromyography are promising control strategies for people with DMD $[13,65]$. Thus, we developed an active trunk support experimental setup to study and compare the performance differences of four different control interfaces of healthy males [66]. The control interfaces used were the (J), (FS), (FF) and surface electromyography (E). The results showed that all those control interfaces have the potential to be used for an active trunk support. In the current study, we wanted to explore which of the four inputs can be detectably used by people with DMD to control an active trunk support.

\subsection{Methods}

\subsubsection{Test set-up}

We performed two experiments with three people with DMD. The first one was an active feasibility study. In this experiment we used the same protocol as in the experiment with healthy people [66]. While healthy people were able to control the active trunk support setup, the participants with DMD were unable to perform the same movements. Therefore we took a step back and performed a second, static experiment with the aim to give more weight to the optimisation of the control interfaces without the active trunk support setup. In this static experiment, we chose to optimise two control 
interfaces from the active study namely, (FF) and (E). The (J) performed well, the (FS) performed unsatisfactory, so both needed no further testing. To optimize the performance of (FF) and (E) a static experiment was performed. Additional advantage of the focus on these two control interfaces was a limitation of the exposure of DMD-patients.

\subsubsection{Participants}

Three people with DMD, between 21-30 years of age, participated in the two experiments. Informed consent was given by all the participants prior to participation. The medical Ethics Committee of Radboud University Medical Center approved the study and the protocol design (NL53143.091.15). Table 5.1 summarises the subjects characteristics. Subjects were recruited through the outpatient clinic of the Radboud University Medical Center Nijmegen. Participants were included if they were older than 12 years of age, non-ambulant, able to understand instructions and if they had a genetically confirmed diagnosis of DMD. Subjects with other disabling diseases affecting the trunk, head or arms, needing continuous ventilation and participating in another study at the time, were excluded.

Table 5.1 Physical characteristics of the subjects.

\begin{tabular}{cccc}
\hline \hline & Subject one & Subject two & Subject three \\
\hline Age [years] & 21 & 21 & 30 \\
Age of diagnosis [years] & 2 & 2 & 2 \\
Age wheelchair confined [years] & 10 & 11 & 17 \\
Scoliosis & Mild & Mild & No \\
Surgical scoliosis correction (age [years]) & No & Yes (17) & No \\
Corticosteroid use & Yes & Yes & No \\
Brooke scale & 5 & 5 & 5 \\
\hline
\end{tabular}

\subsubsection{Experimental Design}

\subsubsection{Active and static experiment}

The experimental design was similar to the previous study [66]. A visual feedback was introduced to the subjects through a screen. Initially, the cursor (5.1, yellow circle) was at the home position 1 
(5.1, blue circle). When the word GO was displayed on the screen it indicated the start of a trial. At a random time between one to three seconds, a target (5.1, red circle) appeared randomly at one of the three locations on the screen. The subjects had to steer the cursor into the target using a control interface in order to complete the trial. After a $2-\mathrm{sec}$ dwell time, the first trial was completed. Then, a blue target was shown at the home position 2 at the top of the screen and the subject had to steer the cursor into the home position 2. When the word GO was displayed on the screen, the subject had to steer the cursor again into the target and complete the extension trial with a 2 -sec dwell time. Finally, the blue home position 1 appeared and the subject had to steer the cursor into home position 1 .

Each target reached from home position 1 or home position 2 was considered as one trial. Trunk flexion describes the movement of the trunk whereby the angle between the upright position of the trunk and the legs decreases. Contrarily, trunk extension increases the angle. The movement from home position 1 to target was considered as trunk flexion and the movement from home position 2 to target was considered as trunk extension. Each block consisted of 18 trials (9 flexion and 9 extension). Before the start of the trials, the subjects were given some time to familiarise themselves with the experiment.

The sizes of the cursor and target were 30 and 100 pixels, respectively. The distances between the home position and the target area were 395, 791 and 1583 pixels.

In the case of the active experiment, the subjects used the Trunk Drive assistive device in order to perform the experiment [66]. No trunk support setup was used for the static experiment.

At the beginning of the experiment, the subjects were asked to sub-maximally contract the muscles where the (E) sensors were placed for 2 seconds. Instructions were given that it should not cause any discomfort. This also applied to the force measurements, whereby the subjects were asked to flex or extend their trunk, or to push / pull their feet sub-maximally. The sub-maximum values were used to normalise the control signal. signal. The (E) sensors were placed on the gastrocnemius/tibialis muscles of two subjects and on the quadriceps of the third subject due to spikes on the (E) signals coming from the gastrocnemius. The same researchers placed the (E) sensors on all the cases following the SENIAM guidelines [50]. 


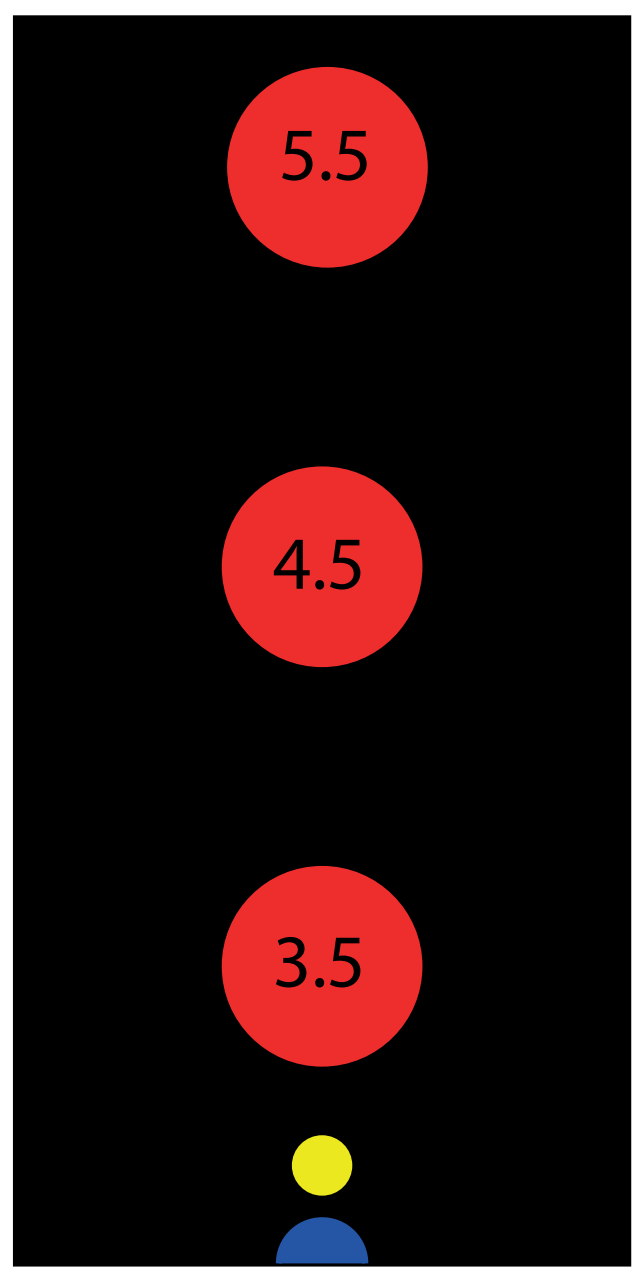

(a)

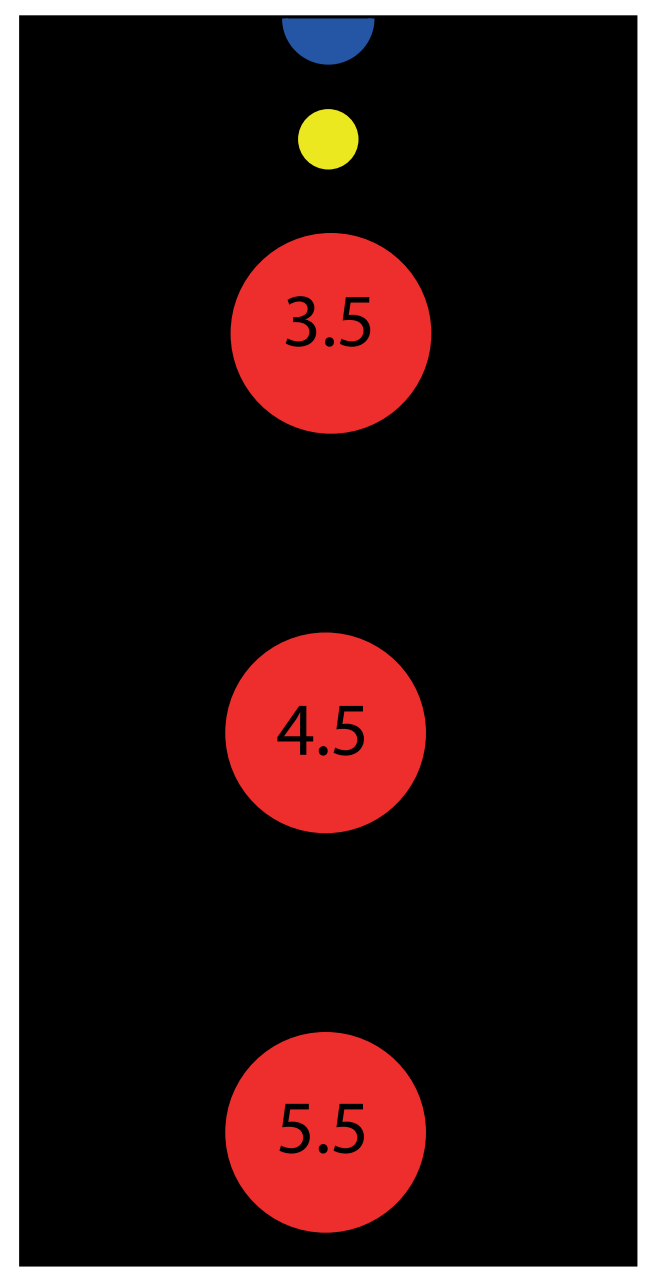

(b)

Fig. 5.1 Graphical user interface. This figure shows the representation of the Graphical User Interface with target position (red circle) at different distances, the home position (blue circle) and the cursor (yellow circle).

\subsubsection{Parameter tuning}

During the active experiment, the researchers tuned the virtual mass and damping values of the admittance model for every subject and for every control interface. If the cursor was moving too slow, the virtual mass was decreased until the subject felt comfortable with the current speed. To avoid 
sudden movements with a high frequency, the virtual damping was increased. The virtual mass and virtual damping made the active trunk support appear as a physical system, which is common for physical human robot interaction [67]. On the other hand, since there was no physical system in the static experiment, we chose to use a different control approach. Here, the percentage of the submaximum contraction, together with a saturation and the dead zone, were tuned by the researchers for each subject individually to achieve the best performance. A decrease in the percentage of the sub-maximum contraction led to faster movements, whereas an increase led to slower and more fatiguing movements. The saturation ensured that a certain speed value could not be exceeded, so the speed remained bounded. Finally, the dead zone ensured that only the voluntary signals would move the cursor.

\subsubsection{Experimental duration}

The number of the control interfaces was different for the active and the static experiment and is described below.

The subjects started the active experiment in the following order: (J), (FS), (E), (FF), consisting of 3 blocks of 18 trials resulting in 54 trials in total. We kept the number of trials per control interface close to the number of trials of a previous study with people with DMD [13].

The subjects started the static experiment with (FF) and then (E) consisting of 1 block of 18 trials. These two control interfaces were considered the most feasible ones since one hand was required to perform the tasks and would not have been available to operate the active trunk support assistive device with the (J).

\subsubsection{Signal acquisition}

The sensor signals were processed using a computer (xPC target, MathWorks Inc., USA) and a data acquisition card (PCI-6229; National Instrument Corp., USA). The sampling frequency was set at $1 \mathrm{kHz}$ with a 16-bit resolution. 


\subsubsection{Signal processing}

All the average signal amplitudes, with a rest state of 2 seconds, were subtracted and the signals were divided by a sub-maximum contraction value. Envelope detection was applied afterwards to the (E) signals using a high-pass Butterworth $(40 \mathrm{~Hz})$, full wave rectifier and a low-pass Butterworth at $(2 \mathrm{~Hz})$. No filtering was used for the (J), (FS) sensor and (FF). Regarding (FS), gravity compensation was obtained and subtracted from the voluntary force. Gravity compensation was obtained during slow trunk flexion $(0.05 \mathrm{rad} / \mathrm{sec})$ where the subjects had to fully relax their trunk. The muscle activation signals were measured with wireless (E) sensors (Trigno Delsys, USA) and the force with a six DoF load sell (ATI mini45).

\subsection{Results}

\subsubsection{Active experiment}

Subject one could perform the experiment with the (J) but not with the (FS) because he could not relax his muscles sufficiently in the device. This led to non-optimal gravity compensation values and consequently an inability to control the active trunk support properly by measuring (FS). Due to technical problems with the force plate, the threshold of the measured force under the feet was higher than the force that the participant could produce with his feet and therefore he was unable to control the active trunk support setup. He could perform only 1.5 blocks out of 3 in total with the (E), because the control was too exhausting.

Subject two had spinal fusion hence his physical point of rotation was misaligned with the point of rotation of the active trunk support. He performed the experiment without the active trunk support with the (J) and the (E). (FS) could not be performed because he was not seated in the trunk support and $(\mathrm{FF})$ failed for the same reason as subject one.

Subject three could only perform the experiment with the (J). (FS) also failed due to unreliable gravity compensation values as we saw in subject one. (FF) failed for the same reasons as described for subjects one and two. Spikes on the (E) signals and co-contraction of the muscles were the reasons 
that (E) failed for subject three.

\subsubsection{Static experiment}

Subject one could perform the experiment with (E) but not with (FF). Stabilizing the cursor on the screen (i.e., to control the movement) was difficult by pushing against the force plate with his feet, because of equinovarus feet (lateral and upwards).

Subject two could perform the experiment with (FF) but not with (E) because there were spikes on the signal when the subject relaxed his muscles. These spikes made it difficult to stabilise the cursor on the screen due to the fact they were unintentional and the subject could not control them.

Subject three could perform the experiment with both (FF) and (E). Regarding the (FF), the subject adapted quickly and no significant adjustments were made to tune the controller. The (E) was weak from the tibialis anterior and there were spikes on the (E) signals. Consequently, the (E) sensors were moved to the left and right quadriceps muscles but at the end of the experiment, the subject experienced cramps in the quadriceps muscles.

Table 5.2 summarises both experiments and the performance with each control interface.

Table 5.2 Feasible control interfaces for both experiments.

\begin{tabular}{lccc}
\hline \hline & Subject one & Subject two & Subject three \\
\hline Active experiment & $(\mathrm{J}),(\mathrm{E})(1,5$ blocks $)$ & $(\mathrm{J}),(\mathrm{E})$ & $(\mathrm{J})$ \\
Static experiment & $(\mathrm{E})$ & $(\mathrm{FF})$ & $(\mathrm{FF}),(\mathrm{E})$ \\
\hline
\end{tabular}

\subsection{Discussion}

The aim of this research was to investigate which control interface can be used by people with DMD to control an active trunk support. For that reason, we performed two tracking task experiments with three subjects with DMD.

A ( $\mathrm{J})$ is not ideal for controlling a trunk support device because it requires a hand to operate the (J) and thus this hand cannot be used for other functions like grasping. Hence, (E) and (FF) were investigated in the static experiment. After tweaking the experimental procedure, two out of three 
participants were able to control the ball on the screen in the static experiment. Also, two participants were able to perform the experiment using the (E) based control interface. Only subject one was consistent with the (E) control. Subject two could perform the active experiment with (E) (but without the device), yet he was unable to perform the static experiment successfully while using the (E) interface. Subject three could not perform the active experiment with the (E) on the gastocnemius/tibialis muscles but after placing the (E) electrodes on the quadriceps muscle in the static experiment he could perform the experiment even though at the end he experienced cramping in both quadriceps muscles. He also pointed out that he could not continue the experiment for more than one block.

Previous studies have shown that force- and electromyography-based control interfaces can be used for controlling an active elbow support on people with DMD whereby the (J) is only used for familiarisation and not for comparison [13]. Both control interfaces proved to be feasible solutions for the three adults who participated in the experiment with a $100 \%$ completion rate for forced-based control interface and $95 \%$ for (E)-based control interface. In our research, the only control interface which worked in all cases was the $(\mathrm{J})$. A major issue that we encountered was the anxiety the subjects felt when using the active trunk support. They could not support their own weight across the whole range of trunk movements due to muscle weakness and therefore the potential instability without a trunk support could have a harmful result. As a consequence, they might not have been able to relax their muscles during the gravity compensation phase. Moreover, people with DMD have significant amounts of fatty tissue concentrated on the abdominal area, which impedes them in trunk flexion. The combination of these two factors probably resulted in non-optimal gravity compensation values for the force-control interfaces and could be a reason why they could not use the (FS) control interface properly. Controlling with leg muscles might have been complicated by the fact the DMD subjects had already been wheelchair bound for more than 10 years. This means that their leg muscles had already been inactive for quite some time, with the consequence of further deterioration of the muscles due to disuse, and possible loss of motor control. Additionally, muscle fatigue sets in earlier because of muscle weakness and disuse. The opposing reasons, together with the progressive disease severity, cause the movement time of each control interface for each subject in the static experiment to be longer (Fig. 5.2) than that of healthy participants found in the literature, except for the (E) 
performed by the third subject who achieved lower movement times than the healthy controls [66]. An explanation could be the exceptional immediate familiarization of the subject with the (E) control interface. Moreover, the individual results might be a consequence of the difference in the severity of the disease among the subjects.
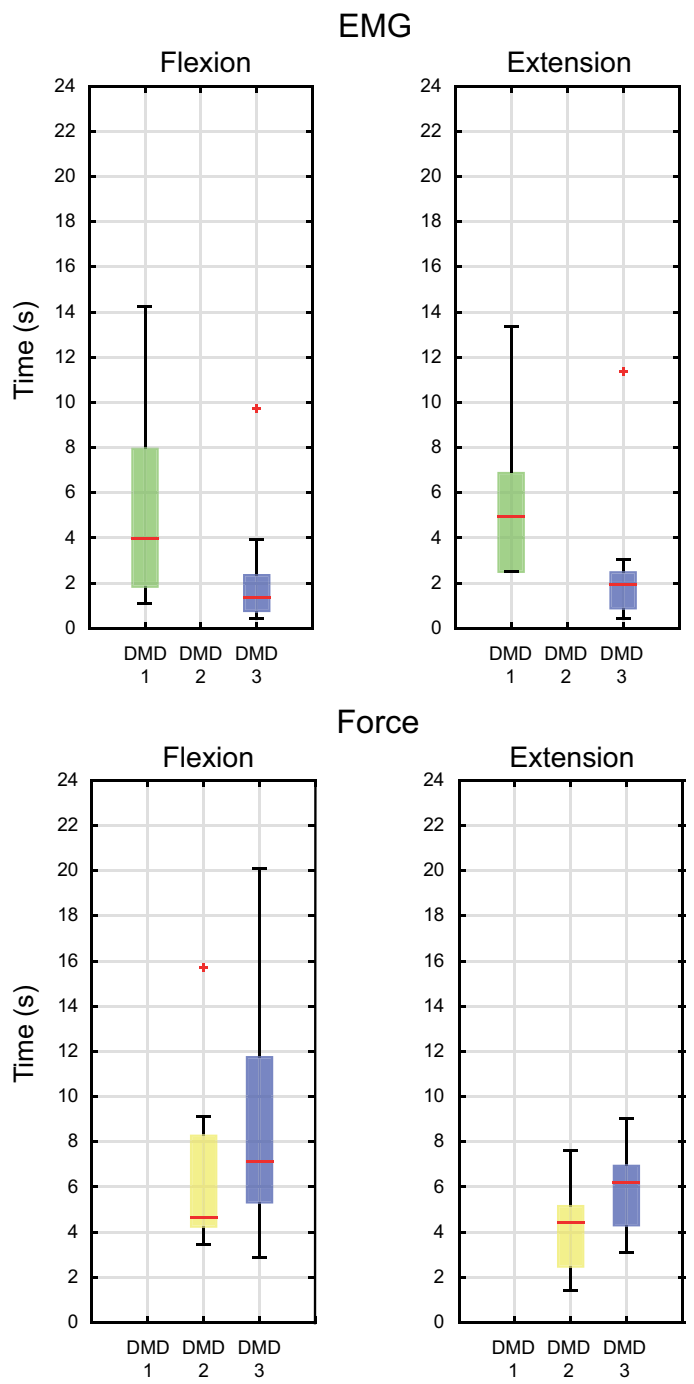

Force

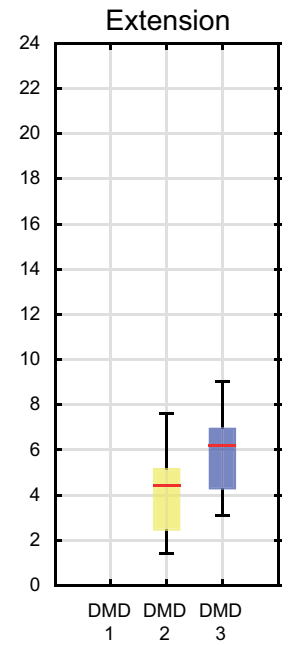

Fig. 5.2 Measured Time box plots. This figure shows measured time of (E) and (FF) control. 
Time and fatigue were crucial factors in the static experiment. Tuning of the parameters was time consuming in some cases, but time to find the right parameters was limited due to rapid fatigue. Thus, the signals should be investigated further with multiple sessions of the same experiment. Also, changing to adaptive control and training might help in tuning the parameters more effectively [68]. We did not experience this in the experiment with the healthy participants where the tuning parameters were set at constant throughout the whole experiment with values based on a two subject pre-experimental procedure. Customised tuning of each control interface for people with DMD should be based on factors related to disease stage and severity.

Furthermore, the muscles of the DMD subjects legs are not used to contracting since they are confined to a wheelchair for many years. Their leg muscle capacity is low and fatigue occurs rapidly. Additionally, motor control can be lost with time, causing co-contraction as seen in subject three. A known saying that is applicable to people with DMD is Use it or lose it [14]. To avoid such a phenomenon, [69] they should follow an assisted bicycling training of legs and arms. Consequently, rehabilitation should focus on keeping the muscles as active as possible, starting at the early stages of the DMD, as well as on the trunk section.

\subsection{Conclusions}

Two experiments were performed with three people with DMD with the aim to investigate the use of different control interfaces with an active trunk support device. Based on the results of the active experiment, it is clear that the (J) was a feasible solution for all subjects. Alternatively, (FF) as well as (E) can also be used as control interfaces, but both of them need customized tuning for each subject. 


\section{CHAPTER 6}

\section{General discussion}

\subsection{Introduction}

Trunk movement is essential for performing daily tasks [15]. When coupled with arm movement, the arm reach can be increased substantially [20], allowing people to grab a wide range of objects over a wide area and transport them to or from the body. ADL, such as picking up a glass of water, is a complex motor task and the interaction between the trunk and arm is essential $[16,18]$. To support this process in people with muscle dystrophy, like DMD, several arm supports have been developed and studied. However, a trunk support was lacking. A passive version is of use in the early stage of the disease whereas an active trunk support is very beneficial for people with DMD in a later stage when they are incapable of using a passive trunk support. The Symbionics project was involved in designing a passive, as well as an active trunk support system. This thesis concentrates on the design and the testing of control interfaces for controlling an active trunk support, in order to convert the user intended movement into a device movement. Several control interfaces were created and evaluated by performing experiments on people without and with DMD to find the most promising control interface(s) that can drive an active trunk support. We scored each control interface for each experiment based on the output of the experimental procedure and we adjusted the scale based on the amount of comparisons. Speed and accuracy criteria were scored based on the quantitative performance on each experiment. Then, we took the average of every criteria for calculating the largest score. The average was used since we did not expect any outliers. All the criteria had the same weighing since we believe 
that all of them were equally important.

\subsection{Interpretation of findings}

We suspected (E) is hard to obtain from abdominal muscles, therefore we wanted to establish we can get better results with a non-intuitive (E) interface. In the first experiment, an evaluation was performed in 2-D, because it was assumed that the trunk support will have two degrees of freedom (in a sagittal and frontal plane). To limit the burden on DMD patients, the experiment was performed with people without DMD. A comparison was made between the performance and learning behaviour of intuitive (E)s from trunk muscles and non-intuitive (E)s from a leg muscle control interface used with an active trunk support. We found that the subjects can steer the cursor significantly faster with the non-intuitive leg control interface than the intuitive trunk control interface. The sluggishness of the intuitive trunk control interface can be explained by the fact that the (E) signals from the trunk muscles are perturbed by respiratory muscle activity and the existence of body fat tissue. The results (table 6.1) clearly show that the non-intuitive control interface, the (E)s from the leg muscles, had a higher score for most of the criteria than the (E)s from the trunk muscles.

Table 6.1 Intuitive and non-intuitive control interface scores.

\begin{tabular}{ccc}
\hline \hline $\begin{array}{c}\text { Physiological } \\
\text { phenomena }\end{array}$ & \multicolumn{2}{c}{ Electric current of muscle } \\
\hline Sensor & \multicolumn{2}{c}{ (E) electrode } \\
\hline Signal measured & $\begin{array}{c}\text { (E) from } \\
\text { trunk muscles }\end{array}$ & $\begin{array}{c}\text { (E) from leg } \\
\text { muscles }\end{array}$ \\
\hline Criteria & & \\
\hline Intuitiveness & 1 & 0,3 \\
Independence & 1 & 1 \\
Robustness & 0,3 & 1 \\
Autonomy & 0,3 & 1 \\
Customizable & 0,3 & 1 \\
Price & 0,3 & 0,3 \\
Speed & 0,3 & 1 \\
Accuracy & 0,3 & 0,3 \\
Result & 0,48 & 0,74 \\
\hline
\end{tabular}

As a next step we wanted to find an optimal control interface therefore, we evaluated the (E) 
control interface with the $(\mathrm{J})$ and force based controllers on people without DMD. Due to the fact that a trunk movement in the sagittal plane requires a considerable amount of power, which translates into vast electric motors, the actuation of a second degree of freedom would have complicated the mechanical design. Thus, it was decided to design a 1-D active trunk support. We found that the (FS) and (J) were faster than the (FF) and (E) (more than $40 \%$ ). However, the difference between them was not statistically significant, but there was a significant difference between (FS) on the one hand, and (E) and (FF) on the other. This result can be explained by the fact that a (J) and (FS) can be used to control the trunk more intuitively whereas (FF) and (E) are considered to be less intuitive. Regarding the rest of the performance metrics, the difference in absolute values was negligible. (FS) was the most fatiguing interface based on the questionnaire. The users' overall preference on the questionnaire was the $(\mathrm{J})$ because it is the most common control interface. As shown in table 6.2, each control interface has advantages and disadvantages, so we decided to include all control interfaces for further experimental investigation with people with DMD.

As a further step, the signal produced by every control interface was used as an input in an admittance model. The virtual mass and damping were tuned for every control interface based on a pre-experimental procedure. Tuning of the virtual values is subjective and can limit the performance of the assistive device. Thus, more sophisticated controllers were investigated to improve the performance. We designed an experimental method for evaluating three different admittance controllers. The admittance controllers, which were tested based on time only, were: constant parameters, feedforward force and variable parameters.

The control laws of the feedforward and variable admittance parameters resulted in smaller movement times compared to the admittance with constant parameters. This indicates that the regularly used standard admittance can be improved easily by adding feed forward forces or using a simple intention detection algorithm to modify the admittance parameters. Subjects feel more supported and their motor skills improve with the extra given support. The admittance with feedforward force and with variable parameters was always faster than admittance with constant parameters for flexion. The same pattern was seen with extension but without significant differences between the parameters. It is clear from the scores (table 6.3) that more sophisticated admittance controllers can improve the 
Table 6.2 (J), (FF), (FS) and (E) from leg muscles scores.

\begin{tabular}{ccccc}
\hline $\begin{array}{c}\text { Physiological } \\
\text { phenomena }\end{array}$ & Force & $\begin{array}{c}\text { Movement of } \\
\text { small body } \\
\text { segments }\end{array}$ & $\begin{array}{c}\text { Electric } \\
\text { current of } \\
\text { muscle }\end{array}$ \\
\hline Sensor & Force/Torque Sensor & $(\mathrm{J})$ & (E) electrode \\
\hline Signal measured & $($ FF) & $\begin{array}{c}\text { Force on } \\
\text { trunk }\end{array}$ & Fingers & $\begin{array}{c}\text { (E) from } \\
\text { lower } \\
\text { extremity } \\
\end{array}$ \\
& & & & muscles \\
\hline Criteria & & & & \\
\hline Intuitiveness & 3 & 5 & 5 & 3 \\
Independence & 4 & 5 & 1 & 3 \\
Robustness & 4 & 1 & 4 & 2 \\
Autonomy & 2 & 5 & 5 & 5 \\
Customizable & 4 & 4 & 5 & 5 \\
Price & 5 & 5 & 5 & 3 \\
Speed & 3 & 5 & 5 & 3,50 \\
Accuracy & 3 & 3 & 3 & \\
Result & 3,50 & 4,13 & 4,13 & \\
\hline
\end{tabular}

performance of an active trunk support.

Based on the results of the two experiments, summarised in 6.4 , it is clear that the $(\mathrm{J})$ was a feasible solution for all subjects. Alternatively, (FF) and (E) can also be used as control interfaces, but both need customized tuning for every subject. (FF) control was slower for the DMD subjects compared to the healthy controls, but there was no difference in speed with the (E), although finding the right muscles for the task is a challenge. (FS) scored zero in all of the requirements since none of

Table 6.3 Controller scores.

\begin{tabular}{cccc}
\hline \hline Controller & $\begin{array}{c}\text { Normal } \\
\text { admittance }\end{array}$ & Feed forward & $\begin{array}{c}\text { Variable } \\
\text { admittance }\end{array}$ \\
\hline Criteria & & 3 & 3 \\
\hline Intuitiveness & 3 & 3 & 3 \\
Independence & 3 & 3 & 3 \\
Robustness & 3 & 2 & 1 \\
Autonomy & 2 & 3 & 3 \\
Customizable & 3 & 3 & 3 \\
Price & 3 & 2 & 3 \\
Speed & 1 & 2 & 2 \\
Accuracy & 2 & 2,63 & 2,63 \\
Result & 2,50 & & \\
\hline
\end{tabular}


Table 6.4 Control interfaces score for experiment with people with DMD.

\begin{tabular}{ccccc}
\hline $\begin{array}{c}\text { Physiological } \\
\text { phenomena }\end{array}$ & Force & $\begin{array}{c}\text { Movement of } \\
\text { small body } \\
\text { segments }\end{array}$ & $\begin{array}{c}\text { Electric } \\
\text { current of } \\
\text { muscle }\end{array}$ \\
\hline Sensor & Force/Torque Sensor & $(\mathrm{J})$ & (E) electrode \\
\hline Signal measured & $($ FF) & $\begin{array}{c}\text { Force on } \\
\text { trunk }\end{array}$ & Fingers & $\begin{array}{c}\text { (E) from } \\
\text { lower } \\
\text { extremity } \\
\end{array}$ \\
& & & & muscles \\
\hline Criteria & & & & \\
\hline Intuitiveness & 3 & & & 3 \\
Independence & 4 & 0 & 5 & 4 \\
Robustness & 4 & 0 & 4 & 3 \\
Autonomy & 2 & 0 & 5 & 2 \\
Customizable & 4 & 0 & 5 & 5 \\
Price & 5 & 0 & 5 & 1 \\
Speed & 1 & 0 & 5 & 2,63 \\
Accuracy & 1 & 0 & 5 & \\
Result & 3,00 & 0,00 & 4,38 & \\
\hline
\end{tabular}

the subjects could perform the experiment with it.

\subsection{Control interface selection overview}

The $(\mathrm{J})$ has the advantage in that it is the most commonly used control interface for assistive devices (e.g., electrical wheelchairs) by individuals with muscular weakness. Hence, this was considered the easiest and most straightforward method to control an assistive device. In the experiment with people without DMD, the (J) performed similarly to (FS) although it was always the better control interface. The people with DMD could also control the active trunk support with the (J) in the active experiment. Yet, the major drawback of using a $(\mathrm{J})$ is that the function of one hand is sacrificed whenever a person wants to move the trunk since it is a parallel system.

The (FS) control interface was considered the most intuitive one. Gravity compensation is needed in order to distinguish the voluntary forces from gravity or joint stiffness forces. However, the fact that it has to act on the upper body complicates matters. Although both groups of participants had difficulties in fully relaxing their muscles, which is important to achieve proper gravity compensation, those without DMD could control the active trunk support using the (FS) whereas the participants with DMD could not. Additionally, in the case of the participants without DMD, the interface was sensitive 
to respiration, which resulted in small oscillatory movements during the dwell time when the subjects were trying to keep their trunk at a certain angle.

The (FF) control interface was slower in the experiment with people without DMD than the one using a sensor at the sternum, but gravity compensation was not necessary and the position of the sensor was not very critical. Although it is a parallel system requiring slight movements of the feet, and it is slightly slower than the other control interfaces, it may be a solution for people with DMD because using the feet to control trunk movement is not a functional sacrifice. Moreover, two out of three participants with DMD could perform the control task. The third subject had difficulty in pushing against the force plate with his feet, because of equinovarus feet.

(E) control performance was strongly dependent on where the sensor was placed on the muscles. It was easier to get a signal from the tibialis muscle to control the device but it was more difficult to find the right sensor location on the gastrocnemius so that the subject could control the device with ease. It should be mentioned that the subjects needed some familiarisation time at the beginning, to get used to the fact that they had to move their trunk by contracting their leg muscles. Although all the subjects were able to adapt to that procedure within minutes, two DMD subjects could not perform the control task because there were spikes on the signal when they relaxed their muscles. These spikes made it difficult to stabilise the cursor on the screen because they were unintentional and the subjects could not control the task. One subject finished the (FF) control interface test very quickly so we had time to move the (E) sensors to the left and right quadriceps muscles. After that, he could complete the experiment but then he experienced cramps in the quadriceps muscles.

The experiments demonstrated that, in all cases, the $(\mathrm{J})$ is the quickest and most acceptable control interface compared to (FS), (FF) and (E) for the people without and with DMD. However, a joystick is not ideal to control a trunk support device because it requires a hand to operate the joystick and thus this hand cannot be used for other functions like grasping. Since the people with DMD were not able to use the (FS) control interface, (E) and (FF) were investigated in the static experiment. Tuning the control interface parameters was time consuming in some cases, and the time to find the right parameters was limited due to rapid fatigue. Thus, the signals should be investigated further with multiple sessions of the same experiment and the control interfaces have to be customized to every 
DMD subject.

\subsection{Decisions and limitations}

\subsubsection{Focus Group and 1-Dof vs multi-Dof}

We made two important decisions at the beginning of the project. To begin with, the experiments should first be done with people without DMD and then with people with DMD. The main reason was to decrease the experiment time on people with DMD so as to reduce the chances of fatigue during the experiment.

Secondly, we changed the plans from a 2DoF trunk support to a 1-DoF trunk support. The reason was that DMD patients became fatigued rather quickly, so it was better to investigate a relatively simple assistive device first before moving onto more complicated structures.

The benefits of introducing more degrees of freedom are an increase in mobility and arm reach in the frontal and transverse plane but the 1-Dof device was not able to support or even restrict this. More degrees of freedom in a potential trunk device would give DMD patients the same movement capabilities and freedom as users without DMD. On the other hand, increasing the Dof results in an increase in mechanical complexity due to the fact that the actuation in the sagittal plane requires high torque motors. Since no active trunk supports had been reported in the literature, we decided to start by investigating this with the simple 1-DoF active support system. Moreover, we were not convinced that 2-DoF was really necessary but this should be investigated further.

\subsubsection{Position vs speed vs acceleration control}

The order of control indicates the number of integrators between the input and the output of the system. In general, the position control (zero order) is the best choice for precision control since precision offers a clear advantage in reaching a target [70]. The disadvantage of position control is that the input signal has to be active in order to keep the cursor inside the target for the dwell time which can be a fatiguing factor for the subjects (pushing the (J), pushing the force sensor, contracting 
the muscles for the (E)). Speed control (first order), on the other hand, is more difficult than position control and the information processing rate is decreased because of the increasing order of control [70]. The advantage of speed control over position control though, is that the input signal does not have to be active in order to keep the cursor inside the target and as result is less fatiguing. Another approach could be acceleration control. Acceleration control could be useful due to the fact that the subjects can activate the movement by a simple burst on the control interface that could create a constant velocity and thus they do not have to maintain the control interface until they reach the target. A disadvantage is that it needs a lot of training before the subjects can control it sufficiently.

In our experiment, we also wanted to check the ability of the subjects to maintain a specific position with minimum fatigue and to see if they could perform the experimental task with no training. Thus, we decided to choose the speed control and, in order to compensate for the decrease in precision, we chose targets with a relatively bigger diameter. This decision was beneficial since the bigger diameter fulfilled the accuracy requirement of $3 \mathrm{~cm}$ and at the same time compensated for the decrease in the precision of the speed control. Moreover, the trunk is not made for fine movements so a small diameter target would increase the difficulty of the task. The acceleration control approach might be useful for people with DMD since it requires the input signal to be less active than the position and speed control but this approach would need several training sessions.

\subsubsection{Fitts' law}

Only the diameter or the distances of the targets of the experiments were varied. Thus, the effect of Fitts' law was only investigated in relation to target size or distance. This aspect, as well as keeping the experimental time short per subject, could have the following consequences: a) a decrease in the number of repetitions per individual target which gives poor results b) needing many subjects because each condition would have to be performed by a different candidate.

Despite Fitts' law seeming to hold for the three experiments, the R values are lower than in other studies [53]. The low $R$ values can be explained by the fact that: a) a steady state in learning behaviour was not reached b) dwell time was used instead of tapping or pressing a button c) the muscles that 
were involved in the tasks are not made to perform the same fine movement tasks as the hand.

\subsubsection{Admittance values}

The admittance values were tuned based on a pre-experimental procedure involving 2 subjects. The pre-experiment helped us find the optimal virtual mass and damping values for each of the control interfaces. On the one hand, the values of the virtual masses of the control interfaces are close, on the other hand, the values of the virtual damping differ noticeably because of the nature of the input signal in the admittance model. A larger virtual damping value is needed for the $(\mathrm{E})$ to attenuate the high input in the admittance model. Reducing the virtual damping value would result in a higher overshoot.

This approach is subjective and limits the performance of the assistive device. Chapter 4 examines the performance of different controllers. Indeed, feed forward and variable admittance performed better but a pre-experimental procedure was also needed to tune the gain values of the different coefficients.

\subsubsection{Mechanical limitations of the experimental trunk support}

The gear ratio backlash and the electronics of the motor resulted in mechanical play, giving 0 to 20 pixels in the GUI. Thus, only some of the trials started at 0 or 1680 pixels (starting points for flexion end extension respectively), even though all the subjects were asked to move the device to the mechanical end stops. We did not compensate for this non equality between trials since we considered it to be negligible.

\subsection{Future work}

\subsubsection{Active device first}

As described in Chapter 1, we assumed that people with DMD should be first introduced to a passive support system and as the DMD progresses, more support will be provided by an active support. This 
approach has the disadvantage in that people with DMD using the passive trunk support can get tired in the middle of the day and then, because of the fatigue, they will hesitate to use the trunk support. As was shown in the Jansen et al. study, the deterioration in boys with DMD can be delayed with assistive cycling [69]. Taking this into consideration, we propose earlier use of an active trunk support by people with DMD whereby the caregiver is able to choose the level of assistance for daily usage or the resistance of the training.

\subsubsection{Control interfaces and rehabilitation}

The leg muscles can be used to control an active trunk support instead of the trunk muscles but it is important to keep the muscles of the trunk active as well. Otherwise they will weaken further. The phenomenon of the extra muscle deterioration in people with DMD due to inactivity is widely known as Use it or lose it [14]. Such a phenomenon can be avoided by following an assisted cycling training of the leg and arms as suggested Jansen et al. [69]. Consequently, rehabilitation should be focused on keeping the muscles as active as possible starting in the early stages of the DMD, including the trunk and leg section. A solution is that people with DMD can play a game with the configuration described in Chapter 5 to keep their trunk and leg muscles active. Alternatively, better performance might be achieved by combining the information from both the trunk and leg muscles in order to anticipate the disadvantages of both signals. Moreover, several control methods, except for the direct control, could be used like pattern recognition or abstract decoding [41, 42]. A disadvantage though, is that pattern recognition requires several (E) signals, which means the sensor has to be attached to the skin for a longer period.

\subsubsection{A multi-DoF control system}

Different segments are involved in the movement of the trunk (pelvis, lower lumbar, upper lumbar, lower thoracic, upper thoracic) [18]. Consequently, an active trunk support should provide multi-DoF support. However, since no active trunk supports have been reported in the literature, we decided to start by investigating the simple 1-DoF active support system. Future designs should include lateral 
bending and axial rotation. The performance of the control interfaces would differ if the complexity of the experimental task were increased by increasing the DoFs.

\subsection{Conclusion}

According to our results, (FF), a non-intuitive control interface, might be the best method for people with DMD to control an active trunk support. Some DMD patients might perform better with an (E) from the leg muscles. The only intuitive control interface that can be used is a $(\mathrm{J})$ but then the function of one hand has to be sacrificed. The decision as to which control interface works best must be made per individual. 


\section{REFERENCES}

[1] A. Kornberg and E. Yiu, "Duchenne muscular dystrophy," Neurology India, vol. 56, no. 3, p. 236, 2008.

[2] "Symbionics; Avaliable from: http://www.flextension.nl/projecten/symbionics/."

[3] "Flextension; Avaliable from: http://www.flextension.nl/en/."

[4] J. R. Mendell and M. Lloyd-Puryear, "Report of MDA muscle disease symposium on newborn screening for Duchenne muscular dystrophy," Muscle and Nerve, vol. 48, pp. 21-26, jul 2013.

[5] M. Eagle, J. Bourke, R. Bullock, M. Gibson, J. Mehta, D. Giddings, V. Straub, and K. Bushby, "Managing Duchenne muscular dystrophy The additive effect of spinal surgery and home nocturnal ventilation in improving survival," Neuromuscular Disorders, vol. 17, pp. 470-475, jun 2007.

[6] E. M. Yiu and A. J. Kornberg, "Duchenne muscular dystrophy," Journal of Paediatrics and Child Health, vol. 51, pp. 759-764, aug 2015.

[7] M. Eagle, S. V. Baudouin, C. Chandler, D. R. Giddings, R. Bullock, and K. Bushby, "Survival in Duchenne muscular dystrophy: improvements in life expectancy since 1967 and the impact of home nocturnal ventilation," Neuromuscular Disorders, vol. 12, pp. 926-929, dec 2002.

[8] M. M. H. P. Janssen, A. Bergsma, A. C. H. Geurts, and I. J. M. de Groot, "Patterns of decline in upper limb function of boys and men with DMD: an international survey.," Journal of neurology, vol. 261, pp. 1269-88, jul 2014. 
[9] M. A. Grootenhuis, J. de Boone, and A. J. van der Kooi, "Living with muscular dystrophy: health related quality of life consequences for children and adults," Health and Quality of Life Outcomes, vol. 5, p. 31, jun 2007.

[10] W. Stuberg, "Home Accessibility and Adaptive Equipment in Duchenne Muscular Dystrophy: A Case Report," tech. rep., 2001.

[11] S. Pandya, J. Andrews, K. Campbell, and F. J. Meaney, "Rehabilitative technology use among individuals with Duchenne/Becker muscular dystrophy," Journal of Pediatric Rehabilitation Medicine, vol. 9, pp. 45-53, feb 2016.

[12] T. Rahman, W. Sample, R. Seliktar, M. T. Scavina, A. L. Clark, K. Moran, and M. A. Alexander, "Design and Testing of a Functional Arm Orthosis in Patients With Neuromuscular Diseases," IEEE Transactions on Neural Systems and Rehabilitation Engineering, vol. 15, no. 2, pp. 244$251,2007$.

[13] J. Lobo-Prat, P. Kooren, M. Janssen, A. Keemink, P. Veltink, A. Stienen, and B. Koopman, "Implementation of EMG- and Force-based Control Interfaces in Active Elbow Supports for Men with Duchenne Muscular Dystrophy: a Feasibility Study," IEEE Transactions on Neural Systems and Rehabilitation Engineering, pp. 1-1, 2016.

[14] M. Jansen, I. J. de Groot, N. van Alfen, and A. C. Geurts, "Physical training in boys with Duchenne Muscular Dystrophy: the protocol of the No Use is Disuse study.," BMC pediatrics, vol. 10, p. 55, aug 2010 .

[15] I. Aprile, M. Rabuffetti, L. Padua, E. Di Sipio, C. Simbolotti, and M. Ferrarin, "Kinematic Analysis of the Upper Limb Motor Strategies in Stroke Patients as a Tool towards Advanced Neurorehabilitation Strategies: A Preliminary Study," BioMed Research International, vol. 2014, pp. 1-8, 2014.

[16] H. Sveistrup, A. S. Schneiberg, A. P. A. Mckinley, A. B. J. Mcfadyen, A. M. F. Levin, S. Schneiberg, P. A. Mckinley, Á. M. F. Levin, B. J. Mcfadyen, and C. B. J. Mcfadyen, "Head, 
arm and trunk coordination during reaching in children," Exp Brain Res, vol. 188, pp. 237-247, 2008 .

[17] I. Flatters, F. Mushtaq, ·. Liam, J. B. Hill, R. J. Holt, and R. M. Wilkie, "The relationship between a child's postural stability and manual dexterity Mark Mon-Williams," Exp Brain Res, vol. 232, pp. 2907-2917, 2014.

[18] L. H. C. Peeters, I. Kingma, G. S. Faber, J. H. van Dieën, and I. J. M. de Groot, “Trunk, head and pelvis interactions in healthy children when performing seated daily arm tasks," Experimental Brain Research, vol. 236, pp. 2023-2036, jul 2018.

[19] L. H. Peeters, I. J. de Groot, and A. C. Geurts, "Trunk involvement in performing upper extremity activities while seated in neurological patients with a flaccid trunk A review," Gait and Posture, vol. 62, pp. 46-55, may 2018.

[20] A. G. Dunning, M. M. H. P. Janssen, P. N. Kooren, and J. L. Herder, "Evaluation of an Arm Support With Trunk Motion Capability," Journal of Medical Devices, vol. 10, p. 044509, sep 2016.

[21] M. N. Mahmood, L. H. C. Peeters, M. Paalman, G. J. Verkerke, I. Kingma, and J. H. van Dieën, "Development and evaluation of a passive trunk support system for Duchenne muscular dystrophy patients," Journal of NeuroEngineering and Rehabilitation, vol. 15, p. 22, dec 2018.

[22] J. Lobo-Prat, P. N. Kooren, A. H. Stienen, J. L. Herder, B. F. Koopman, and P. H. Veltink, "Noninvasive control interfaces for intention detection in active movement-assistive devices," Journal of NeuroEngineering and Rehabilitation, vol. 11, no. 1, p. 168, 2014.

[23] E. A. Corbett, E. J. Perreault, and T. A. Kuiken, "Comparison of electromyography and force as interfaces for prosthetic control.," Journal of rehabilitation research and development, vol. 48, no. 6 , pp. 629-41, 2011.

[24] J. Lobo-Prat, A. Q. Keemink, A. H. Stienen, A. C. Schouten, P. H. Veltink, and B. H. Koopman, 
"Evaluation of EMG, force and joystick as control interfaces for active arm supports," Journal of NeuroEngineering and Rehabilitation, vol. 11, p. 68, apr 2014.

[25] P. M. Fitts, "The information capacity of the human motor system in controlling the amplitude of movement,"

[26] P. M. Fitts and J. R. Peterson', 'INFORMATION CAPACITY OF DISCRETE MOTOR RESPONSES *," Tech. Rep. 2, 1964.

[27] S. Zhai, J. Kong, and X. Ren, "Speedaccuracy tradeoff in Fitts' law taskson the equivalency of actual and nominal pointing precision," International Journal of Human-Computer Studies, vol. 61, pp. 823-856, dec 2004.

[28] M. Williams and R. Kirsch, "Evaluation of Head Orientation and Neck Muscle EMG Signals as Command Inputs to a HumanComputer Interface for Individuals With High Tetraplegia," IEEE Transactions on Neural Systems and Rehabilitation Engineering, vol. 16, pp. 485-496, oct 2008.

[29] S. M. Wurth and L. J. Hargrove, "A real-time comparison between direct control, sequential pattern recognition control and simultaneous pattern recognition control using a Fitts' law style assessment procedure," Journal of NeuroEngineering and Rehabilitation, 2014.

[30] M. R. Williams and R. F. Kirsch, "Evaluation of head orientation and neck muscle EMG signals as three-dimensional command sources," Journal of NeuroEngineering and Rehabilitation, vol. 12, p. 25, mar 2015.

[31] A. Q. Keemink, R. I. Fierkens, J. Lobo-Prat, J. S. Schorsch, D. A. Abbink, J. B. Smeets, and A. H. Stienen, "Using position dependent damping forces around reaching targets for transporting heavy objects: A Fitts' law approach,” in 2016 6th IEEE International Conference on Biomedical Robotics and Biomechatronics (BioRob), pp. 1323-1329, IEEE, jun 2016.

[32] Y. Cha and R. Myung, "Extended Fitts' law for 3D pointing tasks using 3D target arrangements," International Journal of Industrial Ergonomics, vol. 43, pp. 350-355, jul 2013. 
[33] L. H. C. Peeters, I. Kingma, G. S. Faber, J. H. van Dieën, and I. J. M. de Groot, "Correction to: Trunk, head and pelvis interactions in healthy children when performing seated daily arm tasks," Experimental Brain Research, vol. 237, pp. 289-289, jan 2019.

[34] P. K. Artemiadis and K. J. Kyriakopoulos, "Emg-based control of a robot arm using lowdimensional embeddings," IEEE Transactions on Robotics, vol. 26, pp. 393-398, April 2010.

[35] E. E. Cavallaro, J. Rosen, J. C. Perry, and S. Burns, "Real-time myoprocessors for a neural controlled powered exoskeleton arm," IEEE Transactions on Biomedical Engineering, vol. 53, pp. 2387-2396, Nov 2006.

[36] C. Brinkman, R. Porter, and J. Norman, "Plasticity of motor behavior in monkeys with crossed forelimb nerves," Science, vol. 220, no. 4595, pp. 438-440, 1983.

[37] M. I. Chris Wilson Antuvan and P. Artemiadis, "Embedded human control of robots using myoelectric interfaces," IEEE Transactions on neural systems and rehabilitation engineering, vol. 22, pp. 820-827, July 2014.

[38] E. B. Thorp, F. Abdollahi, D. Chen, A. Farshchiansadegh, M.-H. Lee, J. P. Pedersen, C. Pierella, E. J. Roth, I. Seanez Gonzalez, and F. A. Mussa-Ivaldi, "Upper Body-Based Power Wheelchair Control Interface for Individuals With Tetraplegia," IEEE Transactions on Neural Systems and Rehabilitation Engineering, vol. 24, pp. 249-260, feb 2016.

[39] S. M. Radhakrishnan, S. N. Baker, and A. Jackson, "Learning a novel myoelectric-controlled interface task," Journal of Neurophysiology, vol. 100, no. 4, pp. 2397-2408, 2008.

[40] I. S. MacKenzie, "Fitts' law as a research and design tool in human-computer interaction," Hum.-Comput. Interact., vol. 7, pp. 91-139, Mar. 1992.

[41] C. Cipriani, C. Antfolk, M. Controzzi, G. Lundborg, B. Rosen, M. C. Carrozza, and F. Sebelius, “Online Myoelectric Control of a Dexterous Hand Prosthesis by Transradial Amputees," IEEE Transactions on Neural Systems and Rehabilitation Engineering, vol. 19, pp. 260-270, jun 2011. 
[42] M. Dyson, J. Barnes, and K. Nazarpour, "Myoelectric control with abstract decoders," Journal of Neural Engineering, vol. 15, p. 056003, oct 2018.

[43] E. P. Hoffman, R. H. Brown, and L. M. Kunkel, "Dystrophin: The protein product of the duchenne muscular dystrophy locus," Cell, vol. 51, pp. 919-928, dec 1987.

[44] K. R. Wagner, N. Lechtzin, and D. P. Judge, "Current treatment of adult Duchenne muscular dystrophy.," Biochimica et biophysica acta, vol. 1772, pp. 229-37, feb 2007.

[45] L. A. van der Heide, G. J. Gelderblom, and L. P. de Witte, "Dynamic arm supports: Overview and categorization of dynamic arm supports for people with decreased arm function," in 2013 IEEE 13th International Conference on Rehabilitation Robotics (ICORR), pp. 1-6, IEEE, jun 2013.

[46] B. E. Dicianno, R. A. Cooper, and J. Coltellaro, "Joystick Control for Powered Mobility: Current State of Technology and Future Directions," Physical Medicine and Rehabilitation Clinics of North America, vol. 21, no. 1, pp. 79-86, 2010.

[47] V. Maheu, J. Frappier, P. S. Archambault, and F. Routhier, "Evaluation of the JACO robotic arm: Clinico-economic study for powered wheelchair users with upper-extremity disabilities," in 2011 IEEE International Conference on Rehabilitation Robotics, pp. 1-5, IEEE, jun 2011.

[48] K. Abbruzzese, D. Lee, A. Swedberg, H. Talasan, and M. Paliwal, “An innovative design for an Assistive Arm Orthosis for stroke and muscle dystrophy," in 2011 IEEE 37th Annual Northeast Bioengineering Conference (NEBEC), pp. 1-2, IEEE, apr 2011.

[49] K. Lucassen, S. Verros, E. Hekman, B. Koopman, "Evaluation of a Non- Intuitive Leg and an Intuitive Trunk EMG Control Interface as Command Input for a 2-D Fittss law style task,"

[50] R. M. G. R. Hermans, Hermie and G. H. Dr. C. Disselhorst-Klug, “Seniam 2000.”

[51] T. Lenzi, S. M. M. De Rossi, N. Vitiello, and M. C. Carrozza, "Intention-based EMG control for powered exoskeletons," IEEE Transactions on Biomedical Engineering, vol. 59, no. 8, pp. 2180$2190,2012$. 
[52] R. W. Soukoreff and I. S. Mackenzie, "Towards a standard for pointing device evaluation, perspectives on 27 years of Fitts' law research in HCI," Int. J. Human-Computer Studies, vol. 61, pp. 751-789, 2004.

[53] I. S. Mackenzie, A. Seller\$, and W. Buxton\$, “A COMPARISON OF INPUT DEVICES IN ELEMENTAL POINTING AND DRAGGING TASKS,” 1991.

[54] N. Deconinck and B. Dan, "Pathophysiology of Duchenne Muscular Dystrophy: Current Hypotheses," Pediatric Neurology, vol. 36, no. 1, pp. 1-7, 2007.

[55] E. P. Hoffman, R. H. Brown, and L. M. Kunkel, "Dystrophin: the protein product of the Duchene muscular dystrophy locus. 1987.," Biotechnology (Reading, Mass.), vol. 24, pp. 457-66, 1992.

[56] P. T. C. Straathof, J. Lobo-Prat, F. Schilder, P. N. Kooren, M. I. Paalman, A. H. A. Stienen, and B. F. J. M. Koopman, "Design and control of the A-Arm: An active planar arm support for adults with Duchenne muscular dystrophy," Proceedings of the IEEE RAS and EMBS International Conference on Biomedical Robotics and Biomechatronics, vol. 2016-July, pp. 1242-1247, 2016.

[57] W. Hassani, S. Mohammed, and Y. Amirat, "Real-Time EMG Driven Lower Limb Actuated Orthosis for Assistance As Needed Movement Strategy," in Robotics: Science and Systems, Citeseer, 2013.

[58] I. Ranatunga, F. Lewis, D. O. Popa, and S. M. Tousif, “Adaptive Admittance Control for HumanRobot Interaction Using Model Reference Design and Adaptive Inverse Filtering," IEEE Trans. Control Systems Technology, vol. 00, no. 0, pp. 1-10, 2016.

[59] B. Alqaudi, H. Modares, I. Ranatunga, and S. M. Tousif, "Model reference adaptive impedance control for physical human-robot interaction," Control Theory Technology, vol. 14, no. 1, pp. 1$15,2016$.

[60] A. I. Automation, "F/t sensor." www .ati-ia.com. 
[61] A. Morbi, M. Ahmadi, A. D. C. Chan, and R. Langlois, "Stability-Guaranteed Assist-as-Needed Controller for Powered Orthoses," Control Systems Technology, IEEE Transactions on, vol. 22, no. 2, pp. 745-752, 2014.

[62] A. Lecours, B. Mayer-St-Onge, and C. Gosselin, "Variable admittance control of a four-degreeof-freedom intelligent assist device," Proceedings - IEEE International Conference on Robotics and Automation, no. 2, pp. 3903-3908, 2012.

[63] J. R. Mendell, C. Shilling, N. D. Leslie, K. M. Flanigan, R. Al-Dahhak, J. Gastier-Foster, K. Kneile, D. M. Dunn, B. Duval, A. Aoyagi, C. Hamil, M. Mahmoud, K. Roush, L. Bird, C. Rankin, H. Lilly, N. Street, R. Chandrasekar, and R. B. Weiss, "Evidence-based path to newborn screening for duchenne muscular dystrophy," Annals of Neurology, vol. 71, no. 3, pp. 304-313, 2012.

[64] M. Kohler, C. F. Clarenbach, C. Bahler, T. Brack, E. W. Russi, and K. E. Bloch, "Disability and survival in Duchenne muscular dystrophy," Journal of Neurology, Neurosurgery and Psychiatry, vol. 80, pp. 320-325, mar 2009.

[65] J. Lobo-Prat, M. M. Janssen, B. F. Koopman, A. H. Stienen, and I. J. de Groot, "Surface EMG signals in very late-stage of Duchenne muscular dystrophy: a case study," Journal of NeuroEngineering and Rehabilitation, vol. 14, p. 86, dec 2017.

[66] S. Verros, N. Mahmood, L. Peeters, J. Lobo-Prat, A. Bergsma, E. Hekman, G. J. Verkerke, and B. Koopman, "Evaluation of Control Interfaces for Active Trunk Support," IEEE Transactions on Neural Systems and Rehabilitation Engineering, vol. 26, pp. 1965-1974, oct 2018.

[67] A. Q. Keemink, H. van der Kooij, and A. H. Stienen, "Admittance control for physical humanrobot interaction," The International Journal of Robotics Research, vol. 37, pp. 1421-1444, sep 2018.

[68] S. Yao, Y. Zhuang, Z. Li, and R. Song, "Adaptive Admittance Control for an Ankle Exoskeleton 
Using an EMG-Driven Musculoskeletal Model," Frontiers in Neurorobotics, vol. 12, p. 16, apr 2018 .

[69] M. Jansen, N. van Alfen, A. C. H. Geurts, and I. J. M. de Groot, "Assisted Bicycle Training Delays Functional Deterioration in Boys With Duchenne Muscular Dystrophy," Neurorehabilitation and Neural Repair, vol. 27, pp. 816-827, nov 2013.

[70] R. J. Jagacinski and J. Flach, Control theory for humans : quantitative approaches to modeling performance. Taylor and Francis, 2011. 


\section{ACKNOWLEDGEMENTS}

The work presented in this dissertation would not have been possible without the help, support and supervision of many people.

First of all I would like to thank my supervisors. Bart K., Bart V., Edsko and Arjen for their limitless contribution in time, encouragement and ideas making me finalize my $\mathrm{PhD}$. Bart $\mathrm{K}$. thank you very much for approving all my requests in budget expenses. Bart V. thank you very much for your inspiration. Edsko, I really appreciate your immediate availability and your eagerness to discus technical subjects. Arjen, many thanks for your help with designing and criticising my experiments.

To the rest of the Symbionics 2.1 supervisors thank you very much for your support. Imelda thank you very much for your input on my experiments. Jaap and Idsart thank you very much for your help with statistics. Micha thank you very much for assisting me with the mechanical design.

My colleagues of Symbionics 2.1 Laura and Nauzef thank you very much. We had many meetings focusing on problem solving, how to meet the deadlines of the milestones and how to continue with the project. From the first meeting I realized that I had to do with great project mates who were always helpful. Laura, thank very much for you help with EMTC and performing the experiments. Nauzef, thank you very much for your immediate availability in the mechanical support. I wish I could always have people like you in future projects. Also, I would like to thank Anoek for supervising an MSc student and continuing my work regarding the head support.

My colleagues of Symbionics project Hans, Ronald, Laura, Nauzef, Roy, Kostas, Niek, Anoek thank you very much for all the time we spent together in the user committee meetings.

To my office mates Bob and Alex. I know that after my second year I moved to the lab but I realized that I was more productive there rather than in the office. Sorry guys but I did this for science (and to get my $\mathrm{PhD}$ of course).

To the Department of Biomechanical Engineering. Firt of all, I would like to thank the two pillars of the department Lianne and Jeanine. You were always so friendly and helpful. Second, I would like to thank Joan, Arvid and Niek for their valuable help in control engineering, experimental 
design, statistical analysis etc. I learned a lot form you guys. Martijn W., thank you very much for all your help with the electrical installations. Gijs, thank you very much for your help with Python and xPC. Victor, thank you very much for your endless help with electronics. Claudia thanks to you and Hankamp Gears for your contribution into my experimental setup. Serdar, Martijn G., Kyrian, Wolfang, Guillaume, Quint, Ronald, Simone, Mark, Rene, Iris, Amber, Heidi, Vincenzo, thank you very much for your help all this years. Federico and Jakub thank you very much for your support with encoder equipment. Herman and Edwin thank you very much for your precious advises. Wouter and Nikolai thank very much for all your technical support.

Outside of the department, I would like to thank Raffaella for the collaboration, Cindy for the help with EMTC and Marcel for helping in technical problems.

During my PhD I supervised several MSc and BSc students. I would like to thanks Gilian, Koen, Sander, Niels and Jeroen. I learned a lot while I was supervising you and that is a proof that you were very good students.

The Kyrian Quest. I (Zokon) would like to thank Kyrian our GM, Guillaume (Willem/Wilhelmina), Kostas (Kevroar), Wolfgang (Wolf), Ronald (Aelar), Quint (Thirro), Christina (Katniss), Nicola (Alfonse) for the wonderful time we had wondering around in the world of Dungeons and Dragons.

I would like to thank Kostas who was my colleague, roommate and friend for the past four years. I really miss our discussions ranging from work issues to politics. I would like to thank all my friends with whom I spent a lot of time trying to survive Enschede. Special thanks to my trainer Angelo and to all the athletes of Angelo Gym with whom I trained and sparred with.

Last but not least. I would like to thank my parents and my brother. You have been very supportive with anything I did and you were there on my ups and downs. Thank you for everything. Ingrid, I would like to thank you also for your mental support during my $\mathrm{PhD}$ and the lovely time we spent together.

\section{Stergios Verros}

Amsterdam, April 2019 


\section{PUBLICATIONS}

\section{Journal publications}

3. S. Verros, Laura Peeters, Arjen Bergsma, Edsko E.G. Hekman, Gijsbertus J. Verkerke and Bart F.J.M. Koopman Exploring physiological signals on people with Duchenne muscular dystrophy for an active trunk support: a case study, BMC Biomedical Engineering, Article number: 31 (2019).

2. S. Verros, K. Lucassen, E.E.G. Hekman, A.Bergsma, G.J. Verkerke, and B.F.J.M.Koopman Evaluation of intuitive trunk and non-intuitive leg sEMG control interfaces as command input for a 2-D Fitts's law style task, PLoS ONE 14(4): e0214645, Apr. 2019.

1. S. Verros, N. Mahmood, L. Peeters, J. Lobo-Prat, A. Bergsma, E. Hekman, G. J. Verkerke, and B. Koopman, Evaluation of Control Interfaces for Active Trunk Support, IEEE Transactions on Neural Systystes and Rehabilitation Engineering, vol. 26, no. 10, pp. 19651974, Oct. 2018.

\section{International conference publications}

1. P.G. Van Lenthe*, S. Verros*, E.E.G. Hekman, R. Carloni, and H.F.J.M. Koopman, Comparing Assistive Admittance Control Algorithms for a Trunk Supporting Exoskeleton, in 2018 IEEE International Conference on Robotics and Automation (ICRA), Brisbane, 2018, pp. 28282834.

* indicates equal contribution 


\begin{abstract}
ABOUT THE AUTHOR
Stergios Verros was born December 21st, 1983, in Kos (Greece). He completed his studies in Electical Engineering at the University of Applied Sciences of Western Macedonia. After completing his military service as a Second Lieutenant of reserve he started working at the city of Thessaloniki.

Since Electrical Engineering was his passion, he graduated with a BSc from the the Budapest University of Technology and Economics with a minor in Embedded Systems and Control. Then, he followed the Advanced Control and Systems Engineering MSc program at the University of Manchester.
\end{abstract}

In October 2014, he started his $\mathrm{PhD}$ at the department of Biomechanical Engineering under the supervision of Prof. Dr. Ir. Bart Koopman, Prof. Dr. Ir. Bart Verkerke and Ir. Edsko Hekman. 